Portland State University

PDXScholar

5-16-1994

\title{
Technological Organization and Sedentism: Expedient Core Reduction, Stockpiling, and Tool Curation at the Meier Site (35C05)
}

Stephen Coursault Hamilton Portland State University

Follow this and additional works at: https://pdxscholar.library.pdx.edu/open_access_etds

Part of the Anthropology Commons

Let us know how access to this document benefits you.

\section{Recommended Citation}

Hamilton, Stephen Coursault, "Technological Organization and Sedentism: Expedient Core Reduction, Stockpiling, and Tool Curation at the Meier Site (35C05)" (1994). Dissertations and Theses. Paper 4839. https://doi.org/10.15760/etd.6715

This Thesis is brought to you for free and open access. It has been accepted for inclusion in Dissertations and Theses by an authorized administrator of PDXScholar. Please contact us if we can make this document more accessible: pdxscholar@pdx.edu. 
THESIS APPROVAL

The abstract and thesis of stephen coursault Hamilton for the Master of Arts in Anthropology May 16, 1994 and accepted by the thesis committee and the department.
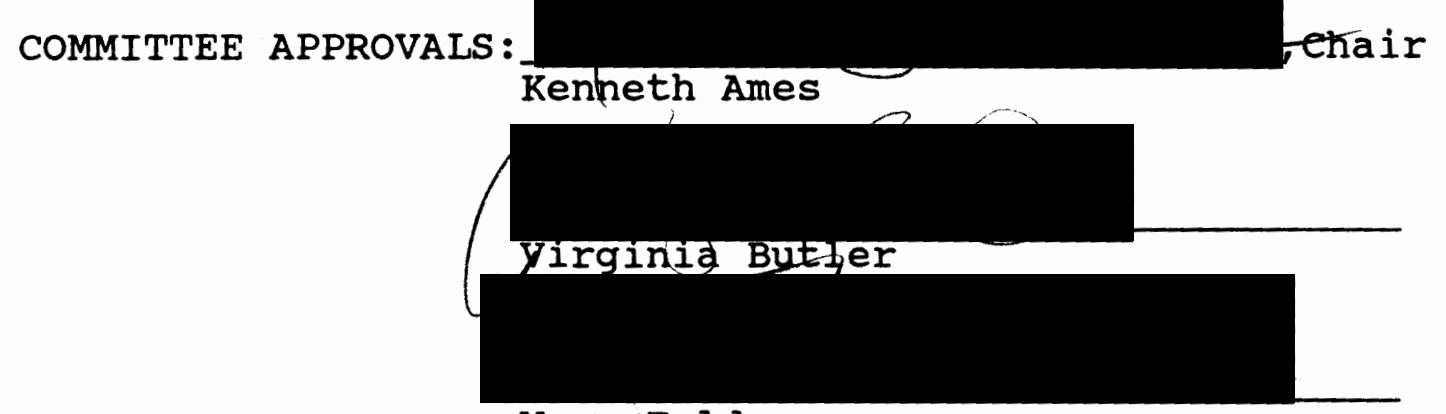

Marc Feldesman

DEPARTMENT APPROVAL

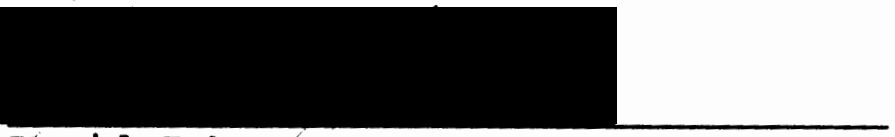

David Johnson

Representative of the office of Graduate studies

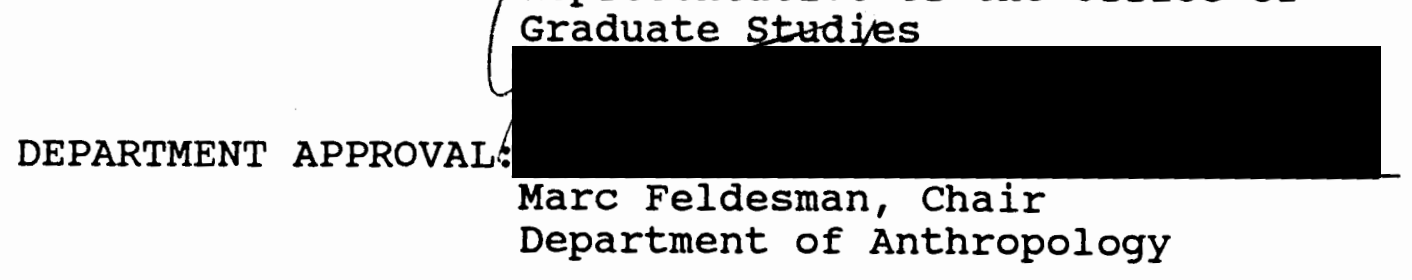

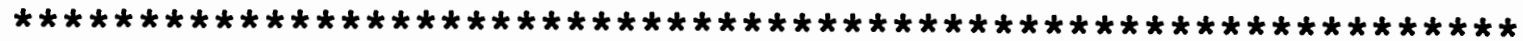

ACCEPTED FOR PORTLAND STATE UNIVERSITY BY THE LIBRARY

b

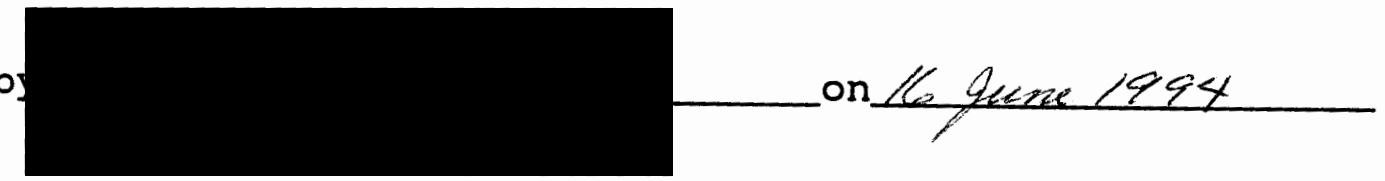




\section{ABSTRACT}

An abstract of the thesis of stephen Coursault Hamilton for the Master of Arts in Anthropology presented May 16, 1994.

Title: Technological organization and Sedentism:

Expedient Core Reduction, Stockpiling, and Tool Curation at the Meier site (35C05).

The Meier site fine-grained lithic assemblage was used to test the hypothesis that a sedentary group will rely heavily on expedient lithic technologies because they stockpile raw material at the residence. At Meier, expedient core reduction provided blanks for a significant number of curated and expedient tools. I propose that sedentism (stockpiling) minimizes energy investments in raw material procurement and blank production while maintaining the ability to efficiently make both curated and expedient tools. Investment in curation is limited to a few tool classes with specialized functions, not transportable design variables. 
TECHNOLOGICAL ORGANIZATION AND SEDENTISM:

EXPEDIENT CORE REDUCTION, STOCKPILING, AND TOOL CURATION AT THE MEIER SITE (35CO5)

by

STEPHEN COURSAULT HAMILTON

A thesis submitted in partial fulfillment of the requirements for the degree of

$$
\text { MASTER OF ARTS }
$$

in

ANTHROPOLOGY

Portland State University

1994 
ACKNOWLEDGMENTS

I am pleased to extend my deepest gratitude to the many people who knowingly and unknowingly provided valuable insights and inspiration for completing this thesis. First, I thank Ken Ames, my committee chair, for his time and efforts in teaching me about archaeology from the ground up. His faith in my ability to produce quality work was and is a tremendous motivation. His supervision while allowing me academic freedom was invaluable in keeping me going and sane. I am also greatly indebted to John Fagan for his editing diligence and constructive criticisms of my original draft. Crucial were his insights into stone tool analysis and his attempts at keeping me empirically grounded in the world of flintknapping. Although a late arrival onto my committee, Virginia Butler's suggestions were of considerable help in the final month of writing. Connie Cash was indispensable at getting me through administrative nightmares, letting me use facilities, and laughing when I needed it most. Aliah Kahn was more than patient as I terrorized her organized archaeology lab. I thank cameron Smith for providing essential data on debitage microwear at the last "minutes" before writing the original draft. My housemates at the NW Irving street house made my life bearable during analysis and initial writing (and provided 
great food). Mom gave me the essential love and deep rooted motivation that only a mother can give. Robert unknowingly provided great inspiration, but I am at a loss as to howmaybe his attitude and smile. Emma gave me that essential love and support at home while putting up with my impossible stress during the final weeks. Finally, I would like to thank the western deserts, mountains and forests for providing a meditative retreat from rationalism- a place where I will spend more time for contemplation and intuitive creation while mingling with all my plant and animal relatives that live there. 
TABLE OF CONTENTS

ACKNOWLEDGMENTS ..........................

LIST OF TABLES......................... vi

LIST OF FIGURES ......................... ix

$\begin{array}{ll}\text { CHAPTER } & \text { PAGE }\end{array}$

1 INTRODUCTION...................... 1

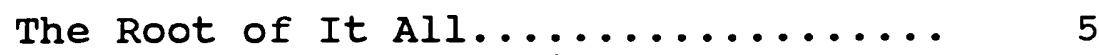

Technological Strategies........... 6

Mobility organization.............. 8

Technological Design............... 11

Expediency and Residential Sedentism. 12

Data Expectations................ 15

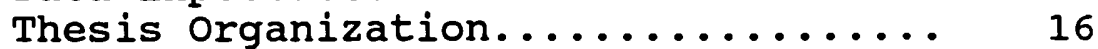

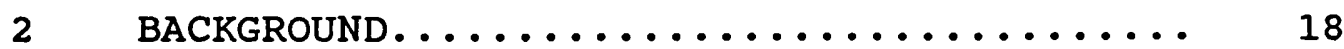

Site Characteristics............... 18

Physical and Social Environment...... 19

Subsistence and Mobility.......... 22

Raw Material Sourcing............ 27

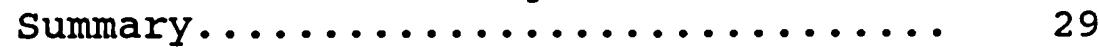

3 LITHIC TECHNOLOGY.................... 32

Flaking Techniques............... 41

Standardized vs. Generalized Core

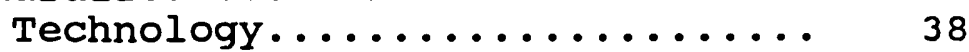

Lithic Technology................. 41

The Utility and structure of a

stockpile................. 43

Assemblage structure............. 46

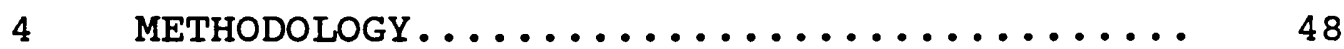

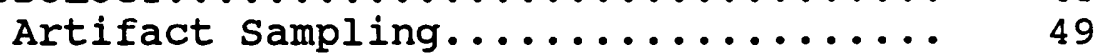

Lithic Raw Material.............. 52

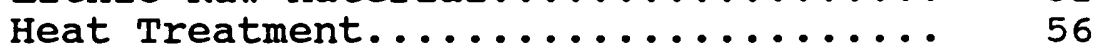

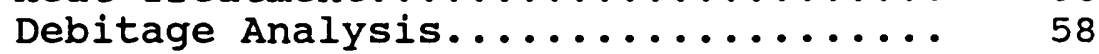

Non-debitage Analysis: Cores, Preforms

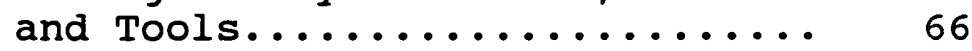

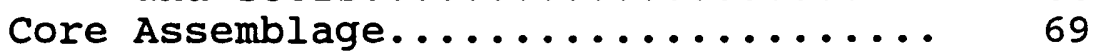

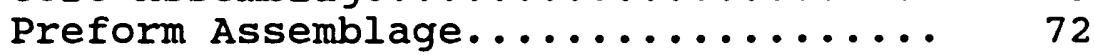

Tool Assemblage................... 72

Inferring Lithic Technological

organization At Meier.......... 
CHAPTER

PAGE

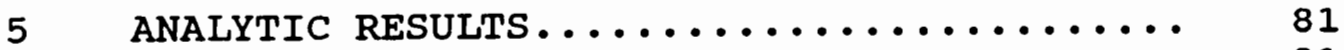

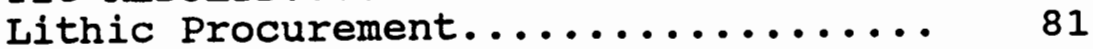

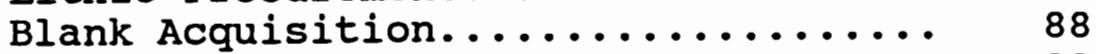

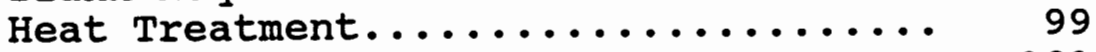

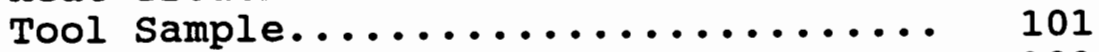

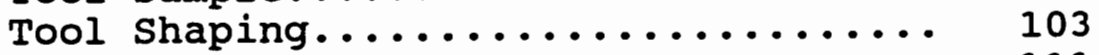

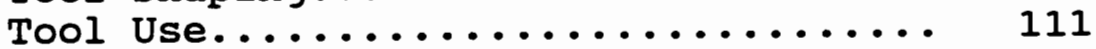

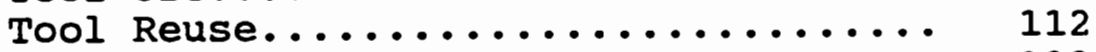

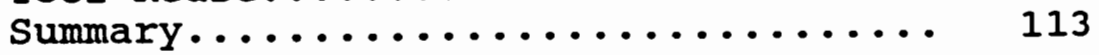

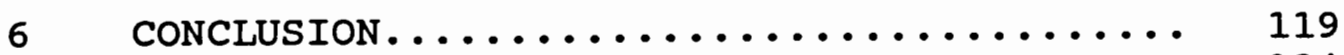

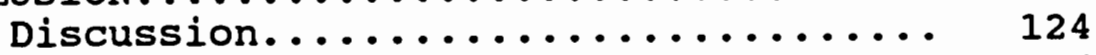

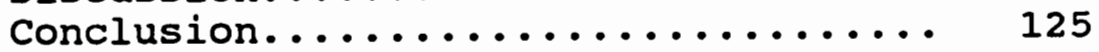

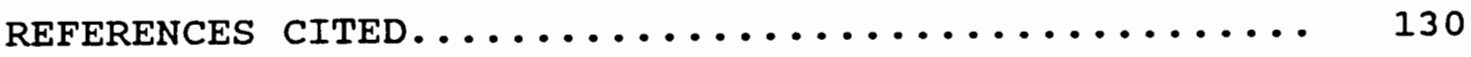

APPENDIX

1 SUMMARY OF C. SMITH'S MICROWEAR ANALYSIS.. 136

2 ORIGINAL AND REVISED ARTIFACT FREQUENCIES • 142

3 MINERALOGICAL CLASSIFICATION AND

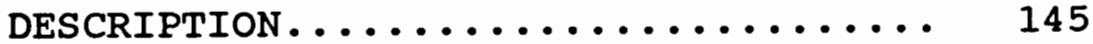

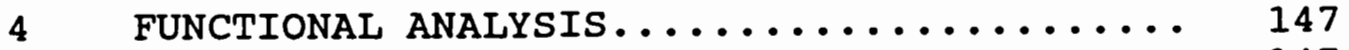

Methodology................. 147

Analytic Results............... 153

5 DEBITAGE DATA SUMMARY .................. 162 


\section{LIST OF TABLES}

TABLE

PAGE

1 General Lithic Artifact Classes.......... 48

2 Lithic Analysis Samples............... 50

3 Raw Material Quality Classification....... 55

4 Raw Material Source classification........ 56

5 Flake Blank Heat Alteration Stage classification.................... 57

6 Interior Flake Classification............ 60

7 Sullivan and Rozen Typology............. 62

8 Ranking of Variables Used to Evaluate Energy Expenditure for each Activity set of the Lithic system............... 78

9 Meier Site Fine-grained Flake-stone Assemblage.................... 81

10 Core and Debitage Source Based on Cortex Character...................... 82

11 Size Measurements of Cores and Tools....... 84

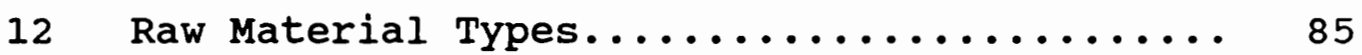

13 Raw Material Quality for Core Assemblage.... 86

14 Raw Material Quality for Tools........... 86

15 Raw Material Test and Core Frequencies..... 87

16 Frequencies of Flaking Technology for Cores and Debitage............... 89

17 Tested Raw Material Flaking Technology...... 90

18 Mean Length and Weight of Core Artifacts for Each Flaking Technique.......... 91

19 Frequency of Generalized and Standardized

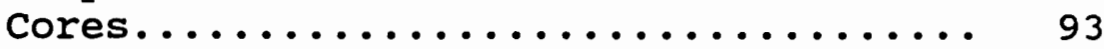


20 List of Intentional Blanks and Opportunistic Blanks for Cores and Tools.......... 97

21 Frequency of Heat Alteration............ 99

22 Stage of Heat Alteration on Tool Blanks..... 100

23 Number of Shaped Tools and Preforms in

Each Technological Category.......... 103

24 Frequencies of Expedient and Curated Tools for each Ranked Shaping Types.... 104

25 Number of Ranked Shaping Types for each

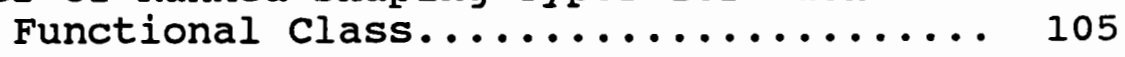

26 Number of Type 4 Bifacial Tools and All

Preforms for each Technological Class.. 106

27 Number of Hafted Tools................ 111

28 Number of Expedient and Curated Tools for

Each Functional Class.............. 112

29 Raw Material Quality of Expedient and Curated Tools for Each Functional

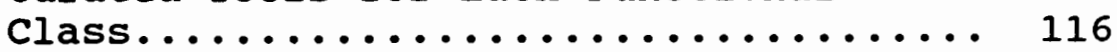

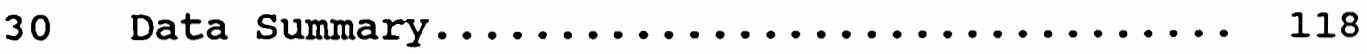

31 Evaluation of Energy Investment for each

Activity set of the Lithic Technology.. 119

32 Used Flake Dimensions, Typology and

Microwear Traces................. 140

33 Basic Statistics of Used and Unused Flake

Flake Weights................... 141

34 Summary of Microwear Analysis Data ....... 141

35 Original and Revised Artifact Proportions

Based on Re-examination of Assemblage

Samples....................... 142

36 Absolute Frequency of Tools in each Sample According to Ranked Shaping Type and

Reuse......................... 143 
37 Original and Revised Estimates of Tools for each Ranked Shaping Type and Reuse.... 144

38 Frequency of Arrow Point Types and Their Pettigrew (1977) Typology Correlates... 154 


\section{LIST OF FIGURES}

1 Map of the Lower Columbia River Region Showing the Wapato Valley and the Location of the Meier Site..........

2 The Meier Site Excavation Units in Relation to House 1B.................... 20

3 Map of Reconstruction Habitat Distribution within the Meier Site Catchment Area..

4 Relationship of Lithic Raw Material According to Sharpness and Durability.

5 Character of Bipolar and Freehand Percussion Fractures According to cotterell and Kamminga $(1987,1990) \ldots \ldots \ldots \ldots \ldots \ldots \ldots$ 


\section{CHAPTER 1}

\section{INTRODUCTION}

Understanding technological organization, particularly flaked stone technology, has recently been a major research goal for many archaeologists. A plethora of studies was stimulated by Binford's propositions about how people organize behavior (Binford 1977, 1978a, 1978b, 1979, 1980). Members of society organize behavior around many activities (eg. social, ceremonial, and subsistence). My research focusses on the relationship between two aspects of culturemobility and technology. The many ways people organize behaviors involved in tool manufacture, use and maintenance are referred to as the organization of technology (Nelson 1991). Similarly, the many ways people apply strategies to move around the landscape are called mobility organization (Kelly 1992).

of course, it is necessary to have material to make tools for use. Some activities are conducted where materials for tools are found while other activities require people to carry materials to the location. When material is not found at the activity location, people must solve the problem of transporting required material or tools to carry out the tasks. The bulkiness of a load is constrained by 
moving. Technological organization must work within those constraints. The more people move, the less they will carry. And, the longer they stay, the more they can accumulate. This argument applies to any kind of material. For this research, I am concerned with stone as a material for making tools.

My research goal is to test the hypothesis that people will use an expedient technology when either (a) raw materials are plentiful, or (b) when raw materials can be stockpiled or stored in large amounts (Nelson 1991; Kelly 1985; Parry and Kelly 1987). Expedient lithic technologies tend to be materially expensive (low tool to raw material ratio) and therefore applied in situations where a lot of material is available. Sedentism creates a condition where bulk material supplies can be established (stockpiling) and used (Nelson 1991; Kelly 1985; Parry and Kelly 1987). Expedient strategies are applied when possible to save time and energy in overall technological effort. In situations where material is readily available (naturally or stockpiled), expedient strategies will be applied in order to achieve a goal as quickly as possible, effectively saving time for other activities. The more raw material is available, the greater the ability to use expedient strategies.

The archaeological assemblage I used for testing the above hypothesis is the lithic industry of fine-grained stone left by people at the Meier site (35CO5). The site 
was occupied over a period of approximately 400 years from 1400 A.D. to 1800 A.D. (Ames et al. 1992). At present, the Meier site is the most extensively excavated and analyzed site in the Wapato Valley (Portland Basin) of the Lower Columbia River Basin (Figure 1). My research is the first detailed technological study of Meier site artifacts. This research can be used as a basic theoretical and analytic framework for future analysis of Meier. In addition, it can serve as a comparative data base for future regional studies relating to the organization of technology (including other materials such as bone, antler, shell, wood, and fiber).

The research may also be of particular interest to broader studies of technology because it provides lithic data from an unusual economic and social context. First, the group of people were residentially sedentary huntergatherers (Ames et al. 1992*), a combination that has always been very uncommon in the world. Second, they existed within a region that is historically documented as having social classes (Hajda 1984), an unusual sociopolitical context for stone tools made by hunter-gatherers. Additionally, the stone industry is complemented by a well preserved bone/antler industry, providing the data with an often missing technological component. Unfortunately, wood and other plant fibers are too poorly preserved to complete the inventory of raw materials. 


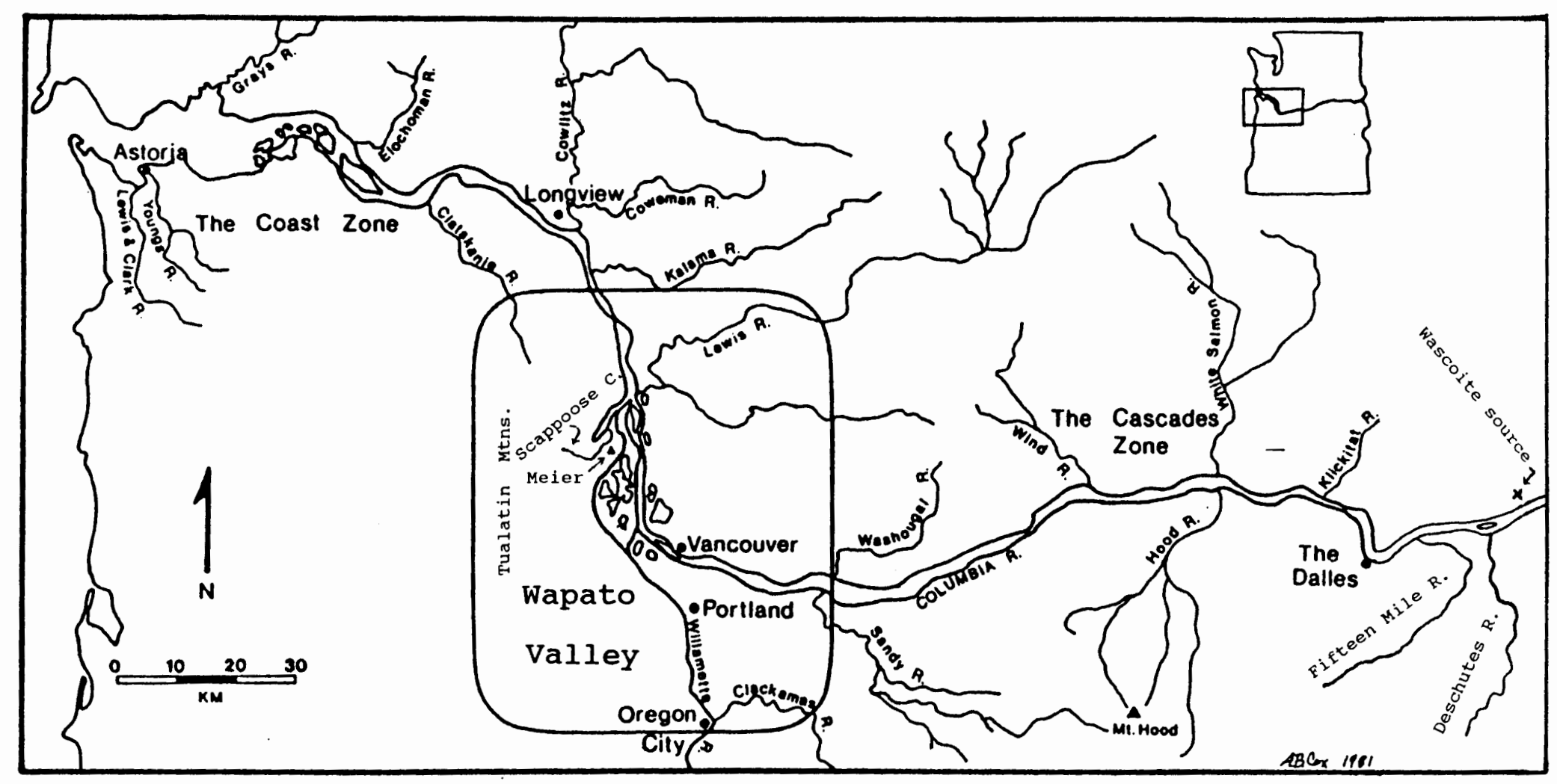

Figure 1. Map of the Lower Columbia River Region Showing the wapato Valley and the Location of the Meier site. 


\section{THE ROOT OF IT ALL}

The theoretical framework for studying mobility and technological organization is well developed and has been recently reviewed by Nelson (1991). She defines technological organization as "...the selection and integration of strategies for making and using tools" (Nelson 1991:57). Strategies are "...problem-solving processes that are responsive to conditions created by the interplay between humans and their environment" (Nelson 1991:58). In a broad view, the organization of strategies is conditioned by economic, social, ideological and environmental variables (Nelson 1991).

Within an economic framework, strategies function to solve survival problems by manipulating the flow of energy. For example, Kelly defines organization as "...the way in which differing amounts of time and energy are invested in various activities" (1983:277). The degree to which these strategies are conditioned by natural selection is debatable (Keene 1983). In evolutionary ecology models, economics (cost/benefit) are used to predict optimal solutions. In an evolutionary context, optimal solutions are expected because natural selection is working on the culture as a whole (Winterhalder and Smith 1981, Jochim 1989). Thus, behavioral organizations are expected to maximize efficiency (Jochim 1989). This is particularly true for technologies 
geared at food getting (Torrence 1989; Nelson 1991). Although optimal solutions are rarely, if ever, actually achieved because people have to balance competing strategic goals, researchers can use expectations based on optimal models (either formal or informal) to compare results (Torrence 1989; Jochim 1989; Nelson 1991). It is within this basic optimal framework that analysts predict the technological organization that will exist within a set of environmental, social, economic and ideological variables (Nelson 1991:61).

\section{TECHNOLOGICAL STRATEGIES}

Technology is organized by implementing three basic strategies-curation, expediency, and opportunism (Nelson 1991). Decisions about implementing strategies are contingent on planning for future conditions. Curation is a strategy of caring for material (raw material, core, preform, tool, tool-kit) in anticipation of (1) inadequate material for making tools at the location of use and (2) time constraints for making tools during the activity (Nelson 1991). Technological effort is implemented before the activity to compensate for constraints in material or time. Curation strategies include advanced manufacture, transport, reshaping, and storage of raw material, cores, preforms, and tools. Overall, curation strategies take more 
effort in shaping (either core or tool or both), but are materially conservative after the core and/or tool is shaped.

In contrast, expediency is a strategy where minimal technological effort is applied before the activity in anticipation of (1) adequate material for making tools at the location of use and (2) minimal time constraints for making tools during the activity (Nelson 1991). Expedient strategies include various ways of making, using, and discarding a tool during the activity. In general, expedient technologies minimize shaping effort (usually constrained by the activity at hand) but cost more in material where they are used.

Finally, opportunism is a strategy whereby technological effort is applied during an activity that was unanticipated (Nelson 1991). In this case, technological effort is a response to the immediate conditions of the activity. In both expedient and opportunistic strategies, "...tools are made and used at the time and place of need, not in advance of need" (Nelson 1991:65). The difference is that like curation, expedient strategies are part of the overall planning process while opportunistic strategies are not. Usually, all three strategies are implemented in various combinations to make up the total organization of technology. 


\section{MOBILITY ORGANIZATION}

Although my research pertains to a group of huntergatherers, mobility strategies may be used by groups exercising many very different subsistence strategies, including agriculture (Hard and Merrill 1992). My thesis assumes that mobility organization affects technological organization. Mobility strategies are the patterns of individual and group movement over the landscape (Kelly 1983, 1985, 1992). Like all organizational aspects of behavior, mobility strategies may differ from group to group and through time according to differences in the environment- physical, social, ideological and technological. The components of mobility that vary are distance of movement, frequency of movement, and location on landscape (ie. repetition of site use)(Kelly 1983, 1985, 1992). Kelly divides mobility strategies into four "dimensions"- residential, logistical, long-term, and migration. Residential mobility is the movement of an entire group's living place. Logistical mobility is the movement to and from the primary living place by part of the group (Kelly 1985). Long-term mobility is the "...cyclical movements of a group among a set of territories" (Kelly 1992:45). Finally, migration is a group's permanent abandonment of a territory (Kelly 1992).

As a basis for discussion, I contrast three types of 
residential mobility: sedentary, semi-sedentary, and nomadic. Sedentism is the "...year-round, continuous use of a site by a single co-habiting group" (Kelly 1985:10; also see Kelly 1992:49). Assuming that long-term mobility and migration do not frequently interrupt this pattern (critical in determining the utility of stone tool stockpiles), distance and frequency of moves is zero and the place of residence is constant for long periods of time. This contrasts with semi-sedentism which is "...the repeated, though seasonal occupation of a site" (Kelly 1985:10). There is some degree of movement (not explicitly defined) and the annual use of at least one location by the entire group for some part of the year. Long term reuse of a site in this pattern is again contingent on relatively infrequent long-term moves and migration. Finally, nomadism is when a group frequently moves and rarely ever lives in the same place twice. At the extreme, nomadic groups move their residence more frequently than semi-sedentary groups and never reuse a living place. There are of course many kinds of strategies for moving residences over the landscape that incorporate different degrees of distance, frequency, and repetition of residential location. A discussion of this variability is, however, beyond the scope of this paper.

Logistical mobility is used for acquiring and transporting resources to the primary group. A task group (as small as an individual) moves over the landscape in 
order to locate, "capture" and bring resources back to the primary group for use or consumption. These resources may have undergone field processing prior to transportation back to the residential base. Although the movement of an entire group (residential mobility) may get the group closer to desired resources, it still may be necessary to use logistical mobility to obtain those resources. Hence, many people must use some degree of logistical mobility to survive, but a group does not necessarily have to move their residence.

The degree of logistical mobility can be evaluated in terms of distance and time travelled by task groups (Kelly 1983). For example, using time as a measurement, day-long procurement trips are easily contrasted with overnight forays. Additionally, task group size is a significant variable (Winterhalder and Smith 1981). The number of people can affect the amount and diversity of resources appropriated and the amount of time spent on the foray. Most discussions about logistical mobility incorporate residential mobility in order to compare two settlement systems- foragers and collectors. Theoretically, collectors tend to have low residential mobility and high logistical mobility while foragers rely on high residential mobility and low logistical mobility. As is often pointed out, this is an over-generalization (Kelly 1992).

Terrain and method of travel (eg. walk, canoe, sled, 
train, car, plane etc.) affect both mobility strategies. These variables affect the amount of area that can be covered and the amount of material (tools and resources) that can be carried during movements. For example, less distance can be covered in areas that are mountainous than on flat, open terrain. Secondly, canoes and sleds are a more efficient means of covering long distances with more material than walking, if the terrain is suitable.

The Meier site was occupied by a residentially sedentary group. Logistics incorporated walking and canoe travel in a flood plain valley with abundant interconnected waterways and lakes. Canoes facilitated mobility by increasing the area and amount of resources and gear (and other commodities) that could be transported to and from the site.

\section{TECHNOLOGICAL DESIGN}

Transportability is the most relevant design feature for studying the link between technological and mobility organization (Nelson 1991). In general, the stuff that people bring with them when they travel is constrained by size (mass and dimension). For logistical forays the stuff is usually "personal gear" (and resources on the return trip). For residential moves, all personal gear and stored resources may be moved. obviously, people make important 
choices about what is brought with them. If they plan to move a lot, then they will make things transportable by making them small, lightweight, and durable. Tool-kits are made smaller by removing waste and extending and broadening the use-lives of tools.

For logistical forays, various design strategies can be applied to personal gear to minimize size. The typical strategies are (1) to precede transportation and use of material with core, preform and tool manufacture to remove "waste" and increase manufacture success (Kelly and Todd 1988; Kelly 1988; Parry and Kelly 1987) and (2) design flexibility, versatility, and maintainability to extend the use-life and broaden the functional potential of each tool (Nelson 1991:70-73; see also shott 1986). Although more material or time may be incorporated into the making of each transportable core or tool, fewer tools are needed for the same amount of work than tools used once without maintenance. Hence, applying shaping strategies to lengthen and broaden use-life before transport minimizes the material needed during forays.

\section{EXPEDIENCY AND RESIDENTIAL SEDENTISM}

Why do we expect a positive correlation between expedient technologies and residential sedentism? Fundamentally, we expect people to use expedient strategies 
when possible because less effort is committed to shaping material. But, expedient technologies require large quantities of material at the location of use (Parry and Kelly 1987). For example, during an activity, the production of many non-maintainable tools is wasteful as compared to bringing a single tool designed for a variety of purposes and repeatedly resharpened. Residential sedentism provides the opportunity to stockpile large quantities of raw material to overcome this problem.

There is a positive correlation between generalized (or unstandardized) core reduction and expedient tool manufacture and use (Kelly 1985; Parry and Kelly 1987). Generalized core reduction is used to minimize core shaping time while maximizing the number of flake blanks produced (Parry and Kelly 1987) and possibly the diversity of flake shapes (Teltser 1991). This is a logical strategy if someone wants to make many tools quickly with little effort in shaping core and tool. Diversity might be an added benefit when various tasks are employed during a single activity set or where the "debris" can be saved for later. Hence, generalized core strategies can be employed to facilitate expedient technologies. Generalized core technologies are not expedient strategies per se. They are merely part of the expedient strategy- the process of making the tool flake-blank during the activity. They also are part of the curation strategy if the "waste" products are 
saved as potential core and tool blanks.

The material cost of maintaining generalized core technologies can be high.

Since the flakes have a low edge-to-weight ratio, a core is used up quickly. And, since the objective is to obtain a flake which is both easily handled and of appropriate size for the task at hand, several flakes may be struck from a core before a usable one is removed (Kelly 1985: $131-132$ ).

The waste factor causes generalized core technologies to depend on high quantities of material. If material does not occur naturally at the site, then people have to import and store large quantities of material. Sites that are continuously or annually reused for long periods of time (eg. long-term sedentary and semi-sedentary residential sites) give the occupants an opportunity to develop quite large stockpiles allowing for generalized core reduction (Nelson 1991; Parry and Kelly 1987). With large stockpiles, expedient strategies can be used often at a residence. The stockpile is of course very bulky. It is site furniture (Binford 1978a, 1978b), not packed up and transported as a whole.

Most explanations of expedient technologies gloss over the fact that stockpiling itself is a form of curation. Material is transported and stored in anticipation of use. Expedient, curated and opportunistic strategies can be applied to material from the stockpile. In general, unless 
there is a raw material source at the locality of use, all expedient strategies are contingent on curated strategies of transport and possibly stationary storage of raw material in some form. I will discuss the utility of stockpiling in terms of curation in the third chapter, Lithic Technology.

\section{DATA EXPECTATIONS}

Curation entails expending energy to store material for future use. Most curation strategies involve the shaping and maintaining of cores and tools to lengthen and broaden their use-lives in order to minimize the material carried to activity areas, time spent during tasks, and failure rates during tasks (Nelson 1991). In general, the more curation used in a technology, the more energy is expended in purposefully modifying stone. In contrast, technologies that are primarily expedient tend to minimize effort in deliberately modifying stone.

Because people at Meier were residentially sedentary, I expect that the technology was primarily expedient. I infer the amount of energy expended in the lithic technology by identifying raw material source and quality, flaking strategies, and amount of flaking. I expect the Meier assemblage to have characteristics of low energy input (expedient). These include (a) local raw materials that are brought to the site with no prior modification, (b) cores 
that do not have standardized shapes (generalized cores), (c) tools that are not or minimally shaped (informal tools), and (d) tools with no maintenance (reuse). I expect few artifacts that show high energy input (curated characteristics) such as (a) exotic raw materials that were shaped before being brought to the site, (b) cores that have standardized shapes, (c) extensively shaped tools (formal tools), and (d) maintained (reused) tools.

\section{THESIS ORGANIZATION}

The introduction of this thesis has provided an overview of the study and the theoretical context within which data was collected and analyzed. Chapter 2 summarizes the physical and social context of the Meier site, providing information about mobility organization in the wapato valley. The chapter discusses the relationship between Meier mobility strategies and subsistence, terrain, lithic raw material distribution, and transportation methods. This background chapter is followed by a more detailed discussion of Iithic technology (chapter 3 ). I describe how flaking strategies and core reduction strategies are related to energy expenditure and mobility organization. Additionally, I present a model of stockpiling. Chapter 4 reviews the attributes, typologies, and methods used in my analysis. To close the chapter, I discuss how these attributes and 
typologies are used to infer curated and expedient strategies of the Meier lithic technology. The results of the analysis (chapter 5) are organized by six behavioral components of the lithic reduction system - raw material procurement, blank acquisition, tool shaping, tool use, tool reuse, and heat treatment. To conclude this thesis (chapter 6), I present a model of the lithic technological organization at Meier based on the six behavioral components. These components are discussed in terms of expedient and curated strategies and how they were related to the mobility organization of the Meier group. 


\section{CHAPTER 2}

\section{BACKGROUND}

\section{SITE CHARACTERISTICS}

The Meier site is a residential locale where at least one house (possibly two) was standing and occupied at any given time. Between 50 and 100 people probably lived there (Ames et al. 1992). The Meier archaeological project focused primarily on one house (house 1B) (Ames et al. 1992) (Figure 2). It was a large (approximately 15 meter by 30 meter) cedar plank house, similar to those described by early European travelers in the Wapato Valley. During occupation of the site, the framework of the house was restructured at least 9 to 15 times and the house plan was reconfigured at least once. Below the plank floor, a complex of pathways and pits was constructed -- forming a cellar -- to facilitate bulk storage of gear and food. Given the ease of which the soil there can be formed, the cellar layout may have been remodelled more often than the floor or frame. The interior structural plan is too complex to summarize here (see Ames et al. 1992).

Continual renovation of the cellar extensively mixed the cultural material at the site. For example, the basement was restructured by building and filling walk and crawl spaces and storage pits. Pit walls and other basement 
structures were constructed from cultural and non-cultural soil mixtures called "reworked fill" (Ames et al. 1992). The basement was constructed with basil sediments, reworked fill, boulders and cobbles, and wood planks and posts.

As one can imagine, determining depositional chronologies within the site is extremely difficult. Based on six charcoal radiocarbon dates, occupation of house IB has been calculated to be between $1400 \mathrm{AC}$ and $1800 \mathrm{AC}$, a 400 year period (Ames et al. 1992). This occupation period includes the latter part of Pettigrew's (1981) Multnomah 2 phase $(700-200 \mathrm{bp})$ and all of the Multnomah 3 phase (200 $115 \mathrm{bp})$. Pettigrew defined these cultural phases using projectile point seriation on a limited testing project throughout the Wapato Valley. The occasional presence of flaked glass, shaped iron artifacts and glass trade beads further supports final occupation of Meier during early European contact.

\section{PHYSICAL AND SOCIAL ENVIRONMENT}

A number of studies have focused on the Wapato Valley's environment (Saleeby 1983, Hamilton 1990a) and Chinookan social organization (Hajda 1984, Boyd and Hajda 1987). I have constructed a one day site-catchment area based on canoe and foot travel over the surrounding terrain to study the site's biogeographic and social settings (Hamilton 


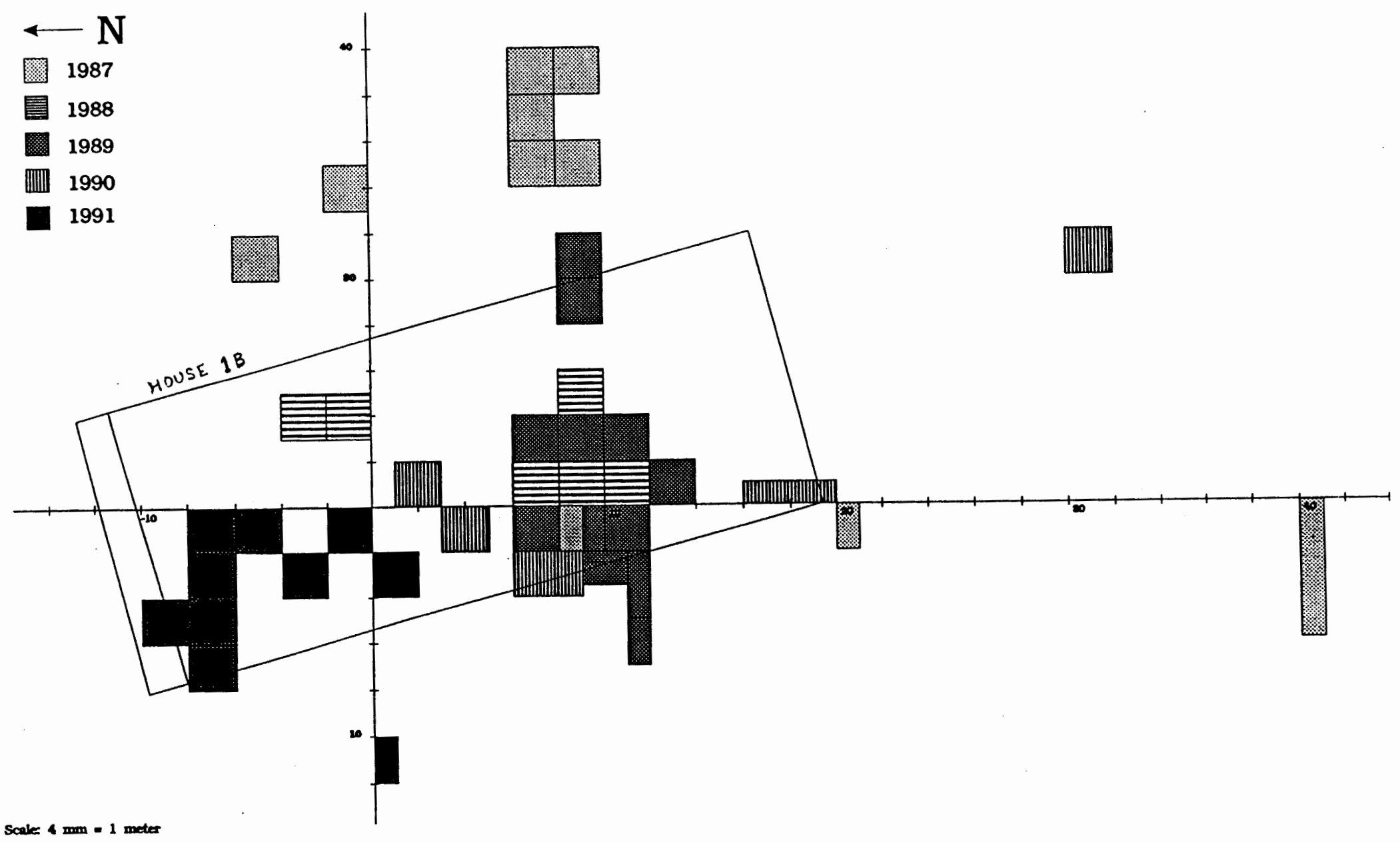

Figure 2. Meier Site Excavation Units in Relation to House 1B. 
1990a). The following summary is based on this study.

The Meier site is in the Wapato Valley section of the Lower Columbia River Valley. The Wapato Valley is part of the Puget-willamette trough running north and south between the cascade mountain range and coastal mountain range (Figure 1). The Meier site is located on the bottomlands of the wapato Valley. The bottomlands have many floodplain features including low terraces, marshes, lakes, channels, and islands.

The Meier site is located on Missoula flood gravels deposited 13,000 years ago during the termination of the Bretz glacial floods (Mullineaux et al. 1978:178). The site is at approximately 20 feet above sea level, just above the pre-dam yearly flood-zone. It sits on the shore of what was once Kilmore Lake. People living at the site had direct canoe access to other waterways, including the columbia River. The "villa" was located at the ecotone between the shallow lake, a dry meadow, and an oak woodland. In general, the spatial distribution of resources and habitats around Meier was clumped but diverse and rich. The sitecatchment area I constructed includes eight different environmental habitats: grassland (21\%), oak woodland (5\%), conifer forest (51\%), riparian (9\%), brush (part of grassland), riverain (not measured), lacustrine (11\%), palustrine (3\%)(Figure 3 ). The habitat proportions within the site catchment are listed in parentheses. These 
habitats represent all seven major habitats that exist in the Wapato Valley (Franklin and Dyrness 1973).

Major resources in subsistence and trade that have been emphasized in historical literature for the Lower columbia people are salmon, sturgeon, eulachon (smelt), camas and wapato. Preliminary analysis of faunal and botanical material from the site suggests that elk, deer, migratory bird, salmon, sturgeon, acorns and hazelnuts were heavily processed at the Meier site (Saleeby 1983; Hamilton 1990a; Ames et al. 1992). Micro-botanical remains from bulk samples have yet to be analyzed but wapato and berries undoubtedly added considerably to the food-base.

\section{SUBSIBTENCE AND MOBILITY}

The variety of subsistence tasks carried out at the site is most obviously reflected in the tools collected from Meier. In addition to the lithic industry of fine-grained material described in this study, a major bone/antler industry and heavy duty stone industry were recovered. Although significant wood and fiber industries were undoubtedly used, few identifiable wood and fiber artifacts were preserved at the site. The heavy duty stone industry includes such tools as hammerstones (bipolar and percussion), anvils (for stone and softer material- possibly bone, antler and fibers), mauls, mortars, pumice bowls, 


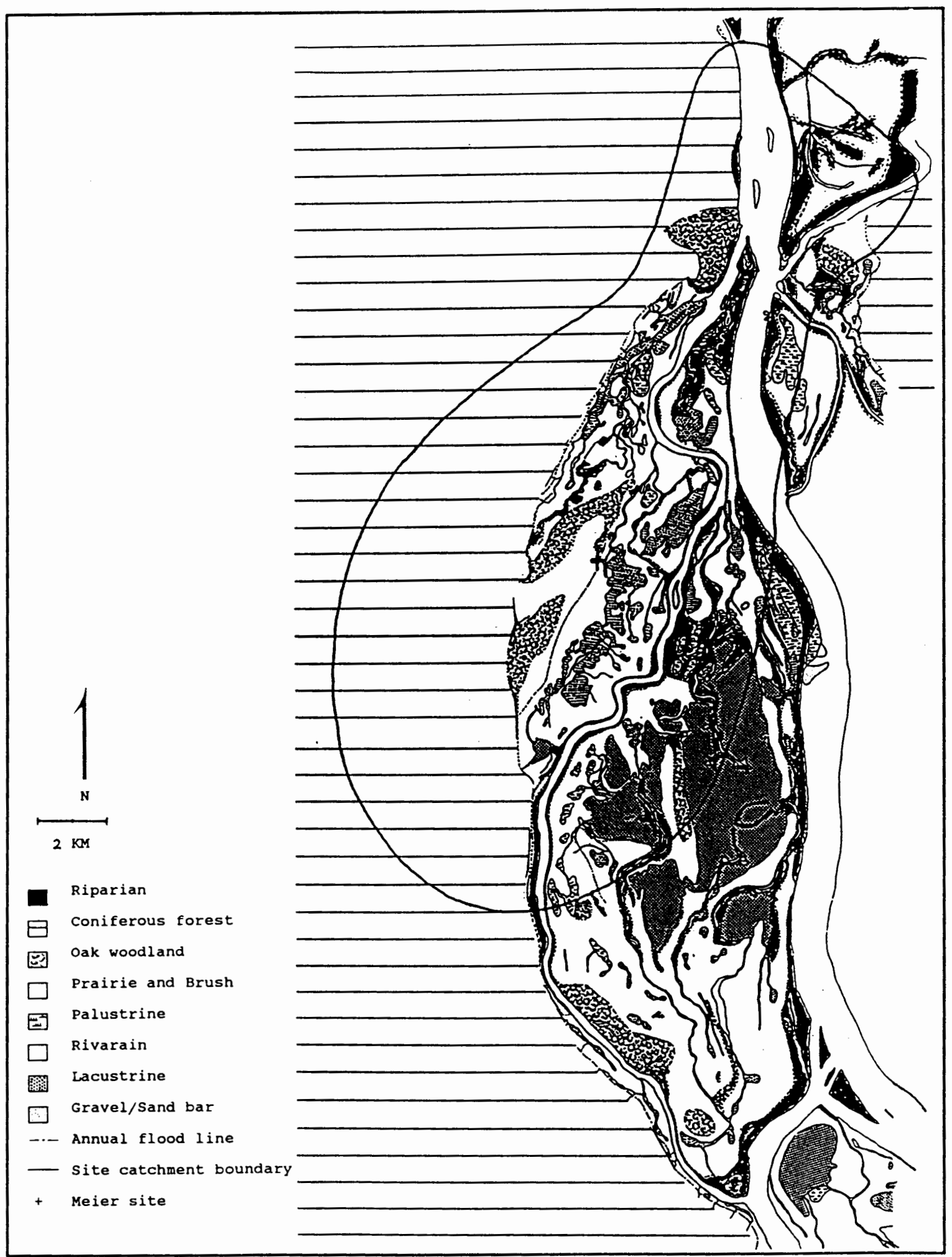

Figure 3. Map of Reconstructed Habitat Distribution within the Meier site Catchment Area (Hamilton 1990a). 
ground adze blades, net sinkers, and abraders. Surprisingly few flaked cobble choppers were recovered. The bone/antler industry includes harpoon equipment, perforators, scrapers/shavers, chisels, and wedges. The tools suggest a vast array of extraction, processing, manufacturing and construction tasks carried out at and away from the site. However, a discussion of the specifics is beyond the scope of this paper.

A paucity of local archaeological research and the quick and almost complete decimation of the wapato valley population by disease in the early 1830's (Boyd 1975) leaves much to be learned about chinookan culture in the area. Nevertheless, we do know some relevant things.

Before European contact, all people in the area were hunter-gatherers who relied heavily on canoes for transport. Efficient use of canoes on extensive waterways of the wapato Valley allowed for a potentially large area for foraging and collecting. Canoes made bulk transport of resources more efficient than walking, particularly if traveling upstream to obtain the resources, subsequently coasting home with the load. Saleeby's faunal analysis of the Meier site midden found the presence of all skeletal elements of large animals suggesting a subsistence strategy in which bulky resources could be "captured" and brought back to Meier for processing. Elk and Deer are the most abundant of these. Because they were readily available in the area, these meat 
resources were probably procured with little logistical mobility. Nevertheless, many resources were probably collected from localities requiring more than one day of travel (eg. anadromous fish).

Saleeby (1983) and I argue that ecological diversity within the Wapato Valley could have allowed sedentism by the Wapato Valley's inhabitants, including those of the Meier site. The historically documented periods of food stress were late winter and early spring (Saleeby 1983). Stored hazelnuts, acorns, wapato, salmon and sturgeon may have alleviated this seasonal stress. The investment in the cellar at Meier supports an inference that storage played a major subsistence role. In addition, trade played a critical role in distributing more spatially and temporally clumped resources such as wapato and salmon throughout the valley and region (Hajda 1984; Saleeby 1983). The use of canoes aided in transporting bulk material long distances (as compared to walking), expanding the potential foraging area and making extensive trade possible.

To further complicate subsistence, a high population density in the wapato Valley may have caused resource stress. Estimates of populations by early travelers were quite high in the area. Hadja and Boyd (Hajda 1984; Boyd and Hajda 1987) explain historical data as showing that many of the people living around the wapato valley had at least social, subsistence, and familial relations with people 
permanently living in the wapato Valley. Such relations facilitated a structured situation in which hinterland peoples periodically came into the area for resources and social events. Based on Lewis and clark observations of village distribution and population (Hajda 1984), approximately 5,200 people shared the site catchment area with Meier in Spring, but only 1,600 people in Fall (Hamilton 1990a). The actual carrying capacity for the area has not been estimated. To deal with resource stress caused by dense population, periodic long forays for hunting, fishing, gathering, and trading were undoubtedly used to acquire resources from outside the valley. Historical descriptions support an argument that the people in the Wapato Valley had a well established and elaborate trade system within and outside the valley well before EuroAmerican contact (Hajda 1984; Ruby and Brown 1976).

Boyd and Hajda (1987) suggest the Wapato Valley had a permanent, sedentary population with a spring-summer influx of people. The Meier site probably represents one of the many permanently occupied communities in the wapato valley. Looking at the landscape, distribution of resources, and recorded village distribution at the end of occupation, there was no place for Meier people to move that would benefit them anymore at any time of year. They already had easy access to other people and critical resources throughout the year. Basically, if they did not want to 
move, they did not have to.

\section{RAW MATERIAL SOURCES}

Fine-grained silicious lithic resources available to Meier people include outcrops, exposures of Missoula cobbles (ie. Troutdale formation), and river and stream gravels. The raw material distribution of cryptocrystalline silicates (CCS) around the site is in a gradient of increasing quality with distance. Low quality, abundant local materials are alluvial gravels on the valley floor and outcrops in the Tualatin Mountains. High quality lithic material can be obtained relatively long distances from the site (eg. Wascoite and Biggs chert approximately $210 \mathrm{~km}$ up the Columbia River). Hence, high quality outcrop sources are considered exotic raw material while alluvial gravels are locally available.

Virtually all lithic material used at Meier was derived from alluvial gravels. Such gravels are ubiquitous in river and stream beds throughout the region (although virtually absent in streams of the Tualatin Mountains). These CCS cobbles are likely eroded from formations in the cascade and Coastal mountains and Missoula gravel deposits along the Columbia River corridor. Further investigation is needed to determine more precisely the distribution of cobble sources and their utility as exploitable resources (abundance, 
quality, and seasonal availability). A small percentage of the Meier assemblage is from small river worn pebbles of obsidian. Because these probably came from the same gravels as the ccs used at Meier, sourcing the obsidian may provide information on gravel source locations. Similar methods of chert sourcing should also be applied.

The closest known lithic cobble source is $2 \mathrm{~km}$ from Meier ${ }^{1}$. This source was likely accessed by walking over flat, dry grassland and oak woodland. Most additional cobble sources are various eroding exposures of the Troutdale formation (Missoula flood deposits) along the banks of the Columbia River and gravel beds in tributary river mouths along the Columbia and willamette rivers (eg. Eckert 1987). These sources are further away and most accessible by canoe.

Alluvial gravels are a locally occurring and readily available fine-grained lithic resource. Given the large number of gravel sources in the area, it is reasonable to assume that a sufficient supply of cobbles was available within a round trip of no more than 1 or 2 days. Cobble collecting may have been embedded in other procurement activities such as fishing ${ }^{2}$. In such cases, cobble

${ }^{1}$ The source is a four mile stretch of scappoose Creek that flows over Missoula flood deposits where it passes within $2 \mathrm{~km}$ of the Meier site (Figure 1).

${ }^{2}$ For example, I have collected ccs river cobbles at the Sandy River mouth and Clackamas River mouth. Both places are also known fishing localities. Anadromous fish, 
localities chosen for exploitation would have been contingent on their relationship to other resources. The cobble sources could have been at fishing localities (eg. tributary river mouths of the columbia) or along foray routes. Canoes would have facilitated carrying the load of raw material with other resources.

All of the known local gravel sources are in river and creek channels. Availability of river cobbles is seasonally constrained by high water covering gravel bars in late fall through spring, particularly in late spring when mountain snow melt floods the region. For example, gravel bars in Scappoose Creek were completely covered by water in March of 1994. Stockpiling at a residential site could compensate for this seasonal availability.

\section{SUMMARY}

In summary, the house was probably continuously occupied for 200 - 400 years. There was a tremendous amount of energy and resources invested in building the plank house with a deep, complex cellar for storage (Ames et al. 1992). Although there may have been people moving in and out throughout the year, people were probably living in the

including eulachon historically and presumably prehistorically ran up the Sandy River. The Clackamas River mouth is adjacent to Willamette Falls, an ethnographically documented salmon and lamprey fishing locality. 
house all year long. The group of 50 - 100 people living in the house practiced a hunter-gatherer subsistence strategy. They had a wide range of resources readily available. Major resources include deer, elk, various anadromous fish, wapato, berries, hazelnuts and acorns.

These hunter-gatherers were primarily foragers. Most resources were probably procured with little logistical mobility, but longer forays and trade supplied a good portion of imported resources. Raw materials for making fine-grained lithic tools could be obtained in the surrounding area and possibly through the elaborate trade network. As ethnohistoric evidence suggests, canoes facilitated bulk collecting and transport of raw material (as well as food) while permitting exploitation of a larger area in shorter periods of time than walking. A complex network of waterways throughout the floodplain that interconnected lakes and marshes with each other, the Willamette River and Columbia River made canoe access to a broad range of resources possible. Overall, gear and resources transported during logistical forays is little constrained by size where mobility organization emphasizes short forays with canoes. Because resources could be transported in bulk form, people could save time in the field by processing at their living place.

of course, all of this has important implications for lithic technology at Meier. First, they were large game 
hunters. Hence, we expect lithic tool kits to meet such functional requirements. Second, a wide variety of manufacturing and processing tasks are carried out at residential sites like Meier. For example, stones with sharp durable edges (ie. various obtuse edges) are required for the shaping of bone and wood tools, two major industries at Meier. Thus, we expect a variety of processing and manufacturing type tools such as cutters, shavers, scrapers, gravers and perforators.

The continuous use of the site for close to 400 years permitted a relatively stable system of stockpiling and associated expedient technologies for on site tasks. Alluvial gravels could be obtained locally, but most efficiently during seasons of low water. In addition, canoes facilitated transport of ample raw material and larger tool-kits, relieving the possible pressures of putting energy into making transportable lithic cores and tools. Given what is known about mobility and raw material availability at Meier, curation should have been applied mostly in situations where time during tool use was crucial or risk of failure high (as in projectiles for hunting), rather than for transportation or material conservation. 


\section{CHAPTER 3}

\section{LITHIC TECHNOLOGY}

In this chapter I describe in more detail relevant stone technologies. I begin by discussing two basic flaking techniques - freehand percussion and bipolar percussion. I then compare the advantages and disadvantages of standardized and generalized core reduction. Next, I put standardized and generalized core reduction into the context of particular lithic technologies - biface technology, blade/microblade technology and flake technology. After discussing lithic technology, I discuss a model of stockpiling as a curation strategy for facilitating expedient strategies through raw material availability. Throughout the chapter, lithic technology is discussed in terms of mobility through transportability design minimizing size while maximizing functional diversity and use-life, and non-transportability - minimizing technological effort while using abundant material.

\section{FLARING TECHNIQUES}

Cores were reduced at Meier using three basic techniques- freehand percussion, bipolar percussion, and pressure. Only three pressure cores (ie. microblade cores) 
were identified in the assemblage. Because pressure flaking played such a minor role in the lithic core technology at Meier, I avoid discussing the energetics involved.

studies in brittle solid mechanics have found fundamental differences in the way freehand percussion and bipolar percussion fracture stone. These fundamental differences and observations by contemporary flintknappers aid in understanding the advantages and disadvantages of the two techniques.

When using direct freehand percussion, the core is held in one hand and struck by a percussor on its margin. Generally, the angle of the striking platform must be less than 90 degrees. The product of the blow is a Hertzian flake (Crabtree 1972; Cotterell and Kamminga 1987, 1990). The shape and size of the flake can be controlled by the size and material of the percussor and the amount and direction of applied force (Crabtree 1972). Highly standardized cores, such as conical blade cores and Solutrian bifaces, attest to the control that can be applied by highly skilled people when using the percussion technique. Once a standardized core (including percussion bifaces) has been produced, there is little waste when producing flakes from the core because Hertzian fractures tend to be shallow and follow flake scar ridges on the surface of the core. Hence, there is a high success rate in making flakes with good edges suitable for both expedient 
cutting tasks (Parry and Kelly 1987) or subsequent shaping.

In contrast, the bipolar technique is less easily controlled (Kelly 1985; Parry and Kelly 1987). When using the bipolar strategy, the object piece is set on an anvil and its top struck by a percussor. The fracture is caused by wedging and fracture directed by compression between the two poles of contact- anvil and hammer (Cotterell and Kamminga 1987, 1990). Because the fracture (or fractures) passes through the core, rather than following the surface, the product types may vary widely (Shott 1989a; Draper 1992). Most bipolar flakes and remnant cores have few sharp edges. If standardized flakes with a high ratio of edges per unit mass are desired, the bipolar strategy would likely not be used to make blanks. On the other hand, if long, sharp edges are not always desired, then more bipolar flakes and remnant cores can be used. In fact, the bipolar method can be advantageously used to increase the number of blanks and diversity of blank forms where a variety of expedient tools are desired. Additionally, more straight flakes can be produced from a small rounded pebble than direct freehand percussion (John Fagan, personal communication 1991).

There are other advantages to using the bipolar method. Bipolar reduction is most useful as a strategy for increasing the number of potential striking platforms. The added striking platforms lengthen the potential reduction 
trajectory of the core ${ }^{3}$. The bipolar technique is particularly advantageous when dealing with round and small source material. First, it can be used to reduce items with striking platforms as great as 180 degrees. This doubles the 90 degree maximum for freehand percussion. It can also be used on other platforms that cause problems with freehand percussion. Hence, otherwise exhausted percussion cores continue to be reduced by applying bipolar strategies.

second, the reduction trajectory of material can be lengthened by using the bipolar technique to reduce nuclei that are otherwise too small for efficient freehand percussion. The anvil is used as a brace and flake length maximized because the fracture passes completely through the piece. Hence, bipolar reduction is used to recycle exhausted tools (Kelly 1983, Parry and Kelly 1987) and exhausted percussion cores. The bipolar method makes small, rounded source material economically usable and may be used to intensively reduce material where raw material sources are small in size and scarce. Bipolar technology is very effective for reducing alluvial gravels.

If the bipolar technique is discriminately employed, it can lengthen reduction sequences with little waste. Differences in the amount of waste created during bipolar

${ }^{3}$ The core reduction trajectory is the variety of ways a nucleus can be reduced to produce flake blanks. The reduction trajectory is lengthened by removing more flakes from the nucleus than is possible using only the freehand percussion technique. 
reduction may be related to the context of its use (Fagan, personal communication 1993). For this reason, I do not assume that bipolar reduction is a wasteful strategy of reduction. It is perceived as an effective strategy to reduce small or rounded material, increase flake diversity, and make specialized forms of core tools and flake blanks. Bipolar reduction is also viewed as expedient in terms of the low energy costs in forming bipolar cores as compared to standardized blade and freehand percussion biface cores.

There is controversy over the use of various bipolar products (flakes and cores). Most recently, Shott (1989a) and LeBlanc (1992) have debated over the use of pieces esquillees as cores or wedges. Shott (1989a) and Draper (1992) have additionally described bipolar products as useful for expedient tools of differing functions. The advantage of using the bipolar technique for tool production is that one can remove mass quickly from small pieces (Parry and Kelly 1987). Tabular and bifacial core-tools are easily produced because flakes pass from one pole to the other, hence, removing mass all the way across the face of the tool. The flat ends (facets) in contact with the anvil and hammer tend to be crushed but are useful as wedge bits and shavers for more heavy-duty work. In addition, straight, sharp edges on a single flake margin can be quickly manufactured by intersecting fractures on the sides of the blank not in contact with the anvil or hammer. This can 
result in both tabular (pieces esquillees) and columnar products. These may be useful for cutting and shaving. The blunted ends of columnar pieces may also be useful for perforating (in conjunction with sharp obtuse flake-scar ridges on the sides of the tool) and graving (LeBlanc 1992). Finally, thin, flat, and straight flake blanks can be efficiently produced from the later stages of core reduction (once a pieces esquillees or columnar form has been generated).

In summary, bipolar reduction is an efficient and fast technique to reduce small rounded pieces of material (eg. alluvial gravels and exhausted percussion cores). It can function to conserve material when raw material is scarce by being employed to reduce exhausted tools and cores (Kelly 1985). Bipolar reduction can be used for making specialized forms such as straight core tools (eg. pieces esquillees and columns) and thin, flat, and straight flake blanks. Finally, as the ethnographic literature reveals, the bipolar technique can be used effectively for quickly "smashing" cobbles to produce flakes for expedient use (Kelly 1985, Parry and Kelly 1987).

To conclude, bipolar reduction can be used to reduce cores and shape tools. As with percussion flaking, bipolar flaking should be considered as a potential strategy for reducing stone in flake blank production and tool shaping. The bipolar technique can be used effectively for a variety 
of purposes. The context in which it is used is critical in understanding its efficiency as a strategy.

\section{STANDARDIZED VS. GENERALIZED CORE TECHNOLOGY}

Standardized and generalized core technologies differ from each other in several key aspects and each is useful for particular circumstances. Functionally, standardized cores produce a desired tool-blank shape. Most formalized core technologies are designed to repeatedly produce flakes with high sharp-edge per unit mass ratios (Parry and Kelly 1987). For example, the primary strategy in formalized blade and biface systems is to maximize flake length while maintaining thin flakes with sharp edges.

In contrast, generalized cores produce more varieties of flake shapes. Kelly and Parry (1987) assert that their exists no planned flake form. In fact, as mentioned above, the desire may be to create product diversity for a wide range of expedient functional edges. The sharp-edge to mass ratio is accordingly less than that for most standardized core technologies (Kelly 1985; Parry and Kelly 1987). The number of flakes produced from a single core is directly related to the shape and size of the original piece of raw material.

Generally, there is more energy expended during shaping of standardized cores than unstandardized cores. 
standardized cores are usually deliberately shaped and have well prepared platforms to minimize flake failures (Nelson 1991; Kelly 1985). In contrast, unstandardized cores are not shaped. The resultant morphology is a product of taking advantage of the nucleus shape rather than creating a particular core shape. For the standardized core technology, energy is expended into shaping a core before producing flakes for tools. In contrast, little energy is invested in preliminary shaping of generalized cores. However, some energy is spent creating platforms when none are available (eg. using the bipolar technique to split a rounded nodule to create a new freehand percussion platform). This occurs throughout the core reduction process. In general, the generalized core technology does not emphasize repeatedly creating a preconceived core shape. To some extent, the shape of the cores are dependant on the shape and size of the raw material nodule. In addition, this shape may change radically through the reduction sequence because of choices made on removing individual flakes and creating new platforms. This adds considerably to diversity of core shapes (and therefore flake shapes) in unstandardized technologies.

Because there is no preconceived core shape and no formalized core-shaping in expedient core technologies, a wider variety of nuclei is available to the flintknapper. Thus, eclectic sources of lower-grade material can be used. 
However, when reducing unstandardized cores for specific kinds of flake-blanks, more material may be wasted. Essentially, standardized core technologies are more materially efficient for specific flake types once they have been shaped, but obtaining the desired nucleus and shaping the core costs more in time and effort (and possibly material).

Platforms on unstandardized cores are not prepared or are only minimally prepared to make flake removal possible (Parry and Kelly 1987). Preparation is usually limited to light percussion and abrading to rid platforms of overhangs and to regularize edges. Platform preparation on prepared cores can be extensive to minimize flake failures that will often destroy the core that was painstakingly made.

Because standardized cores are designed to successfully produce a flake with every blow, less mass is needed to make the same number of usable flake blanks. Additionally, standardized cores consistently produce flake blanks with a high edge-to-mass ratio. Hence, there is a lot of workable edge on each flake-blank. These are efficient transportable design features that make standardized cores practical for mobile groups. By being transportable, they can be easily carried and flake blanks efficiently produced as needed for either curated or expedient tools. In contrast, generalized cores are materially inefficient and therefore not part of tool-kits that are extensively transported (Kelly 1985). 
Generalized core technologies are primarily used when lithic material is readily available (Nelson 1991; Kelly 1985;

Parry and Kelly 1987; Bordes and Crabtree 1969).

stockpiling is a means by which people can be sure there are large quantities of material readily available for unstandardized core technologies (as well as standardized core technologies) when people plan to stay and repeatedly use the location.

\section{IITHIC TECHNOLOGY}

In this section I briefly discuss two strategies that use standardized core reduction and one that uses unstandardized core reduction. Standardized cores can be designed in different ways to fulfill certain needs. Two often cited technologies that use different standardized core designs in high mobility situations are biface core technology and blade core technology (including microblade). In a biface technology, a tool is created by substantially flaking the periphery of a blank on both faces. The resulting biface has the potential of being used simultaneously as a standardized core, a generalized tool (flexible, versatile, and maintainable), and a hafted reliable tool (Kelly 1988). These combined "organizational roles" make bifaces efficient for providing material, functional diverseness, and reliability in one transportable 
design. Blade technologies are transportable because, when the core is well prepared, they are efficient at quickly producing many long, narrow flakes with a high edge-to-mass ratio (Morrow 1987; Parry and Kelly 1987; Kelly 1985; Nelson 1991). For these reasons they are often used as replacement blades in multi-component cutting tools such as sickles. As discussed above, unstandardized cores are not specifically designed. Rather, nodules are reduced in certain ways depending on the nodule and the task at hand. Unstandardized cores are used in what Kelly (1985) terms "flake technology." Flake technology is used with expedient strategies to save production time during the activity at hand (Kelly 1985; Parry and Kelly 1987). In general, tools are produced quickly using unstandardized cores. The tools are minimally shaped, used once and discarded with little or no maintenance. Flakes selected as tools are usually efficient because flakes can be empirically tested for the task at hand (Parry and Kelly 1987:287).

Although the ethnographically known groups using flake technologies are all highly mobile, Parry and Kelly postulate that stockpiling by sedentary people could be used to facilitate flake technologies (Kelly 1985; Parry and Kelly 1987). Stockpiling high quantities of material would be used to overcome the wastefulness that can result from unstandardized core reduction and the immediate discard of tools when their utility is gone. 
In summary, the type of expedient flake technology described by Parry and Kelly (1987) are not transportable because they have a high waste factor. This may be compounded by the use of poor quality gravel sources making many nodules unreliable for transport. Flake technologies will be used when possible because shaping time of cores and tools is minimized while functional efficiency remains high. For highly mobile people, the use of flake technologies is contingent on natural raw material distribution. When they are in areas with naturally occurring raw material, they may use flake technologies. But when planning to be away from stone sources, conservatory strategies will be implemented such as blade technologies and biface technologies. In contrast, residentially sedentary people can procure and store large quantities of material. Storage counteracts the problem of distance to raw material sources during activities. It maintains the ability to use flake technologies for expedient and opportunistic strategies, saving time and effort in modifying stone. The stockpile can, of course, also supply material for biface technologies and microblade technologies used at and away from the site (Nelson 1991).

\section{THE UTILITY AND BTRUCTURE OF A BTOCKPILE}

The stockpile is an integral part of the argument that 
expedient technologies will be emphasized by more sedentary people. Thus, I think it is worthwhile to more fully explain the utility and factors influencing the structure of the stockpile.

A stockpile is the available material base from which potential tool blanks may be selected or manufactured. Stockpiles are created by the accumulation of raw material that is collected, stored, reduced, used, and discarded at a site. They are, therefore, composed of material in all stages of manufacture (Nelson 1991). Stockpiles are not transportable. They are, however, dynamic through time. They may vary according to (1) the amount, size, and type of raw materials imported (2) the flaking strategies applied (3) the various tools and cores transported and discarded away from the site, and (4) the intensity of material use. Material from the stockpile may be used for all three technological strategies- curated, expedient, and opportunistic.

Because the stockpile serves to store all manufacture stages, it provides the material means of acquiring many differently shaped tools quickly. More diversity may be created by importing a wide variety of material types. High-quality material is particularly important for curated cores and tools that need to be precisely shaped for reliability, maintainability, flexibility, and transportability (Kuhn 1991; Bamforth 1990; Kelly 1985; 
Crabtree 1964). Such material has less chance of failing during shaping and use than low-quality material with flaws that hinder control of flaking and obstruct otherwise functional edges. A reliable use-life is particularly important in high risk situations where material or time is not readily available during resource procurement tasks (Kelly 1985; Torrence 1983, 1989). Shaping stone before it is transported from the source insures the reliability of the material (Nelson 1991). In general, we expect highquality materials to be used in technologies that frequently use curated strategies. In contrast, more low-quality materials will likely be used in technologies that frequently use expedient strategies because the use-life of tools and cores is short. Additionally, low-quality material can be used when material is readily available for replacement tools. Working at a raw material source and building a stockpile are two ways to insure that enough material is available (Nelson 1991).

At residential sites, there may exist a division between shared and personal raw material. For example, a stockpile of manufacturing debris may be more communal than other personal caches of raw material. Personal caches might contain hard-to-obtain high quality material and shaped cores and blanks for valued tools. In contrast, the communal stockpile may contain already worked material including cores, blanks, discarded preforms and "exhausted" 
tools and debitage. In the communal stockpile, most of the material would be easily obtained, low-quality nodules and small pieces of the high-quality raw material with little potential use-life remaining. In Binford's (1978a, 1978b) terms, the communal stockpile is "site-furniture" while a cache of high investment material (nodules, cores, blanks, preforms, tools) is "personal gear."

The stockpile provides a ready-to-use, diverse population of raw material for making or selecting tool blanks. Diversity of material shapes and types makes stockpiling an efficient practice at residential sites where many different processing and maintenance tasks are carried out in a single local (including the manufacture of curated tools). It seems probable that the more sedentary the group, the more efficiently the stockpile can be maintained. Essentially, the residential stockpile is a reliable, expedient raw material source.

\section{ABSEMBLAGE STRUCTURE}

To close the chapter, I list the expected assemblage structure for expedient and curated technologies. For expedient technologies there should be:

(1)* high frequency of unstandardized (generalized) cores (2)* high frequency of flake tools that are minimally shaped and maintained

(3) high frequency of non-used waste material relative to tools

(4) high frequency of core reduction flakes relative to 
tool shaping flakes and resharpening flakes

(5) * high frequency of poor material

(6)* low frequency of heat treatment (when needed for shaping material)

In contrast, curated technologies should have:

(1)* high frequency of standardized cores

(2) * high frequency of intensively shaped and maintained tools

(3) high frequency of tools relative to waste

(4) low frequency of core reduction flakes relative to tool shaping flakes and resharpening flakes (given not at core manufacture local)

(5)* high frequency of high-grade material

(6) * high frequency of heat treatment to facilitate tool shaping (when needed for shaping material)

I primarily use those with an astrik (*) to evaluate the Meier lithic assemblage. 


\section{CHAPTER 4}

\section{METHODOLOGY}

This study examines the relationship between mobility strategies and technological organization of small, finegrained flaked tools, not heavy duty, typically more coursegrained, tools (eg. choppers, hammerstones, mauls, abraders, mortars). Although heavy stone technologies are pertinent to studies of mobility and technological organization, they are less frequently part of transportable tool-kits. In addition, the shaping technologies are often quite different because of differing material properties. Finally, flaked stone industries are the most studied in the context of mobility and technological organization, probably because they are well documented in both transported and nontransported tool-kits. The same analytic approach can, of

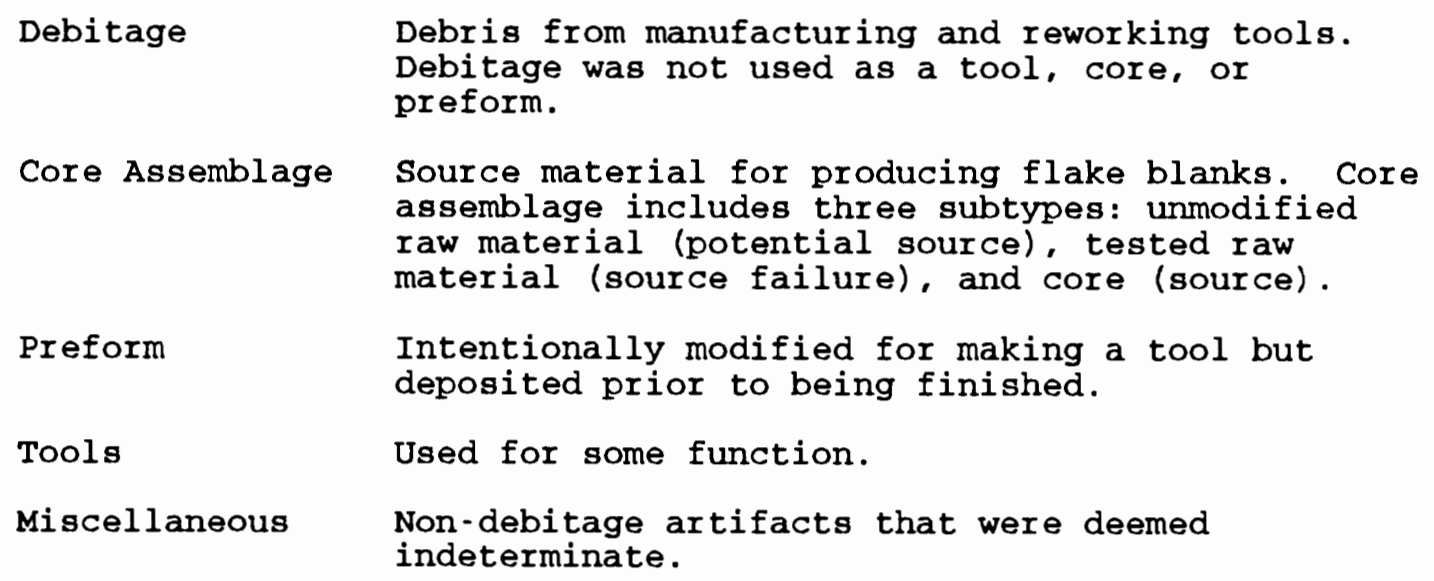

Table 1. General Lithic Artifact Classes. 
course, be applied to any and all industries.

The full set of steps used in making stone tools in a technological tradition is sometimes called a lithic reduction system. The particular steps followed in a particular case is the lithic reduction trajectory. To identify the frequency of artifacts that fell out of the system at different stages, I classified artifacts into five general categories (Table 1 ).

\section{ARTIFACT SAMPLING}

This analysis is based on four samples of artifacts from two populations- field bag debitage and cataloged artifacts (Table 2). Samples were taken to limit the time required for analysis while accurately representing technological variability in the large artifact assemblage of approximately 77,382 specimens excavated from the Meier site'. A $5 \%$ sample of field bag debitage (population 1) was first examined. This first sample (sample 1) is 3,608 specimens from a total of 72,160 debitage artifacts. The field bags contained debitage that was separated by level and feature from $2 \times 2$ meter excavation units. Sample 1 was

\footnotetext{
'The analyzed assemblage contains artifacts excavated during the 1987 - 1990 field seasons, but not 1991 (Figure $2)$. The collection was derived from deposits inside and outside (midden and yard) of house 1B. The northern end of the house was excavated in 1991 and is therefore not included.
} 
taken only from debitage bags that contained more than 10 specimens.

The second population (population 2) includes all 5,222 non-debitage artifacts that were field cataloged at the time of analysis and after my initial field debitage examination. Sample 2 represents the entirety of population 2 . All of these artifacts were at least classified into basic artifact types (core, preform, tool, miscellaneous).

A significant number of "expedient" tools were not recognized in these initial two samples. During my preliminary analysis I became aware that I had wrongly classed a significant number of tools as cores and preforms. Although the tools looked similar to cores and preforms, they had damage that $I$, in collaboration with Cameron Smith (1992), could safely attribute to use-wear. In addition, I was sure that micro-wear analysis would significantly increase the number of "used-flakes" found in the debitage

\begin{tabular}{|llrc|}
\hline Sample & Description & n & $\begin{array}{c}\text { Percentage of } \\
\text { Population }\end{array}$ \\
\hline $\begin{array}{l}\text { Population } 1 \\
\text { sample 1 }\end{array}$ & $\begin{array}{l}\text { debitage assemblage } \\
\text { first exam }\end{array}$ & 72,160 & - \\
mample 4 & micro-wear study & 3,608 & 5 \\
& 1,462 & 2 \\
Population 2 & non-debitage assemblage & 5,222 & - \\
sample 2* & first exam & 5,222 & 100 \\
sample 3* & second exam & 256 & 5 \\
\hline 14t sample of amorphous cores, tabular cores, and early stage \\
preforms. These artifact types were chosen because they had the \\
highest freguency of unidentified tools. Artifact categories \\
other than these do not contain a significant number of \\
unidentified tools.
\end{tabular}

Table 2. Lithic Analysis Samples. 
in the field bags. In order to more accurately describe the assemblage in terms of tool shaping and reuse, I decided to reanalyze a portion of the non-debitage artifacts (sample 3) and use data from a preliminary micro-wear study of specimens from a debitage field bag (sample 4; Smith 1992). This study was done by Cameron Smith and myself.

The third sample, then, is a reanalysis of a segment of population 2. It consists of a $14 \%$ sample $(n=256)$ of nondebitage artifacts that were initially classed as amorphous and tabular cores and "type 2" biface preforms $(n=1,798)$. other non-debitage categories were randomly checked for tools but so few were found that they were not formally reexamined. This more careful examination yielded a significant number of expediently shaped, non-retouched tools. Extrapolating from sample 3, approximately $9 \%$ of the sample 2 preforms and cores are tools.

Finally, the fourth sample is $2 \%$ of population 1 (field bag debitage). The field bag contained artifacts from a single level of a single unit from the in-house deposits of house 1B. The procedure is described in Smith (1992) and summarized here in appendix 1. Suffice it to say that upon observing the debitage with a $10 x-25 x$ dissecting microscope, an estimated $2 \%$ of the overall debitage are probably "used-flakes." This vastly increases the expedient tool category from $n=684$ (based on counts prior to microwear analysis) to $n=2,214$. It also changes related metric 
and qualitative data. For example, there is a higher frequency of "smaller" tools that are made from biface thinning flakes in population 1 than population 2 (cataloged artifacts) .

Because my re-examination (sample 3 and 4 ) significantly changed the estimated number of tool frequencies but were carried out differently, I present the original and revised tool estimates based on each sample (sample 1,2, sample 3 , and sample 3,4 ) in table 35,36 and 37 , appendix 2 .

\section{LITHIC RAW MATERIAL}

When acquiring stone for tools, there are three critical raw material variables to consider- geographic distribution, nodule size, and material quality (Kelly 1985). The importance of geographic distribution was discussed within the context of transportability. Generally, the further stone sources are from the place it is used, the more planning and effort necessary to transport the stone to the use local. Technological strategies will be applied accordingly (eg. conservation of difficult to procure material). Nodule size was discussed above in terms of the necessity of using bipolar reduction on small nodules. Additionally, nodule size may limit the size of items produced (cores and tools). 
Material quality influences the flaking quality of stone. Physical and chemical properties of stone affect how it can be reduced (Goodman 1944; Crabtree and Butler 1964; Kelly 1985; Goodyear 1979; Bamforth 1986) and how effectively it can be used for particular tasks (Goodman 1944 ; Crabtree 1967; Semenov 1964; Keeley 1980; Vaughn 1985). I am particularly interested in how the nature of the raw material affects the shaping of stone.

Raw material quality can be described in terms of material flaws and an overall edge durability-edge sharpness ratio. In general, edge sharpness is inversely proportional to durability (Figure 5) (Callahan 1979:16; Kelly 1985). However, the more durable a stone, the more effort is necessary to remove flakes. The durability and sharpness

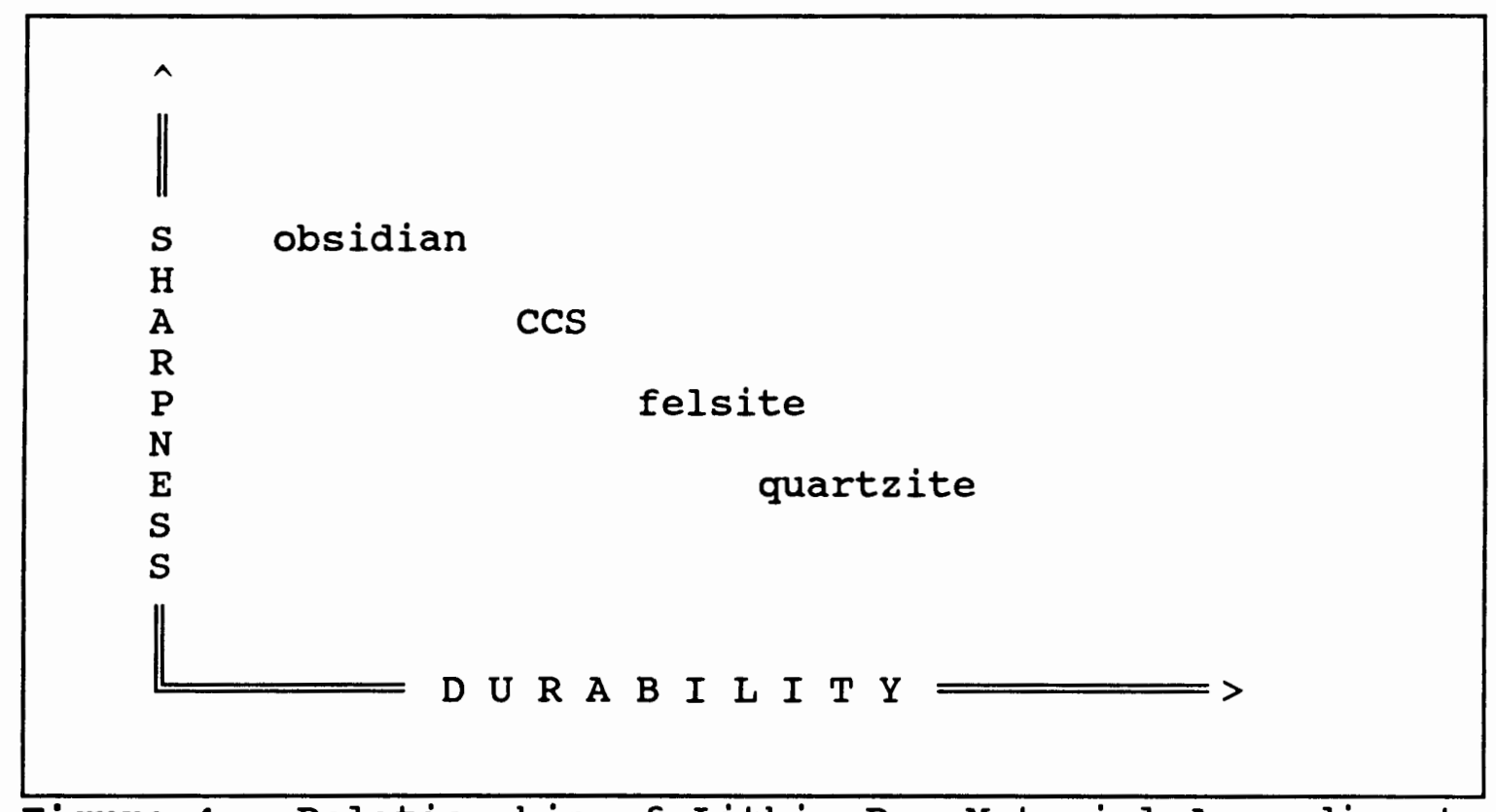

Figure 4. Relationship of Lithic Raw Material According to Sharpness and Durability (Kelly 1985). 
character of raw material influences functional potential of tool edges (see Kelly 1985). I did not quantify durability and sharpness of raw material but, as exhibited in Figure 4, mineralogical types (described below) roughly correlate with this variable (Kelly 1985).

The second aspect of raw material quality, material flaws, affects the reliability of tools. Minimizing failures during shaping and use is crucial for curated tools that have long and variable use-lives (Bamforth 1986). Material flaws include pits, cavities, incipient fractures, and drastic textural variation. Basically, the more flaws in a stone, the more fracture lines are interrupted. Fracture failure or unpredicted fracture directions cause shaping failures that interrupt reduction and function of the tool (Bamforth 1986; Crabtree 1972).

I used a qualitative classification to evaluate material quality. The classification criteria are based on the surface density of flaws (Table 3 ). The most used attribute was the approximate percentage of flawless surface area.

\section{Mineralogical Categories}

Raw materials at the Meier site include five general mineralogical types and one residual category: cryptocrystalline silicate (CCS), obsidian, basalt/felsite, manufactured glass, quartzite and miscellaneous other. 
specimens were typed using three visual characteristics:

color, translucency and texture. of particular significance is the incredible diversity of mineralogical types (and quality) within the CCS category, a consequence of exploiting the regional gravel sources. Appendix 3 provides a brief description of the mineralogical types found in the Meier assemblage to elucidate the variability of raw materials that was used. This diversity may have facilitated making many different tool types by providing a wide range of working edges.

\section{Raw Material sourcing}

I determined where material was procured by examining cortex (natural exterior of nodules) and, to a lesser

\begin{tabular}{|c|c|c|c|}
\hline $\begin{array}{l}\text { Quality } \\
\text { Type }\end{array}$ & $\begin{array}{l}\text { Percentage of } \\
\text { Flawless Area }\end{array}$ & $\begin{array}{l}\text { Average } \\
\text { Size of } \\
\text { Flawless } \\
\text { Areas }\left(\mathrm{cm}^{2}\right)\end{array}$ & Comments \\
\hline Excellent & 1008 & NA & $\begin{array}{l}\text { No flaws on entire } \\
\text { piece. }\end{array}$ \\
\hline Good & $708-998$ & $4<$ & $\begin{array}{l}\text { Flaws present, but none } \\
\text { that would inhibit } \\
\text { flaking or use. }\end{array}$ \\
\hline Fair & $508-69 z$ & $1-4$ & $\begin{array}{l}\text { Flaws that may be } \\
\text { problematic when } \\
\text { manufacturing or using a } \\
\text { tool. }\end{array}$ \\
\hline Poor & $08-498$ & $<1$ & $\begin{array}{l}\text { Laden with flaws to the } \\
\text { extent that a small } \\
\text { biface ( } 2 \mathrm{~cm} .) \text { could not } \\
\text { be manufactured. }\end{array}$ \\
\hline
\end{tabular}

Table 3. Raw Material Quality Classification*. 
extent, interior physical characteristics (Table 4). The source analysis considers geological setting rather than specific source localities. Nevertheless, the four categories used are sufficient for making some general inferences about the organizational roles of local and exotic raw materials. As previously noted, alluvial gravels and low quality outcrops are local while high quality, outcrop cherts are exotic. Thus, quality of material tends to increase with distance from the Meier site.

\section{HEAT TREATMENT}

Heat treatment is a well known technique of annealing cryptocrystalline silicates to facilitate controlled flaking. Thermal alteration may take two forms, heat

\begin{tabular}{|c|c|}
\hline Source & Defining Characteristics \\
\hline High velocity gravela & $\begin{array}{l}\text { Cortex with extensive incipient cone } \\
\text { fractures, crushing and roundness. }\end{array}$ \\
\hline Low velocity gravel & $\begin{array}{l}\text { Cortex is smooth and polished but sub- } \\
\text { angular. }\end{array}$ \\
\hline Opland nodules & Cortex 18 angular. \\
\hline Exotic nodules ${ }^{b}$ & $\begin{array}{l}\text { Sources are ldentifled by interlor physical } \\
\text { characterlstics and are generally of very } \\
\text { high quality. }\end{array}$ \\
\hline $\begin{array}{l}\text { OThese are alluvial } \\
\text { gravela. } \\
\text { Only one source lo } \\
\text { comparing the color } \\
\text { a high guality, mot } \\
\text { luster. }\end{array}$ & $\begin{array}{l}\text { ravels, Including Troutdale formation } \\
\text { lity of exotic material was identified by } \\
\text { nd texture of the stone. This was Wascoite, } \\
\text { ed dark to light brown chert with a waxy }\end{array}$ \\
\hline
\end{tabular}

Table 4. Raw Material Source Classification. 
treatment and heat damage. Thermal alteration was identified by surface color and luster differences on single specimens (Crabtree and Butler 1964). Because the raw material collection was so varied, I made no attempt to extrapolate color and texture of known heated specimens to those without contrasting surfaces (Novick 1987). Hence, my heat treatment estimates are low.

Heat damaged specimens were distinguished from heat treated specimens. Heat damage was identified by potlid scars, craze fractures, and crenated fractures as described by (Purdy 1975; Johnson 1979:25-26).

Artifacts were also classed according to the stage of manufacture to which heat treatment was applied. Classifications were based on observing tool and preform blank remnants. If the original surface of blanks was not removed by manufacture, then determining at what stage the specimen was heat-treated is possible. The categories are listed in Table 5. These categories were subdivided into

\begin{tabular}{ll}
$\begin{array}{l}\text { Heat Alteration } \\
\text { Stage }\end{array}$ & Defining Attributes \\
\hline Heat altered blank & $\begin{array}{l}\text { Two faces present, both showing heat } \\
\text { alteration evidence. }\end{array}$ \\
Heat altered core & $\begin{array}{l}\text { Two faces present with only one showing } \\
\text { heat alteration evidence (presumably the } \\
\text { dorsal surface). }\end{array}$ \\
Post discard & $\begin{array}{l}\text { Both faces present with both showing heat } \\
\text { alteration evidence but no further } \\
\text { modification. }\end{array}$
\end{tabular}

Table 5. Flake Blank Heat Alteration Stage Classification. 
heat damage and heat treated based on the above criteria. Post discard treatment is impossible to identify unless the object somehow fractured after treatment creating comparable surfaces (eg. excavation or trampling damage).

\section{DEBITAGE ASSEMBLAGE}

The debitage analysis was limited to establishing inferences about core reduction and tool manufacture. Fundamental to the analysis was determining what stages of the lithic reduction system are present at the site (Flenniken 1981). The lithic tools of concern here are made by reducing the stones by flaking them. Both debitage and non-debitage artifacts are useful for inferences about the reduction trajectories. Relative amounts of original cortex and relative frequencies of artifact size are common variables used in determining stages of manufacture represented.

Combining these debitage variables with artifact stage classifications (cores, preforms, tools) can provide detailed information about what parts of the reduction system were employed at the site. This information is important in determining what stages of material are being transported to the site, manufactured, used and maintained.

I have used cortical stage variables and size variables to infer manufacturing stages represented by debitage. 
Within the cortical stage typology, I use general form to refine inferences about later stages of reduction.

\section{Cortical stage}

In using cortical stage analysis, I assume "...that a general pattern of decreasing cortex coincides with the reduction trajectory. The more cortex present, the earlier the piece of debitage was removed from the parent stone during the [reduction] procedure" (Hamilton 1990b:81)

For debitage, debris and flakes (the difference defined below) were treated differently. Debris were merely classed as cortical or interior based on presence/absence of cortex. Flakes, on the other hand, were grouped into one of three stage categories according to amount of cortex retained on the dorsal surface of the specimen. A Primary flake retained $90 \%$ or more cortex. A Secondary flake retained less than $90 \%$ cortex. Finally, an Interior flake retained no cortex.

Interior flakes were further subdivided into three stage types: biface thinning flakes (BTF), retouch flakes (RTF), and other interior flakes (OIF) (Table 6).

\section{size}

Flintknapping is a subtractive process (Collins 1975:16). Therefore, during the flintknapping process, 
initial reduction stages can produce many large flakes. As reduction continues, maximum flake size usually decreases. The implication is that assemblages with higher relative frequencies of large flakes represent reduction trajectories emphasizing earlier stages of reduction. Both weight and length can be used to measure size of artifacts.

All debitage specimens were grouped into size ranges using a concentric ring template. In effect, the template measures a range that the maximum dimension of the specimen falls within. The seven size ranges are $0-.5 \mathrm{~cm}, .5-1 \mathrm{~cm}$, 1-2 cm, 2-3 cm, 3-4 cm, 4-5 cm, and $>5 \mathrm{~cm}$.

Like length, weight is often used to infer stages of manufacture. Basically, heavy flakes represent early reduction. Based on a detailed debitage analysis, Teltser (1991) argues that weight is the most reliable single attribute. Unfortunately, weights were only recorded for the sample of debitage used in the micro-wear analysis. These were obtained using Ohous E4000 digital scale

\begin{tabular}{|ll|}
$\begin{array}{r}\text { Flake } \\
\text { Type }\end{array}$ & Description \\
\hline BTF & $\begin{array}{l}\text { Long, narrow, and thin with two flake scars (one dorsal } \\
\text { ridge); curved longitudinal cross-section; often has } \\
\text { prepared, multifaceted platform. }\end{array}$ \\
RTF & $\begin{array}{l}\text { Pressure flakes; approximately } 1 \mathrm{~cm} . \text { long: thin but } \\
\text { often with thick platform. }\end{array}$ \\
OIF & $\begin{array}{l}\text { Miscellaneous flakes including core reduction flakes, } \\
\text { early biface production flakes, other non-biface tool } \\
\text { production flakes, and indeterminate flake fragments. }\end{array}$ \\
\hline
\end{tabular}

Table 6. Interior Flake Classification. 
(accurate to $0.1 \mathrm{gm}$ ).

The number of platform facets and dorsal scars were recorded for flakes but not used in the analysis. These attributes can also be used to measure manufacture stage (Teltser 1991).

\section{Debitage Completeness}

The Sullivan and Rozen (1985) technique was used to class artifacts into general categories of completeness to facilitate reliable inferences about flaking stage and technique. For example, although I attempted to categorize each flake in terms of the flaking technique (pressure, percussion, bipolar) that produced it, I only used platform flakes (flakes with "striking" platform) for inferences because most of the variability is at the platform where the "indentor" initiated the fracture (Cotterell and Kamminga 1987). The Sullivan and Rozen taxonomy provides a means to distinguish platform flakes (Sullivan and Rozen typescomplete flakes and broken flakes) from non-platform flakes (flake fragments and debris).

More obvious is that flake fragments do not represent the size of the original flake removed. Hence, when considering average weights of debitage, it may be useful to know how fragmentary the assemblage is when comparing with other assemblages. For example, smaller average size or weight in an assemblage may have more to do with 
fragmentation then late stage manufacture at the site. The Sullivan and Rozen taxonomy has been heavily criticized as a basis for making behavioral inferences. Because experimentation and other investigations have not correlated frequencies of particular product types with flintknapping behaviors (Amick and Mauldin 1989; Ensor and Roemer 1989), I have not used frequencies of sullivan and Rozen product types alone to make inferences about lithic technology.

I used the Sullivan and Rozen typology to class debitage into four basic categories: complete flake, broken flake, flake fragment, and debris. The Sullivan and Rozen typology is hierarchical. The first stage is to determine whether the specimen is a flake or debris, and the second

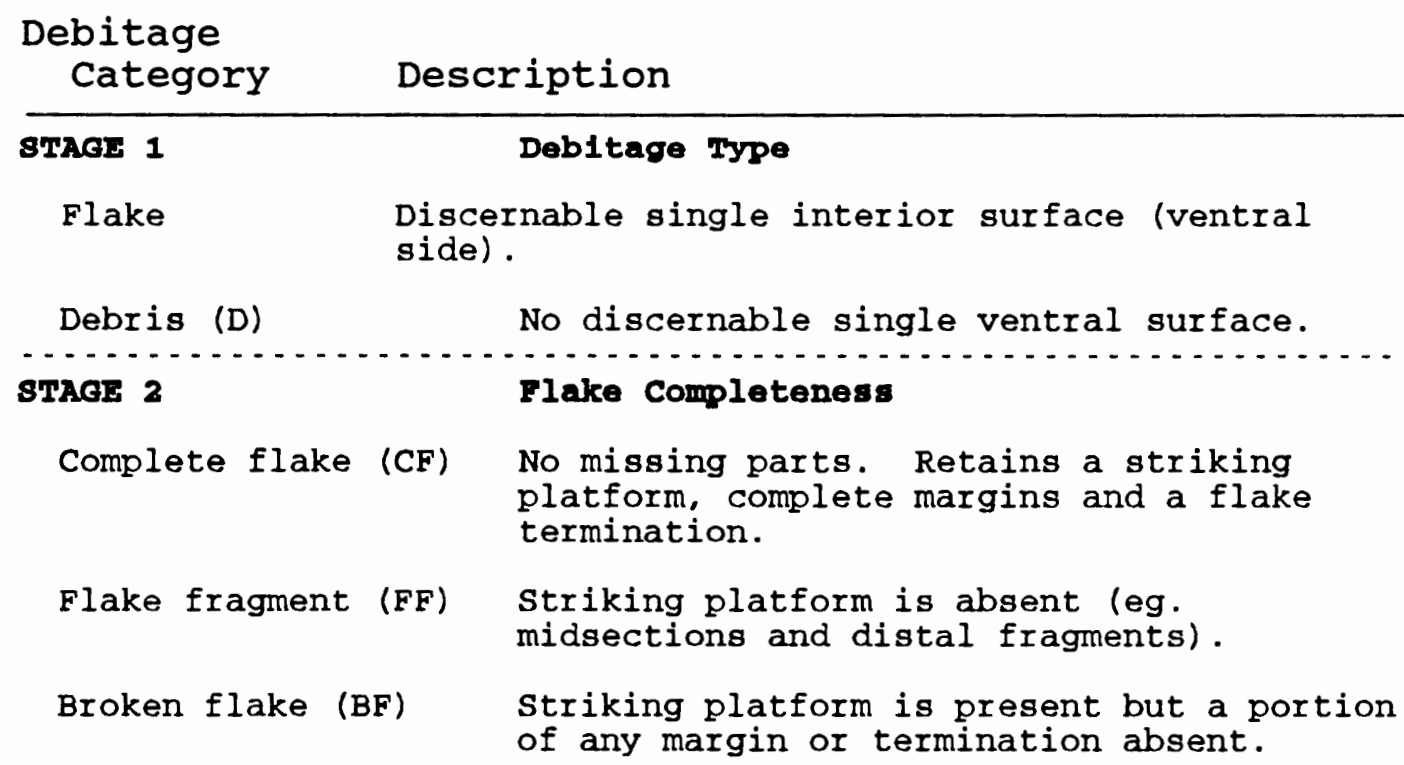

\section{STAGD 2}

Complete flake (CF)

Flake fragment (FF)

Broken flake (BF)

Flake Completeness

No missing parts. Retains a striking platform, complete margins and a flake termination.

striking platform is absent (eg. midsections and distal fragments). striking platform is present but a portion of any margin or termination absent.

Table 7. Sullivan and Rozen Typology. 
stage to determine flake completeness (Table 7).

\section{Flaking Technique}

The strategies used to reduce stone are fundamental in describing lithic technology. Flaking technique refers to how fractures were initiated to shape the stone or produce debitage. Five basic techniques were identified at Meier: freehand percussion, bipolar percussion, pressure, bevelling and crushing. Artifacts were classed according to the three techniques that remove the most mass- freehand percussion, bipolar percussion, and pressure. Any combination of these techniques may be applied to a nucleus to remove mass.

For debitage, only flakes (not debris) were classed according to the three flaking techniques. The ventral surface near the striking platform is the most technologically diagnostic area of the flake because this is where fracture initiation occurs (Cotterell and Kamminga 1987). However, for debitage, I also consider general flake morphology (eg. thickness, curvature) and size as an aid when the platform was either ambiguous or missing.

In general, percussion flakes are large and have pronounced but dispersed bulbs of force with an associated eraillure flake scar. Early stage freehand percussion flakes are often short and wide and curved laterally and transversely. Later stage flakes, particularly on prepared cores (including biface flakes), may be narrower and quite 
flat. The shape may approximate pressure flakes but are generally larger with the distinctive bulb of percussion. In comparison, pressure flakes are generally smaller and have a relatively small but pronounced bulb of force. They are usually long, narrow and thin with parallel flake scars running the entire length of the flake. The compression rings are more regular, covering the entire ventral surface (Crabtree 1972). In longitudinal profile,

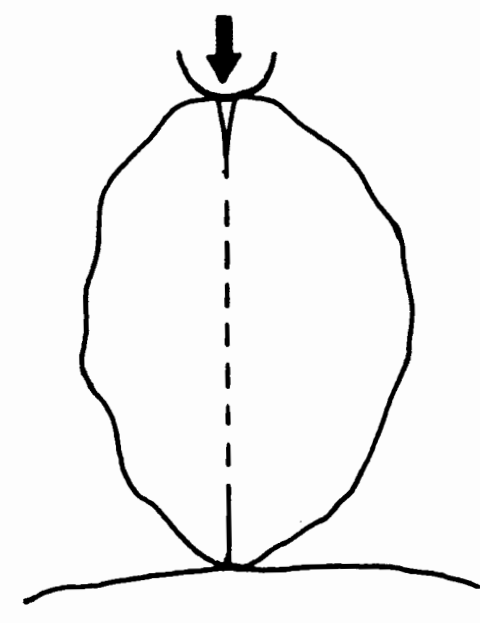

$\mathbf{A}$

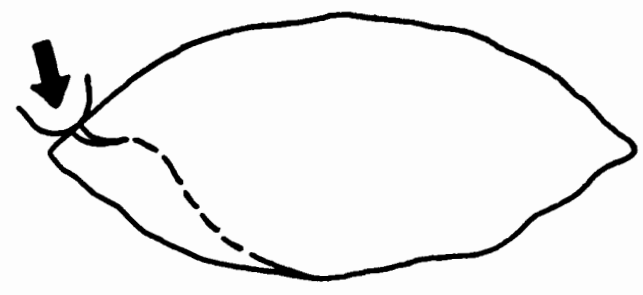

B

(A) Wedging initiated, compression-controlled fracture with axial termination typical of the bipolar technique.

(B) Hertzian initiated, stiffness-controlled feather termination typical of freehand percussion and pressure technique.

Figure 5. Character of Bipolar and Freehand Percussion Fractures According to Cotterell and Kamminga (1987, 1990). 
the flakes are less curvelinear and thinner than freehand percussion flakes. However, retouch pressure flakes and notching flakes are often short and wide.

The most common flake products of freehand percussion and pressure techniques are Hertzian initiated (conchoidal) flakes (Figure 5)(Crabtree 1972, Cotterell and Kamminga 1987). Because both techniques produce conchoidal flakes, they can be difficult to distinguish from each other by fracture characteristics alone. Both exhibit the Hertzian bulb of force and compression rings.

In contrast, bipolar flakes are quite distinct from Hertzian initiated flakes. The bipolar reduction method most commonly produces what cotterell and Kamminga (1987, 1990) term compression flakes. These bipolar flakes are formed by wedging initiation rather than Hertzian (figure 4). Therefore, true bipolar flakes do not exhibit a bulb of force. Crabtree (1972:42) describes the bulb as sheared. Morphologically, the point of fracture initiation on the ventral surface of the flake is flat rather than bulbar. The fracture direction is controlled by compression resulting in a product flake that typically has a straight ventral surface with an axial termination (Figure 5). The compression may cause accentuated compression rings and sometimes an extremely undulating surface. Small flakes, crushing and splintering may occur on one or both platforms, particularly the one with the most contact to a surface 
(either the anvil or hammerstone) (Kobayashi 1975).

Although the ideal compression flake exhibits these characteristics, both Draper (1992) and I (1989) have noted great variability in bipolar product types. Many are thick with a low edge to mass ratio such as those described as a section of an orange. Furthermore, Flenniken (1981) and Tsirk (1979) have discussed "sheared" rather than compression flakes as another common product of the technique. These occur when the fracture does not completely pass from one pole to the other, often resulting in a feather rather than axial termination. And, the products are often transversely curved reminiscent of conchoidal flakes. My experiments revealed that sheared flakes do not exhibit a bulb of force. Finally, John Fagan (personal communication 1993) explains that bipolar flakes are commonly long, thin, and flat. This latter type can be efficiently produced during late stages of bipolar reduction.

\section{NON-DEBITAGE ANALYSIS: CORES, PREFORMS AND TOOLS}

\section{size}

All non-debitage artifacts were measured using vernier calipers. However, only dimensions of complete specimens were recorded for each measurement (length, width, thickness, maximum length). For example, if the stem was 
broken off of a projectile point, then length and maximum length were not recorded. Thickness was only recorded for artifacts that appeared to retain the thickest point on the original artifact. The weight of all artifacts were recorded (and completeness of artifact to control for misleading inferences from fragments). Like debitage, these were obtained using an Ohous 54000 digital scale (accurate to $0.1 \mathrm{gm})$.

\section{Flaking Technique}

Flaking technology was determined by examining flake scars. The criterion used is the same as that for debitage but cores, preforms, and tools show negative flake scars and may exhibit a combination of two or more flaking techniques on a single specimen. The categories include bipolar percussion, freehand percussion, pressure or any combination of these.

\section{Blank Typology}

In general, blanks give information about where material came from and how the blanks were made or acquired. This is crucial in delineating whether they were derived from standardized cores (blade cores or biface cores), or generalized cores.

For a qualitative assessment of what kinds of blanks were selected for cores and tools, blanks were recorded 
according to the same typology used for debitage. The typology aids in describing how blanks were manufactured or what parts of the lithic system they were opportunistically selected from.

By blanks I mean the nucleus or piece of raw material that was selected for a core or tool. For example, at the most general level, most tools are made from a flake-blank. I use attributes exhibited by the blank remnant for classification. Blank remnants are the original surfaces of the worked piece that remain after modification. The utility of the typology is limited because the more a blank is reduced, the less remnant surface remains for identifying significant attributes. For this reason, I make qualitative assessments about the use of particular blank types, but do not quantify these observations.

A wide variety of categories are considered and more than one may apply to a single specimen. Common blank types I refer to in the analysis are debris blank, cortical blank, percussion blank, pressure blank, biface thinning blank, bipolar blank, potlid blank, preform (as a blank) and tool (as a blank: recycling of an exhausted tool). For the core assemblage, I primarily use the following core-blank types: cobble (alluvial worn nodule), nodule (blocky and angular), debris (core fragments), percussion flake, bipolar flake, and cortical flake. 


\section{CORE ASBEMBLAGE}

Cores were the sources of blanks from which artifacts were generated. The core assemblage includes unmodified raw material, tested raw material, and cores.

The unmodified raw material category consists of nodules that are at least $15 \mathrm{~mm}$ long but not modified. Because this category represents potential tool material, the minimum length is based on minimum tool size. Analysis is complicated by the fact that unmodified raw material exists naturally in the Missoula flood deposits at the site. The category tested raw material includes nodules that exhibit minimal alteration. I assume that after flaking, these were deemed structurally insufficient for manufacture of stone tools by the flintknapper. Alteration patterns include crushing, single or multiple flake scars that were decidedly too small to have been used as tool blanks $(<15$ $\mathrm{mm})$, and one or two flake scars that were large enough to have produced usable flakes, but the nodule was discarded because of obvious structural flaws.

Cores are those artifacts that exhibit two or more flake scars that are large enough to represent the successful removal of tool flake blanks (>15 mm) and the material deemed adequate for tool manufacture. 


\section{standardized and Generalized cores}

Cores were most generally classed as either standardized or generalized (unstandardized). standardized (formal, curated) cores are those that were intentionally shaped to remove a standard flake form. Standardized cores have regular flake scars and striking platforms that are extensively prepared. Generalized (informal, expedient) cores are more diverse in form (often polyhedral). Flake scars are often minimal or in many directions and vary in size and shape. The flake scar patterns are more the result of opportunistic flake removal than from a platform that was intentionally set-up or shaped. Platforms may be prepared, but only minimally.

\section{Morphological Typology}

Cores were classed according to general shape and flaking pattern to control for patterns in flaking strategies of unstandardized shapes. Although a wide range of subtypes can be described, almost all cores are best seen as variations of a flexible, opportunistic strategy of flake production. At the most general level, I divided unstandardized cores into four basic forms- biface, tabular, amorphous, and other.

Biface cores are those that are equivalent in form to type 3 and 4 tools according to the ranked shaping typology (below). They are flat, bifacially flaked pieces that are 
completely edged but may have discontinuous flake scars along the margin. The freehand percussion biface cores (and tabular cores described below) are often referred to in the literature as discoid cores, while the bipolar biface (and tabular cores) are often called pieces esquillees.

Tabular cores are approximately flat but are not edged completely around the nucleus. They are equivalent to type 2 tools according to the edging criteria for ranking tools (below).

The remainder of the core forms are variations of polyhedral cores. I labelled these amorphous and other. These cores often exhibit platforms on several sides or edges of the nucleus. They are usually blocky in general shape. Their shape is more the result of optimizing flake removal from various angles and facets of blocky pieces. Many have only two or three flakes removed from them. The following is a brief description of some polyhedral core varieties found at Meier:

-Amorphous cores are multidirectional polyhedral cores. -Multifacet cores have more than two faces with flake scars but were not amorphous. Most are elongate, unidirectional bipolar cores that approximate columnar form. -Two-face cores are blocky with flake scars on only two faces.

-Microblade cores have long, narrow flake scars that were not produced using the bipolar technique.

-Unifacial cores are blocky with flake scars on only one face.

-Single platform cores are blocky with a single-facet or multi-facet platform.

-Miscellaneous cores were to fragmentary to place in a category. 


\section{PREFORM ASSEMBLAGE}

Preforms are those artifacts that were intentionally shaped but never reached the finished tool stage. They were discarded by the manufacturer because of insufficient shape or fracture beyond repair. Preforms represent manufacture failures from biface production. Hence, most information about shaping strategies gained from preforms is related to bifacial tools (almost entirely arrow points).

Preforms were classed as early stage, middle stage and late stage based on the shaping investment typology (below). Early stage is type 2, middle stage type 3, and late stage type 4. Preforms were primarily used to gain information about blank diversity and stage of heat treatment.

\section{TOOI A8SEMBLAGE}

Tools are finished implements with evidence of use. The introduction of Appendix 4 briefly explains the criteria used to identify a tool. For analyzing tools, in addition to the basic artifact attributes (raw material, flaking technique, blank type, and various size measurements), they were classed according to amount of energy put into shaping the tool, tool function, and presence of reuse (resharpening and reworking) . 


\section{Ranked shaping Typology}

All tools were placed into a ranked shaping typology. The aim was to separate artifacts according to the energy invested in shaping artifacts while keeping the classification independent of the functional typology. Shaping energy input refers to the amount of effort put into shaping the tool after obtaining a tool blank. The basic scheme is derived from a biface stage typology in which edging is the primary attribute. The typology is reminiscent of that applied by Bamforth (1991:220; also see Callahan 1979) but not as detailed. Edging refers to the concept of making two faces intersect during biface production. The idea behind the typology is that the more extensively the artifact has been edged, the more energy has been put into producing that artifact. As a basis of comparison, after each description, I have put the equivalent biface stage as defined by Callahan (1979:36-37).

Type 1: No energy input (unmodified blank) is a tool blank that has not been shaped in any way. Tools typically called used/utilized flakes, used cores, and used debris fall into this category. In addition, non-shaped retouched tools (usually unifaces) are included in this group. [Not shaped after Callahan stage 1: obtaining the blank]

Type 2: Low energy input has been shaped but has at least one portion of the margin greater than $3 \mathrm{~mm}$ that has not been edged. The artifact faces may be completely worked 
but the margin not continuously edged. Miscellaneous minimally shaped tools, shaped unifaces (eg. end-scrapers) and some bifaces are traditional classes of tools in this group. Furthermore, most bipolar shaped tools, including type 4 bifaces, are placed in this category. [Progressing toward Callahan stage 2: gone through initial edging process].

Type 3: Middle energy input has completely edged margins circumventing the artifact, but bifacial flaking is not continuous around the artifact. The artifact may be a uniface, partial uniface or partial biface as long as the face surfaces intersect at less than 90 degrees. For example, feather terminations are included as a completed edge. Expediently made bifaces make up most artifacts falling in this category. [Callahan stage 2: edging process completed].

Type 4: High energy input (biface) has contiguous bifacially flaked margins and is completely edged [Callahan stages 3-5: completed biface]. High energy input tools are subdivided by flaking technique. Multi-stage percussionpressure bifaces (eg. large hafted knives) are ranked above percussion (eg. heavy duty cutters) and pressure flaked bifaces (eg. arrow points). As a point of reference, the amount of time invested in making small, bifacially flaked bifaces may be quite small. For example, a bifacially pressure flaked arrow point may be shaped from a flake blank 
in 5-10 minutes.

Using this typology at the assemblage level, a technology with the lowest energy input would have only unmodified blanks (type 1). In contrast, an assemblage showing the highest energy input would have all multi-stage type 4 biface tools. And, type 1 and type 2 tools are expected of expedient technologies while type 3 and type 4 tools are expected of highly curated technologies.

\section{Tool Reuse}

The action of reuse lengthens the use-life of a piece of stone and broadens its functional capability. We expect highly mobile people to design tools that are transportable. One way to do this is to make tools that can be used repeatedly and in a number of functional contexts (Kelly 1985; Shott 1986). One should note, however, that reuse does not necessarily discount expedient strategies. For example, a flake can be removed from a core, used, resharpened during the activity, and then discarded. However, we expect that less reuse will occur when expedient strategies are emphasized with high material availabilitywhere conservation is not a major concern.

There are many different types of reuse exemplified in cultural systems (Schiffer 1976, 1987; Shott 1986, 1989; Nelson 1991). Because their identification relies heavily on functional analysis, I only consider reuse that is easily 
identifiable by artifact morphology. I identify three types of reuse: maintenance, multi-use and recycling.

Maintained artifacts are those that have been reworked to continue their use for the same basic function (eg. cutting, scraping). This includes rejuvenated broken tools and resharpened working edges. Because no micro-wear analysis has been conducted on most artifacts of the analysis, I have equated basic shape to function (morphofunction). If an artifact has been reworked, but no drastic change in working edge is apparent, then this is assumed to be maintenance. Most maintenance on tools that are not type 4 is unifacial pressure retouch. These tools are traditionally classed as unifaces.

For this analysis, multi-use tools are those that were used on different portions of the piece. The used margins are separated by some morphologically distinct feature. The different margins may have been used for the same or different tasks. It is usually impossible to determine what margin was used first. It is possible that either margin could be used at any given time without changing the tool. Recycled tools, on the other hand, are functionally sequential. Modification during use and retouch may inadvertently shape the piece into a blank appropriate for some other use. In this case, recycled tools can be considered a form of opportunistic blank acquisition. In other instances, recycling is done with more effort in 
shaping the exhausted piece. The difference between multiuse and recycle is that multi-use items can be used for either function without modification (contemporaneous), while recycled tools were used for one function and then for another (sequential). To identify recycling without at least some sort of rudimentary morphofunctional

determination is impossible. I identified recycling by obvious morphological shifts in which I could identify the blank as being some other manufactured tool or preform type. Some tools may have been designed to be used for a series of functions through sequential modification. This is referred to as serial design (Nelson 1991) and may be confused with recycling. For this analysis, the recycled primary aspect is considered a type of blank while the final form is the tool, core, or preform. Used cores were not considered a form of recycling but exhausted tools used as cores were. Some examples of recycling sequences at Meier include projectile point to perforator, biface to bipolar core, scraper to bipolar core, tool/preform to projectile point.

\section{INFERRING LITHIC TECHNOLOGICAL ORGANIZATION AT MEIER}

The extent of curation can be gauged by the amount of energy invested in the technology. I use the above typologies and attributes to rank the investment of energy in six behavioral components of the lithic system. Lithic 
activity sets include raw material procurement, blank acquisition, tool shaping, tool use, tool reuse, and heat treatment. These provide a basic framework to discuss data in terms of activities that make-up the technological organization. Each component has a set of attributes that I use to build typologies and rank energy investment (Table 8). Proportional differences of ranked artifact classes within each component are then used to rank activity sets in terms of energy expenditure. I assume that activity sets with high proportions of artifacts showing significant costs in raw material acquisition (eg. high quality material,

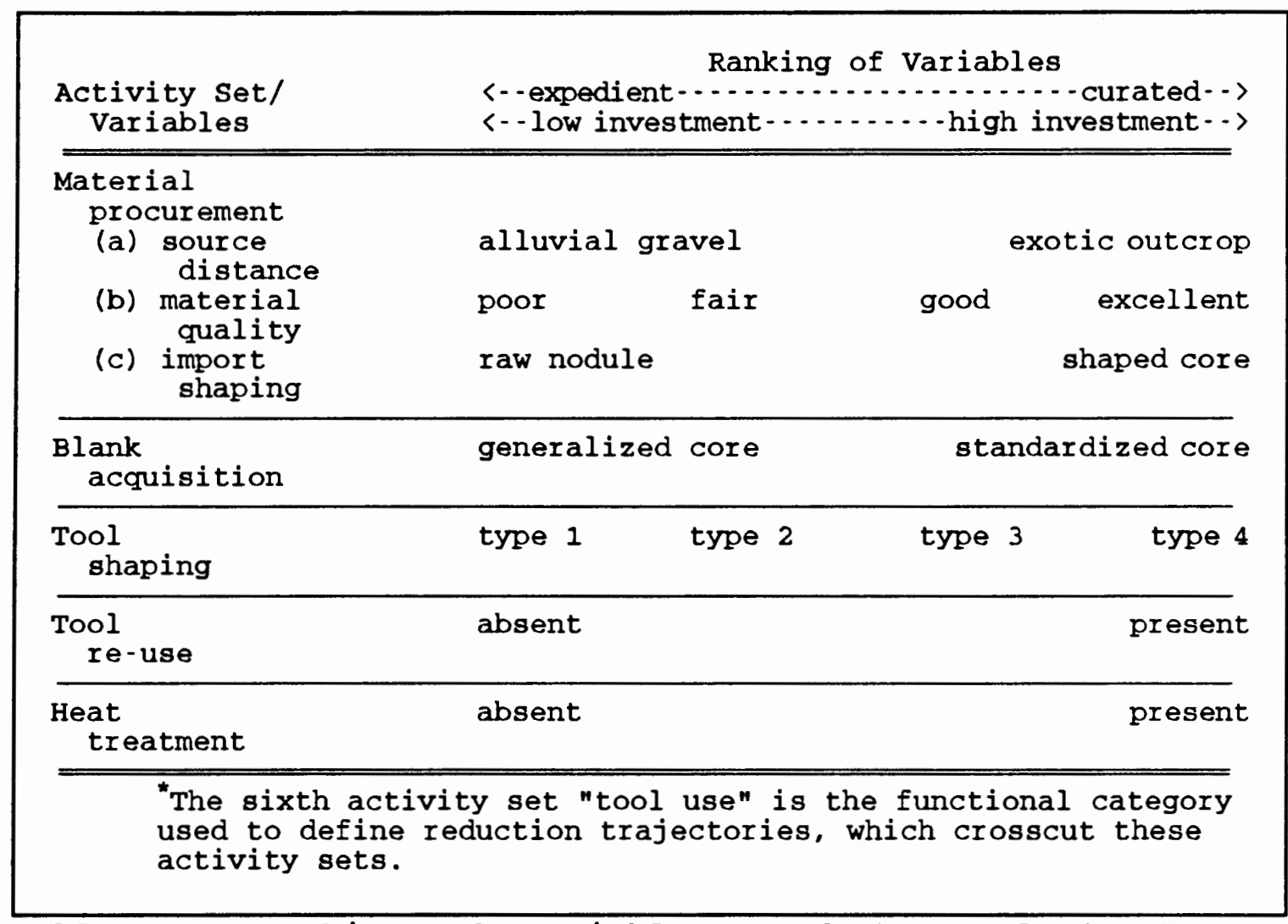

Table 8. Ranking of Variables Used to Evaluate Energy Expenditure for Each Activity set of the Lithic System*. 
exotic source location) and/or flaking (eg. standardized shapes, extensive flaking, and resharpening) had high energy investment. By assuming a positive correlation between energy investment and curation, the more energy invested in each component, the more it is characteristic of a curated technology. Conversely, the less energy invested in each activity set, the more characteristic it is of an expedient technology.

The activity set tool use is delineated by functional analysis of tools. I compare reduction trajectories (the reduction of material while passing through some or all of the activity sets) of major functional classes. By incorporating tool use, I am able to explain at least some variation in technological strategies between reduction trajectories by tool design requirements imposed by tasks (eg. hide scraping, hunting, soft tissue cutting) rather than, for example, logistical mobility.

To conclude the study, I create an empirical model of the Meier lithic technological organization based on the behavioral components (activity sets). The relationships between components (technological organization) is explained by what is known about Meier mobility organization residential sedentism and logistical mobility. I discuss the technological organization using stockpiling as a prominent technological strategy to store raw material. I also consider task requirements (tool function) as a factor 
in causing variation in technological strategies between some reduction trajectories. 


\section{CHAPTER 5}

\section{ANALYTIC RESULTS}

An estimated total of 77,382 fine-grained lithic artifacts were recovered during the 1987-1990 excavations. Table 9 shows the estimated count and relative frequencies of basic fine-grained lithic categories. Appendix 5 provides a data summary for the debitage assemblage. In this chapter I discuss the lithic system in terms of six behavioral components of organization: raw material procurement, tool-blank acquisition, material heat treatment, tool shaping, tool use, and tool reuse. Each component will be evaluated in terms of expedient and curated strategies as they are related to mobility organization.

\section{IITHIC PROCUREMENT}

The logical beginning point for discussing the lithic technological organization is material procurement.

\begin{tabular}{ccccccc} 
& Debitage & Core & Preform & Tool & Misc & Total \\
\hline Count & 70,630 & 940 & 1.766 & 3.781 & 265 & 77.382 \\
8 & 91.3 & 1.2 & 2.3 & 4.9 & 0.3 & 1.0 \\
\hline
\end{tabular}

Frequencies are calculated based on sample 3 and 4 .

Table 9. Meier Site Fine-grained Flaked-stone Assemblage. 
Procurement treats what, where, and how material is acquired, modified, and transported to the site.

Evidence based on the character of cortex on specimens studied indicates that most material was obtained from alluvial gravels. of the debitage and core specimens with cortex, 91\% had been alluvial gravels based on the presence of incipient cone cortex (Table 10). Such gravels are found throughout the wapato Valley region in river and creek beds. The low proportion of outcrop nodules and low velocity alluvial cortex on artifacts suggests some nodules were opportunistically collected when encountered during activities away from major sources, possibly from local streams and outcrops in the Tualatin Mountains. There are known poor quality CCS deposits in the Tualatin Mountains within the catchment area (Fagan, personal communication 1993). The quality of outcrop and low velocity alluvial material at Meier was usually quite poor.

Twenty-three specimens were of exotic lithic materials.

\begin{tabular}{llrr}
$\begin{array}{l}\text { Artifact } \\
\text { Category }\end{array}$ & Source & $\mathrm{n}$ & $\%$ \\
\hline \hline Core & Outcrop & 32 & 6 \\
& Alluvial Low Velocity & 19 & 4 \\
& Alluvial High Velocity & 458 & 90 \\
\hline Debitage $^{a}$ & Outcrop & 33 & 8 \\
& Alluvial & 386 & 92 \\
\hline \hline
\end{tabular}

amirty two cortical debitage was indeterminant.

Table 10. Core and Debitage Source Based on Cortex Character. 
None of these had any cortex, and most are a very high quality chert with a smooth, waxy luster. This material has a color range of mottled light to dark brown. Dan stueber (personal communication 1991), a local fintknapper, visually identified this material as Wascoite. The source location for this material is a primary deposit $210 \mathrm{~km}$. up the Columbia River. None of the Meier Wascoite specimens have its characteristic chalky white cortex. The absence of cortex, the relatively large average size of wascoite flake blanks, and the standardized blank production technology (discussed below), indicates that wascoite was exploited from these primary deposits rather than river gravels. Whether Meier people traded for the exotic blanks or exploited the sources themselves is yet to be determined. If they procured the material themselves, they applied a different, more formalized, blank production technology than is typical of other Meier reduction strategies.

one core, 22 tools but no debitage of exotic material have been identified. However, I did not recognize Wascoite and the other high-quality exotics until the latter part of my data recording. Re-examination of the total assemblage to identify its lithology may be fruitful.

The standardized flake blanks and biface core, relative rareness, and intensive reuse of tools made from exotic material indicate that acquiring this higher quality material was more difficult than alluvial gravels. The one 
known quarry (Wascoite locality) is upriver from the location of what was once Celilo Falls, now inundated by Columbia River water behind the Dalles dam. Canoe travel may have been difficult above the falls and portaging canoes undoubtedly made transport of material more difficult. The increased difficulties in transport may have made production of core blanks near the source locality more feasible then packing bulky nodules. On the other hand, trade in the form of tabular core-blanks for similar reasons is also plausible. Trade in exotic materials (eg. metal) reflecting status and wealth has been demonstrated in the Lower Columbia River Valley (Ames, personal communication 1994) and may apply, as well, to high quality, exotic cherts. The evidence cited above suggests that the lithic sources most used for tool production were river gravel bars. The cobbles were generally small (Table 11). The most accurate estimation of cobble sizes is probably from

\begin{tabular}{|c|c|c|c|c|c|c|c|c|c|}
\hline \multirow{2}{*}{$\begin{array}{c}\text { Artifact } \\
\text { Type }\end{array}$} & \multicolumn{5}{|c|}{ Length (mm) } & \multicolumn{4}{|c|}{ Weight } \\
\hline & $\mathrm{n}$ & $\max$ & $\min$ & mean & SD & $\max$ & $\min$ & mean & SD \\
\hline $\begin{array}{l}\text { Core } \\
\text { Test } \\
\text { Tool } \\
\text { Ex.Tool }\end{array}$ & $\begin{array}{r}940 \\
56 \\
938 \\
14\end{array}$ & $\begin{array}{l}88.2 \\
88.2 \\
90.6 \\
90.5\end{array}$ & $\begin{array}{r}15.0 \\
20.2 \\
8.3 \\
20.2\end{array}$ & $\begin{array}{l}33.0 \\
36.5 \\
28.8 \\
48.2\end{array}$ & $\begin{array}{r}124.1 \\
102.2 \\
131.2 \\
99.0\end{array}$ & $\begin{array}{r}2271 \\
2271 \\
703 \\
635\end{array}$ & $\begin{array}{r}1 \\
23 \\
1 \\
18\end{array}$ & $\begin{array}{r}145 \\
244 \\
43 \\
115\end{array}$ & $\begin{array}{r}221.2 \\
18.5 \\
65.8 \\
91.3\end{array}$ \\
\hline \multicolumn{10}{|c|}{$\begin{array}{l}\text { Key: } \\
\text { Core }=\text { the total core assemblage } \\
\text { Test }=\text { tested raw material. } \\
\text { Tool }=\text { complete tools. } \\
\text { Ex.Tool = complete tools made of e }\end{array}$} \\
\hline
\end{tabular}

Table 11. Size Measurements of Cores and Tools. 
tested raw material. Tools made from exotic material tended to be longer than others suggesting that these were made from larger cores.

Most fine-grained lithic material in the assemblage is cryptocrystalline silicates (non-debitage $=97 \%$; debitage $=$ 988). The cryptocrystalline silicates (CCS) are lithologically diverse, including cherts, jaspers, chalcedonies, and opalites. Among the remaining three percent of the non-debitage class is obsidian, manufactured glass, felsite, and quartzite (Table 12).

The ccs material varies from stone as brittle and sharp as glass to as durable and dull as silicified sandstone. This highly variable source material may have enhanced the efficiency of making tools for a wide variety of tasks by providing tools with working edges of different material strengths and sharpness.

\begin{tabular}{|c|c|c|c|c|c|}
\hline \multirow[b]{2}{*}{$\begin{array}{l}\text { Raw } \\
\text { Material }\end{array}$} & \multicolumn{3}{|c|}{ Non-debitage } & \multicolumn{2}{|c|}{ Debitage } \\
\hline & $\mathrm{c}$ & $r e$ & $\begin{array}{c}\text { Tool/Preform } \\
n\end{array}$ & $\mathrm{n}$ & $(z)$ \\
\hline $\begin{array}{l}\text { Obsidian } \\
\text { Glass } \\
\text { Felsite } \\
\text { Quartzite } \\
\text { Misc. Other }\end{array}$ & $\begin{array}{r}46 \\
4 \\
4 \\
1 \\
-\end{array}$ & & $\begin{array}{r}50 \\
12 \\
12 \\
3 \\
10\end{array}$ & $\begin{array}{r}29 \\
14 \\
16 \\
6 \\
-\end{array}$ & \\
\hline $\begin{array}{l}\text { total } \\
\text { non-ccs }\end{array}$ & 55 & (5) & (2) & 65 & (2) \\
\hline $\begin{array}{c}\text { total } \\
\text { CCS }\end{array}$ & 1036 & (95) & 3657 & 3624 & $(98)$ \\
\hline
\end{tabular}

Table 12. Raw Material Types. 


\begin{tabular}{|c|c|c|c|}
\hline \multicolumn{2}{|c|}{$\begin{array}{c}\text { Raw Material } \\
\text { ouality }\end{array}$} & \multirow{2}{*}{$\begin{array}{c}\begin{array}{c}\text { Number of } \\
\text { Cores }\end{array} \\
168 \\
521\end{array}$} & \multirow{2}{*}{$\begin{array}{c}\begin{array}{c}\text { Percentage } \\
\text { of Cores }\end{array} \\
\begin{array}{c}16 \\
48\end{array}\end{array}$} \\
\hline Low & $\begin{array}{l}\text { Poor } \\
\text { Fair }\end{array}$ & & \\
\hline High & $\begin{array}{l}\text { Good } \\
\text { Excel lent }\end{array}$ & $\begin{array}{r}364 \\
25\end{array}$ & $\begin{array}{r}34 \\
2\end{array}$ \\
\hline
\end{tabular}

Calculated based on sample 2 .

Table 13. Raw Material Quality for Core Assemblage.

The quality of raw material was also variable in terms of flaws. Most cores are materials of poor and fair quality indicating that a generally low-grade material was procured (Table 13). Finished tools have a higher incidence of good quality material, apparently due to selection by the flintknappers (Table 14). The very high proportion of highgrade material among the "used flakes" discovered by the microwear analysis is partially explained by the use of small flakes opportunistically selected from biface manufacture waste.

\begin{tabular}{|c|c|c|c|c|c|c|c|}
\hline \multirow{2}{*}{\multicolumn{2}{|c|}{$\begin{array}{l}\text { Raw material } \\
\text { cuality }\end{array}$}} & \multicolumn{2}{|c|}{$\begin{array}{c}\text { Tools } \\
(\text { type } 1,2)\end{array}$} & \multicolumn{2}{|c|}{$\begin{array}{l}\text { Arrow points } \\
\text { (type } 3,4)\end{array}$} & \multicolumn{2}{|c|}{$\begin{array}{c}\text { Micro-wear } \\
\text { (type 1) }\end{array}$} \\
\hline & & \multirow{2}{*}{$\begin{array}{r}n \\
16 \\
192\end{array}$} & \multirow{2}{*}{$\frac{8}{43}$} & \multirow{2}{*}{$\frac{n}{6}$} & \multirow{2}{*}{$\frac{8}{2}$} & \multirow{2}{*}{$\begin{array}{l}\mathbf{n} \\
-\end{array}$} & \multirow{2}{*}{$\frac{z}{-}$} \\
\hline Low & $\begin{array}{l}\text { Poor } \\
\text { Fair }\end{array}$ & & & & & & \\
\hline HIgh & $\begin{array}{l}\text { Good } \\
\text { Excel }\end{array}$ & $\begin{array}{r}176 \\
42\end{array}$ & $\begin{array}{r}39 \\
9\end{array}$ & $\begin{array}{r}245 \\
\text { NA }\end{array}$ & $\begin{array}{l}87 \\
\text { NA }\end{array}$ & $\begin{array}{r}8 \\
22\end{array}$ & $\begin{array}{l}27 \\
73\end{array}$ \\
\hline
\end{tabular}

*alculated from sample 2 and 4 .

acols do not include arrow points. Arrow points and non-arrow point tools are separated because they were classed differently. Non-arrow point artifacts were described as excellent, good, fair, and poor while for arrow points, excellent was subsumed within good.

Table 14. Raw Material Quality for Tools*. 
The presence of tested raw material (raw material failures) in the core assemblage (Table 15) supports an argument that low-grade material was being collected at the source local in bulk, with little effort at eliminating poor materials by testing. Such a procurement strategy indicates a decision to save time in the field during raw material procurement while expending more effort in transporting a lot of waste material. Canoe travel probably made packing large amounts of cobbles easier than walking, compensating for quickly collecting poor material that had a low toolper-nodule potential.

The "abundance" of raw material failures also implies that they spent their time/energy reducing cobbles at their home rather than at the source or elsewhere despite the expense of transporting poor, inadequate material. Anadromous fish are a second major resource "captured" in river locations. If both resources were procured on the same trip, collecting time may have been limited, hence, material testing not conducted in the field.

Some cores and tools were undoubtedly transported

\begin{tabular}{|lcc|}
\hline Core Type & Count & Percentage \\
\hline $\begin{array}{l}\text { Raw material test } \\
\text { Core }\end{array}$ & 81 & 8 \\
\hline anmodified Raw Material artifacts were not collected \\
during the 1987-1990 field seasons. Fifty-four were \\
recovered during the 1991 field season.
\end{tabular}

Table 15. Tested Raw Material and Core Frequencies. 
during forays. I expect that this material was empirically tested for reliability (ie. high quality) before transport. Technological variation in transported tool-kits could be studied at a regional scale by comparing assemblages of special purpose sites with those of residential sites. Such studies have yet to be conducted for the region ${ }^{4}$.

\section{BLANR ACQUISITION}

I discuss three forms of blank acquisition. The term acquisition is used in a general sense to include three strategies (1) on-site flake blank production (core reduction), (2) selection from curated blanks obtained from elsewhere (off-site flake blank production or trade), and (3) opportunistic selection of non-core reduction products. The only off-site blank acquisition at Meier may be core and tool blanks of exotic material, already discussed. Below, I will describe core reduction and opportunistic selection.

\section{Core Technology: Blank Production}

Both freehand percussion and bipolar flaking techniques were used in core reduction to produce tool and secondary core blanks. Bipolar cores (46\%) are more frequent than

\footnotetext{
${ }^{4}$ Investigation of special activity sites such as those found on the Wapato Valley flood plain during the South Shore survey project (Burtchard et al. 1990) could provide valuable data on transported tool-kits.
} 
freehand percussion cores (36\%). Many show evidence of both bipolar and freehand percussion strategies. Bipolar are probably over-represented and bipolar-freehand cores underrepresented because the bipolar technique was more often used to finish the reduction of cores, removing initial freehand percussion evidence.

Although there are more bipolar cores than freehand percussion cores, the debitage (Table 16) indicates that freehand percussion was used far more often than bipolar techniques for blank production. Based on the large freehand percussion debitage counts, the probability that bipolar reduction erased percussion evidence on cores, and the high proportion (estimated) of percussion blanks, I conclude that the freehand percussion technique was used more than bipolar in blank production. The use of both bipolar and freehand percussion strategies reflects an opportunistic, flexible strategy of core reduction (Parry

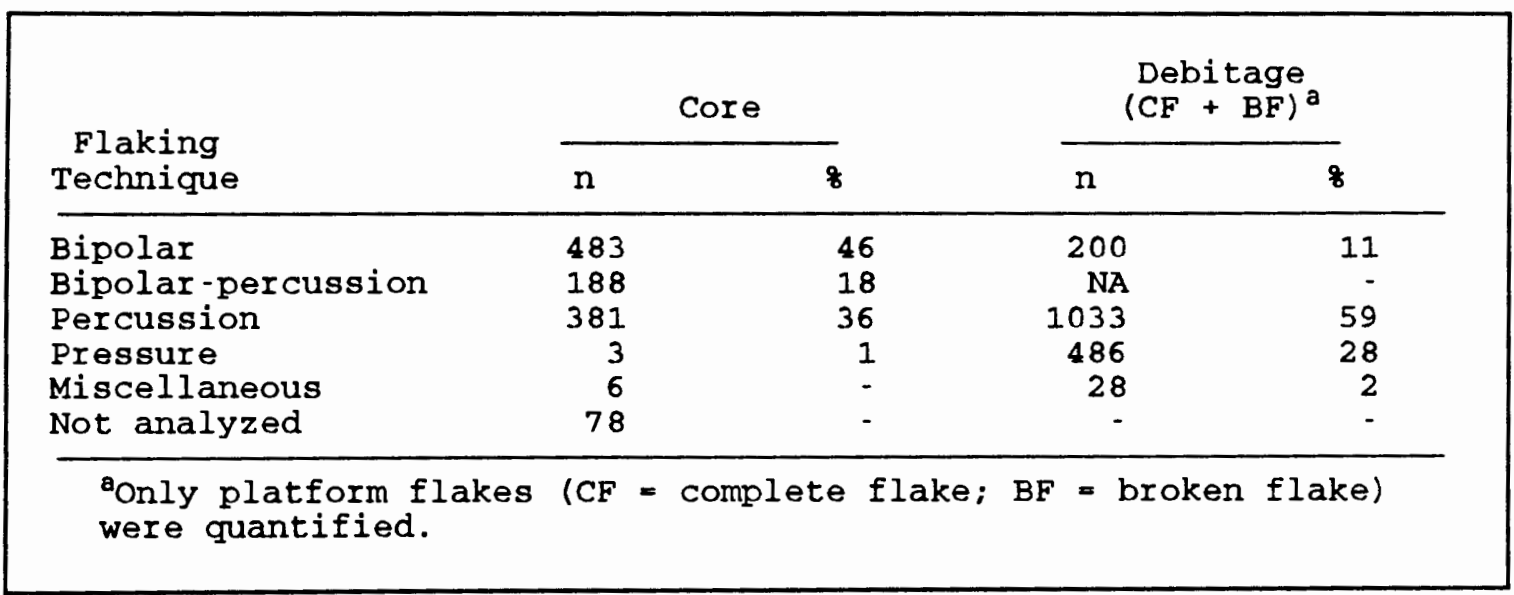

Table 16. Frequencies of Flaking Technology for cores and Debitage. 
and Kelly 1987). This is consistent with difficulties in using an eclectic source of alluvial gravels as the basis for tool production.

The two techniques played somewhat different roles in the core technology. At the Meier site, the bipolar technique was usually used for early reduction to split rounded cobbles. This created striking platforms with angles less than 90 degrees, suitable for freehand percussion. At least 56 cores were started on such split cobbles and nodules, often creating a turtle shaped core blank with a single platform. For those that were tested raw material, twice as many were tested using the bipolar technique than percussion (Table 17).

Bipolar reduction makes removing blanks from small nodules and cores easier because the anvil is used as support during impact. Additionally, because the compression fracture often passes completely through the piece, product length on small cores can be maximized. Not surprisingly, bipolar cores tend to be the smallest cores in the assemblage (Table 17). These small bipolar cores are often referred to as pieces esquillees in the archaeological

\begin{tabular}{|lrr|}
\hline Flaking Technique & $\mathrm{n}$ & $\%$ \\
\hline Bipolar & 45 & 63 \\
Bipolar-percussion & 3 & 4 \\
Percussion & 23 & 32 \\
\hline
\end{tabular}

Table 17. Tested Raw Material Flaking Technology. 
literature for the region. The ease at which small items are reduced makes the bipolar method excellent for recycling exhausted tools and otherwise rejected preforms. Fortyseven (of 148) instances of recycling used the bipolar technique. This count is probably low, many pieces esquillees were probably recycled tools, but the evidence of use erased by reduction.

Core Manufacture (Standardized vs. Generalized):

The core technology used at the Meier site, for the most part, is generalized. Little energy was used in shaping cores to produce standardized flakes. The two exceptions are a semi-conical microblade core and a biface core fragment. Additionally, pieces esquillees may have been a specialized core type for producing standardized flakes. However, although there are numerous pieces esquillees type cores in the assemblage, very few bipolar flake blanks were identified in the assemblage. This issue needs more careful examination than I can provide here.

The unstandardized cores do not have well prepared

\begin{tabular}{|c|c|c|c|c|c|}
\hline \multirow[b]{2}{*}{ Core Type } & \multirow[b]{2}{*}{$\mathrm{n}$} & \multicolumn{2}{|c|}{ Length (mm) } & \multicolumn{2}{|c|}{ Weight (gm) } \\
\hline & & Mean & SD & Mean & SD \\
\hline $\begin{array}{l}\text { Bipolar } \\
\text { Bipolar-percussion } \\
\text { Percussion }\end{array}$ & $\begin{array}{l}434 \\
178 \\
304\end{array}$ & $\begin{array}{l}25.9 \\
38.8 \\
40.7\end{array}$ & $\begin{array}{r}89.01 \\
211.49 \\
103.66\end{array}$ & $\begin{array}{r}6.6 \\
21.1 \\
22.3\end{array}$ & $\begin{array}{l}112.50 \\
233.33 \\
245.78\end{array}$ \\
\hline
\end{tabular}

Table 18. Mean Length and Weight of Core Artifacts for Each Flaking Technique. 
platforms and regularized flaking patterns. As a whole, the cores were not intentionally shaped (manufactured) in such a way as to efficiently produce large numbers of flakes of the same size and shape. The flake scars on cores indicate the production of morphologically diverse flakes (as does the debitage). The overall patterns of reduction vary widely, probably to maximize the number of flakes that could be removed from a piece of raw material without actually making a prepared, standardized core.

This is not to say that there were not particular strategies to reduce lithic raw material. In fact, there are certain flaking patterns that can be repeatedly identified. For example, flat pieces of raw material were often peripherally flaked producing bifacially flaked tabular cores. This, and other reduction strategies, were dependent on certain raw material shapes (eg. large flat percussion flakes; turtle shaped split cobbles), not intentional shaping of the nodule.

Platform preparation was limited to straightening and strengthening edges by minimal bevelling and flaking to remove overhangs and irregularities. No platforms were extensively prepared. As a result, cores were covered with flake failures such as crushing, incipient cone fractures, and hinge and step termination flake scars.

Secondary core-blanks were often selected for flake blank production. These include core debris (large pieces 
of cores; $n=27)$, large percussion flakes $(n=131)$, and bipolar flakes $(n=22)$. Many percussion and bipolar flakes may have been intentionally produced for cores. Most bipolar core-blanks were considered the result of splitting nuclei for core reduction, hence, a flaking technique rather than a secondary core-blank type.

Direct Freehand Percussion Cores $(\mathrm{N}=350)$ :

Most freehand percussion cores are amorphous and tabular cores (Table 19) and expedient by definition. The remainder of the percussion cores are also varieties of expedient cores. Basically, amorphous cores are chunky, polyhedral cores while tabular cores are peripherally flaked, flat cores made either from percussion flakes or

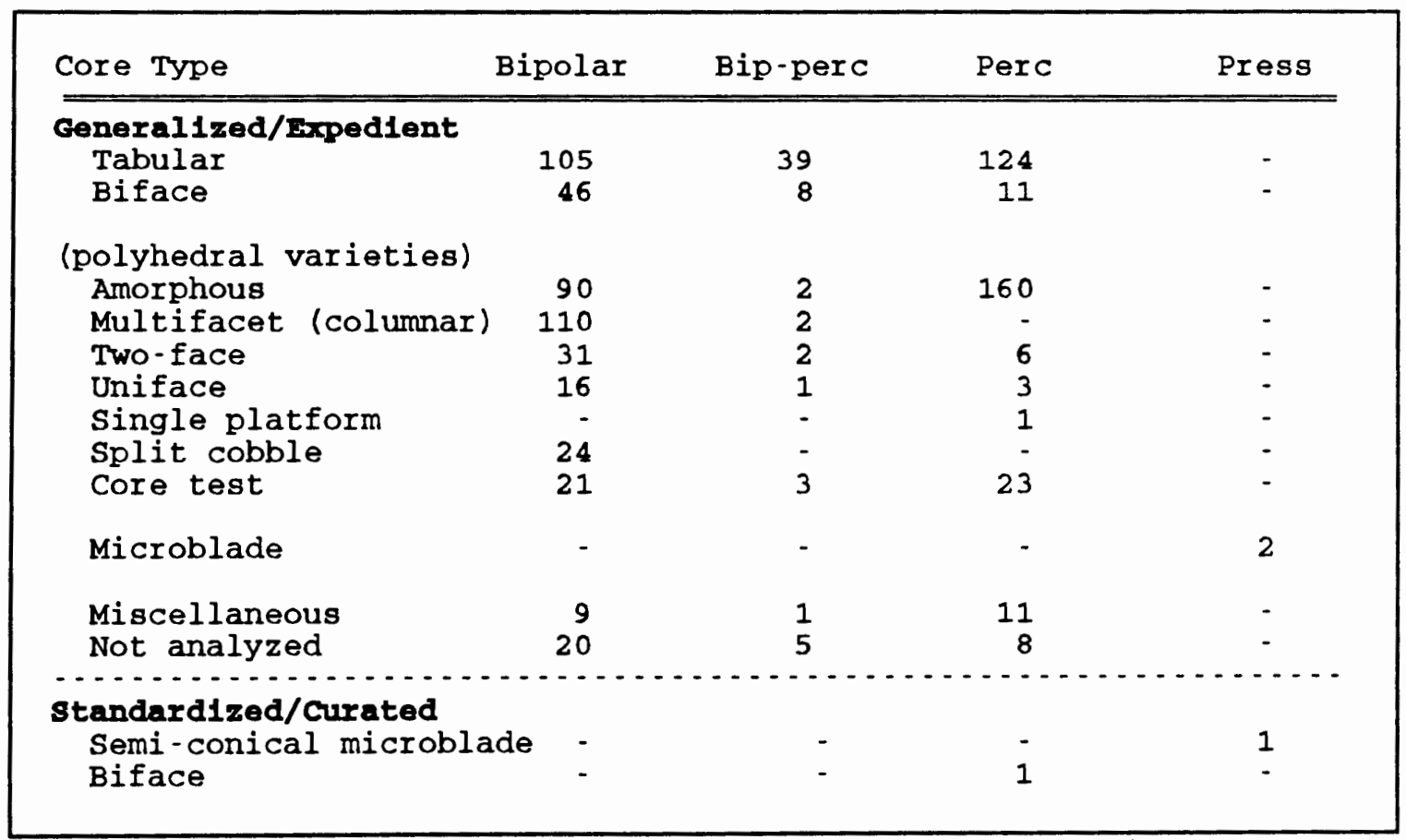

Table 19. Frequency of Generalized and standardized Cores. 
bipolar split cobbles. Tabular cores are technically early stage bifaces (equivalent to type 2 tools) but are usually very rough.

Eleven of the 12 biface percussion cores are best described as expediently produced, small discoidal cores. They are generally not thinned, flakescars do not pass over the midline, and the platforms are not well prepared. One biface percussion core deserves attention. This end fragment of a core is made of the exotic material Wascoite. The fracture is perverse, suggesting it was unintentionally broken during reduction (blank production). It was intentionally shaped into a bifacial form and then heat treated for further reduction. The platforms are highly prepared and flake scars pass completely across one of the faces. The prepared biface may have functioned as a core while being shaped into a bifacial tool. This would be consistent with the multiple organizational roles bifaces can play in technology (Kelly 1988). The large flake scars certainly indicate the possibility that the flakes were used for tool blanks, particularly for the long, unifacially retouched shavers recovered at Meier.

\section{Bipolar Cores $(\mathrm{N}=472)$ :}

Most bipolar cores are tabular, biface, amorphous and multi-faceted (columnar). Tabular and biface bipolar cores are typically referred to as pieces esquillees. These cores 
are usually small indicating that the bipolar technique was used as a strategy to intensively reduce lithics for small tool blanks. These cores were often used as core-tools. Hence, some specimens labelled as bipolar cores may also have been tool preforms and tools with unidentified usewear.

Small tabular and biface (and some collumnar) bipolar cores tend to be redundant in form. They also exhibit redundant flakescar patterns. These factors may indicate their use as standardized cores for producing specialized flake blanks. However, large numbers of flake blanks from these cores have yet to be identified as tools in the study collection. The use of small bipolar flakes as microliths is possible and should be investigated. Small bipolar cores are produced with little effort and skill as compared to, for example, conical microblade cores. Unfortunately, methods of quantifying the efficiency of producing flake blanks between core types has not been adequately established. Due to their high frequency and redundant form, I consider pieces esquillees to be an expedient means of producing a standardized flake form, the purpose of which has yet to be determined.

\section{Bipolar-Freehand Cores $(\mathrm{N}=63)$ :}

The cores exhibiting both reduction techniques were mostly tabular pieces. These cores share the expedient 
character of other bipolar and freehand percussion cores. They merely represent cores that happen to exhibit flake scars from both techniques. Although their numbers seem small, the reality is that more, if not most, cores in the collection were formed by both techniques.

\section{Blade Cores $(\mathrm{N}=3)$ :}

Three micro-blade cores were identified. One of these was a standardized micro-blade core. No classic blades from such standardized cores were found in the samples (derived from 1/4" mesh). The very few blade cores and complete absence of formal blades suggests that investments in blade technology were minimal at Meier.

\section{Diversity of Tool Blanks}

In general, blanks display great diversity in shape and size at the site, supporting the evidence from cores for expedient blank production. Basically, all categories of debitage were used for tool blanks. However, particular flake types were preferred for certain tool types. For example, arrow points were primarily made on small percussion flakes, end-scrapers on larger, thick percussion flakes, and side-shavers on thin, narrow flakes. These preferences do not preclude the use of generalized core technologies for making most of the blanks.

The use of a variety of core products for tool blanks 
supports the expedient and opportunistic nature of tool blank selection. Core products used for blanks included cortical flakes, broken flakes, flake fragments, and debris (Table 20). Heat damaged blanks were also used. These, with blanks from other parts of the lithic system (discussed below: BTF flakes, potlids, and exhausted cores, preforms, tools) form a very diverse set of blank sources.

In addition to producing blanks from cores, people at Meier opportunistically selected material produced from other parts of the reduction sequence for tool blanks. These products result from tool shaping (eg. debitage and discarded preforms), heat treatment (eg. potlids and other debris), and tool use/reuse (reworking edges and recycling exhausted tools). In addition, I consider tools made from

\begin{tabular}{|c|c|c|}
\hline $\begin{array}{c}\text { Blank } \\
\text { Acquisition }\end{array}$ & Core Blanks & Tool Blanks \\
\hline$\frac{\text { Intentional }}{\text { production }}$ & $\begin{array}{l}\text { Alluvial cobble } \\
\text { Outcrop nodule } \\
\text { Percussion flake } \\
\text { Bipolar flake }\end{array}$ & $\begin{array}{l}\text { Percussion flake } \\
\text { Bipolar flake } \\
\text { Pressure flake } \\
\text { Complete flake } \\
\text { Broken flake } \\
\text { Flake fragment }\end{array}$ \\
\hline$\frac{\text { Opportunistic }}{\text { selection }}$ & $\begin{array}{l}\text { Core fragment } \\
\text { Tool } \\
\text { Heat damage debris }\end{array}$ & $\begin{array}{l}\text { Biface thinning flake } \\
\text { Debris (shatter) } \\
\text { Heat damage debris } \\
\text { Preform } \\
\text { Tool } \\
\text { Core } \\
\text { Manufacture debris }\end{array}$ \\
\hline
\end{tabular}

Table 20. List of Intentional Blanks and Opportunistic Blanks for Cores and Tools. 
exhausted cores as opportunistic blanks because they are not necessarily intended as tool blanks when being reduced for flake production (except possibly in the case of large bifaces). Like expediently produced flakes from generalized cores, these products are selected on the basis of shape and material. Usually, they require minimal alteration to be functional and are likely used for expedient tasks.

Included in Table 20 is the list of opportunistic tool blanks found at Meier. Thirty-three percent $(n=10)$ of the tools in the micro-wear analysis were opportunistically selected blanks from biface manufacture debris (biface thinning flakes). This indicates a significant reliance of blanks from arrow point shaping debitage.

opportunistic blank selection was probably a small part of a broader strategy for selecting blanks from a stockpile of previously reduced material. This secondary selection would primarily include choosing core products that were not selected at the time of their production. For example, much of the core reduction may have been directed at making arrow point flake blanks. The flakes not suited for that purpose could be selected later, as needed. Quantifying the intensity of secondary selection would be extremely complex and is therefore left for future studies. For this analysis, I use the presence of opportunistic blanks as an indication of secondary selection, the intensity of which has not been measured. 


\section{HEAT TREATMENT}

A very diverse sample of lithics was chosen for heat alteration including most material types and all stages of the reduction trajectory. Surprisingly, $20 \%$ of the cores were heat altered (Table 21). Most of these specimens are small tabular percussion and bipolar cores that presumably needed heat treatment for further reduction. Twenty-six heat treated and damaged cores were discarded after being tested.

Table 14 summarizes heat alteration events for different stages of manufacture based on blank remnants on tools and preforms. These data show at what stage in the use-life material was heated. Some artifacts were heat treated many times $(n=12)$ and others heat treated at one

\begin{tabular}{|c|c|c|c|c|c|c|c|c|}
\hline \multirow[b]{2}{*}{ Artifact } & \multicolumn{2}{|c|}{$\begin{array}{l}\text { Non-heat } \\
\text { Al tered }\end{array}$} & \multicolumn{2}{|c|}{$\begin{array}{l}\text { Heat } \\
\text { Treated }\end{array}$} & \multicolumn{2}{|c|}{$\begin{array}{c}\text { Heat } \\
\text { Damaged }\end{array}$} & \multicolumn{2}{|c|}{$\begin{array}{l}\text { Heat } \\
\text { Altered }\end{array}$} \\
\hline & $\mathbf{n}$ & 8 & $\mathbf{n}$ & \& & $\mathbf{n}$ & $z$ & $\mathrm{n}$ & z \\
\hline \multicolumn{9}{|c|}{ Nan-debitage } \\
\hline $\begin{array}{l}\text { Core } \\
\text { Tool } \\
\text { Preform } \\
\text { M16C }\end{array}$ & $\begin{array}{l}917 \\
514 \\
244 \\
149\end{array}$ & $\begin{array}{l}80 \\
54 \\
39 \\
64\end{array}$ & $\begin{array}{r}155 \\
268 \\
289 \\
48\end{array}$ & $\begin{array}{l}14 \\
28 \\
47 \\
21\end{array}$ & $\begin{array}{r}76 \\
162 \\
86 \\
36\end{array}$ & $\begin{array}{r}7 \\
17 \\
14 \\
12\end{array}$ & $\begin{array}{r}231 \\
430 \\
375 \\
84\end{array}$ & $\begin{array}{l}20 \\
46 \\
61 \\
36\end{array}$ \\
\hline total & 1824 & 62 & 760 & 26 & 360 & 12 & 1120 & 38 \\
\hline Deb1tage ${ }^{c}$ & 2306 & 68 & 743 & 21 & 486 & 13 & 1229 & 34 \\
\hline Total & 4130 & 64 & 1503 & 23 & 846 & 13 & 2349 & 36 \\
\hline \multicolumn{9}{|c|}{$\begin{array}{l}\text { aspecimens that were both heat treated and heat damaged (n=36) } \\
\text { were counted in each category and multiple episodes of heat } \\
\text { treatment on single specimens (n-12) counted only once. } \\
\text { botal of heat treated and heat damaged specimens. } \\
\text { c } \text { Debitage heat damage does not include potilds (n-73). }\end{array}$} \\
\hline
\end{tabular}

Table 21. Frequency of Heat Alteration ${ }^{2}$. 
stage in their use-lives and later heat damaged $(n=36)$. Heat treatment was usually applied to flakes $(n=129)$ rather than the core before the flake-blank was removed $(n=85)$. However, $67 \%$ of the flake-blanks used for tools identified in the microwear study (sample 4) were flakes removed from heat treated cores or blanks. This high frequency is in part a result of selecting useable flakes from debitage derived from biface production of heat treated flake-blanks. In addition to heat treatment for blank production and tool shaping (including heat treated preforms), an estimated $2 \%$ $(n=65)$ of the tools were heat treated to facilitate refurbishing. Most of these were arrow points, representing 55 of these tools.

Generally, the heat treated material was diverse. The diversity was caused by selecting material of all stages of manufacture, generalized core reduction, and lithological

\begin{tabular}{|lcccc|}
$\begin{array}{l}\text { Heat altered } \\
\text { stage }\end{array}$ & $\begin{array}{c}\text { Tool } \\
(\mathrm{n}=430)\end{array}$ & $\begin{array}{c}\text { Preform } \\
(\mathrm{n}=375)\end{array}$ & $\begin{array}{c}\text { Misc } \\
(\mathrm{n}=84)\end{array}$ & $\begin{array}{c}\text { Micro-wear } \\
(\mathrm{n}=30)\end{array}$ \\
\hline $\begin{array}{l}\text { HT Core } \\
\text { HD Core }\end{array}$ & 84 & 41 & - & 20 \\
\hline HT Blank & 1 & 2 & 2 & - \\
HD Blank & 104 & 117 & - & - \\
HT Preform & 25 & 18 & 9 & - \\
HD Preform & 2 & - & - & - \\
\hline HT Tool & - & NA & - & - \\
HD Tool & 20 & NA & - & - \\
\hline Post-HD & 1 & 36 & 21 & \\
\hline \hline Calculated from sample 1 and 4. & & & - \\
\hline
\end{tabular}

Table 22. Stage of Heat Alteration on Tool Blanks. 
variability. The diversity of heat treated material is related to the generalized and expedient nature of raw material procurement and blank acquisition. However, the large number of heat treated specimens shows significant efforts in making shaped and maintainable tools indicating curation.

\section{TOOL SAMPLE}

The count of finished tools $(n=3,781)$ in the analyzed Meier assemblage was obtained by sampling. The primary problem in identifying tools is locating actual wear on minimally shaped and unshaped tools that were not retouched (see introduction of appendix 4 for a brief description of how tools were identified). My first examination (Table 2: sample 1 and sample 2) of all artifacts identified in the field and debitage field bags produced a total of 1,985 tools. After reexamining a sample of non-tool artifacts, including debitage, it was apparent that many non-retouched lithic tools had not been identified. A second attempt produced an estimate of 3,781 tools. This is significantly higher, approximately double the original count.

Most of the additional tools found during the reexamination are used-flakes (non-shaped, non-resharpened tools). The expedient tools were recognized primarily by a micro-wear analysis of a small and spatially limited 
"debitage" field sample. This sample (Table 2: sample 4) is only $28(n=1462)$ of the total 1987-1990 debitage assemblage $(n=77,382)$. On this basis, I estimate that approximately $2 \%$ of the total debitage assemblage is comprised of expedient (type 1) tools $s^{5}$. This percentage remains accurate after sampling most of the remaining assemblage (Cameron Smith, personal communication 1994). The $2 \%$ estimate raises the frequency of tools by approximately 77\%. Although the accuracy of the estimate is conditioned by a small numerical and a small spatial sample, there is no doubt that there are many used-flakes not included here. This may significantly affect certain inferences in comparing tool categories. I will note where I think my conclusions are so affected. The second large estimate is also based on an effort to identify tools among artifacts in the core assemblage and preform categories. A $14 \%$ sample (Table 2: sample 3) of these artifacts was examined. Tool use was recognized on artifacts originally classed as tabular cores and early stage preforms. A total of 39 tools were identified. This represents approximately $9 \%$ of the preform and core collection of sample 1. These tools included minimally shaped and non-shaped (type 2 and type 1; mostly used cores) artifacts. Based on the re-examination, I revised artifact

${ }^{5}$ As analysis of additional units continues, C. Smith (personal communication 1994) estimates debitage field bags contain an average of $1.8 \%$ used flakes, close to the $2 \%$ used for this analysis. 
frequencies. Table 35, appendix 2 shows the original and revised estimates for general artifact categories. For tools, I recalculated the ranked shaping type and reuse categories based on the tools found during the reexaminations (Table 34 ).

\section{TOOL SHAPING}

Flake scars on tools indicate that various combinations of pressure flaking, freehand percussion, bipolar percussion, beveling and crushing were used to shape tools. Among the debitage, pressure flakes are significantly underrepresented (Table 16) because the sample was collected from 1/4" mesh. Most pressure flakes are the result of shaping and retouching tools. Overall, flake scars on tools indicate that freehand and bipolar percussion were used far less than pressure flaking to shape tools (Table 23).

\begin{tabular}{lrr}
$\begin{array}{c}\text { Flaking } \\
\text { Technique }\end{array}$ & $\begin{array}{c}\text { Number of } \\
\text { Tools }\end{array}$ & $\begin{array}{c}\text { Number of } \\
\text { Preforms }\end{array}$ \\
\hline Bipolar & 32 & 3 \\
Bipolar-percussion & 5 & 4 \\
Percussion & 77 & 122 \\
Bipolar-pressure & 5 & 4 \\
Percussion-pressure & 21 & 87 \\
Pressurea & 1,219 & 1,521 \\
Misc & 1 & 28 \\
Not analyzed & 177 & 28 \\
\hline
\end{tabular}

${ }_{1,116}$ pressure flaked tools are arrow points.

b 169 are type 2 tools; 14 are type 4.

Table 23. Number of Shaped Tools and Preforms in each Technological Category. 
Bevelling and crushing were not consistently quantified as shaping techniques, but were most often used to blunt sharp edges to back tools (side-shavers) and blunt hafting areas on arrow points and end-scrapers. For a brief description of how artifacts were shaped within functional categories see appendix 4. A greater number and variety of expedient tools were not shaped.

\section{Ranked Shaping Typology}

To estimate the relative energy expended making tools, I typed tools according to a ranked shaping typology based on the amount of edging produced during shaping. In general, the less energy placed into edging, the more expedient the shaping strategy. The estimated frequency of tools within this taxonomy is shown in Table 24 . The most frequent tool type is type 1 (non-shaped blanks), the lowest energy input for shaping tools. The second most frequent

\begin{tabular}{|c|c|c|c|c|c|c|}
\hline Re-use & Type 1 & Type 2 & Type 3 & Type 4 & Unknwn & Total \\
\hline $\begin{array}{c}\text { Exped } \\
8\end{array}$ & $\begin{array}{l}1872 \\
(50)\end{array}$ & $\begin{array}{l}339 \\
(9)\end{array}$ & $\begin{array}{l}1 \\
(1)\end{array}$ & - & $\begin{array}{c}2 \\
(1)\end{array}$ & $\begin{array}{l}2214 \\
(59)\end{array}$ \\
\hline$\underset{8}{\text { Curate }}$ & $\begin{array}{l}194 \\
(5)\end{array}$ & $\begin{array}{l}173 \\
(5)\end{array}$ & $\begin{array}{l}76 \\
(2)\end{array}$ & $\begin{array}{l}1106 \\
(29)\end{array}$ & $\begin{array}{c}5 \\
(1)\end{array}$ & $\begin{array}{l}1554 \\
(41)\end{array}$ \\
\hline$\underset{8}{\text { Unknwn }}$ & $\begin{array}{l}12 \\
(1)\end{array}$ & $\begin{array}{c}2 \\
(1)\end{array}$ & - & - & - & $\begin{array}{l}14 \\
(1)\end{array}$ \\
\hline $\begin{array}{c}\text { Totals } \\
8\end{array}$ & $\begin{array}{l}2066 \\
(55)\end{array}$ & $\begin{array}{l}524 \\
(14)\end{array}$ & $\begin{array}{l}79 \\
(2)\end{array}$ & $\begin{array}{l}1106 \\
(29)\end{array}$ & $\begin{array}{c}7 \\
(1)\end{array}$ & $\begin{array}{l}3781 \\
(100)\end{array}$ \\
\hline
\end{tabular}

Table 24. Frequencies of Expedient and Curated Tools for each Ranked-Shaping Tool category. 
are type 4 (late-stage bifaces), the highest energy input tools. Finally the lowest frequency of tools are type 2 and type 3 (middle range energy input tools).

The blanks of non-shaped tools (Type 1) primarily include flakes (used flakes), but debris and cores as well. Rejected preforms were undoubtedly used opportunistically as type 1 blanks, but were likely misidentified as shaped tools. Non-shaped tools were used for all functions except (by definition) generalized knives and projectile points (Table 25).

High energy input tools (Type 4) are late-stage bifaces that can be easily curated. Bifaces can be made in many ways with a wide range of energy costs. For this reason, I subdivided the category into pressure flaked, pressurepercussion flaked and percussion flaked, clarifying the typology in terms of differential investments of energy. Such refinement is particularly important in light of

\begin{tabular}{|lrrrr|}
\hline $\begin{array}{l}\text { Functional } \\
\text { Class }\end{array}$ & Type & Type & Type & \multicolumn{1}{c|}{ Type } \\
\hline Projectile point & 1 & 2 & 3 & 4 \\
Scraper & 217 & 14 & 63 & 1049 \\
Shaver & 115 & 33 & - & - \\
Cutter & 80 & 21 & - & 1 \\
Perforator & 14 & 41 & 3 & 11 \\
Wedge & 1 & 4 & 22 & - \\
Knife & 1 & 4 & - & - \\
Saw & 5 & 17 & 1 & - \\
Graver & 8 & 11 & 3 & 27 \\
Tool & 11 & & & \\
\hline
\end{tabular}

Table 25. Number of Ranked Shaping Types for each Functional class. 
Kelly's (1985, 1988) argument that large percussion bifaces are important tools for residentially mobile huntergatherers. He argues this on the bases of the potential functional diversity, as well as the maintainability and reliability of large bifaces. At Meier, large percussion and multi-stage percussion-pressure flaked bifaces are rare (Table 26). The large, hafted chevron and pentagonal knife blades are the most likely candidates for use as gear in high mobility situations. That only six were recovered suggests their occasional use in need for forays away from the house, while their paucity indicates that biface technology was not a significant strategy. Canoes likely played a significant role, effectively relieving size constraints on tool-kits during forays.

The overwhelming majority of bifaces are small pressure flaked tools (mostly arrow points; $n=1,126$ ). Of the three types of bifaces, pressure are the least costly in terms of energy and time. This is particularly true of small bifaces made on small flakes. Small bifaces are generally not as functionally flexible and cannot be used effectively as

\begin{tabular}{|ccccc|}
\hline $\begin{array}{c}\text { Artifact } \\
\text { class }\end{array}$ & Percussion & $\begin{array}{c}\text { Percussion- } \\
\text { pressure }\end{array}$ & Pressure & Misc. \\
\hline $\begin{array}{c}\text { Bifacial } \\
\text { tool } \\
\text { Bifacial } \\
\text { preform }\end{array}$ & 11 & 11 & 1172 & - \\
\hline
\end{tabular}

Table 26. Number of Type 4 Bifacial Tools and All Preforms for each Technological Class. 
secondary cores except for microlith production during the thinning process. Hicks (1991) reports that numerous assemblages throughout the Northwest Coast region have microliths made from biface thinning flakes. This contention is supported at Meier by use-wear on a significant number of small biface thinning flakes in the microwear analysis ( $n=10 ; 33 \%$ ) (Table 34, appendix 1). Arrow points were also recycled into hafted perforators and other tools at Meier, but their use as generalized tools is usually limited by their small size.

The small size of arrow points is, however, advantageous in relation to raw material procurement. Most obviously, when considering artifact mass, more arrow points can be made then larger tools such as hafted knives with the same amount of material. Additionally, poor quality material can be used because flaws are more easily avoided when using small blanks. For example, in the Meier collection, almost all cobbles have flaws, but, there are more small areas with no flaws than large areas. Hence, many small flake-blanks can be produced with no flaws, but few large ones. This argument can be extended to tool size in general.

Type 2 and type 3 have the fewest tools. Low energy input tools (Type 2) were manufactured more quickly (measured by less edging and qualitatively by fewer flake scars) than traditional bifaces. The category is 
functionally very diverse (Table 25). The type 2 category includes many tools traditionally termed unifaces and minimally shaped bifacial tools. In addition, all bipolar shaped tools were classed as type 2. Type 2 tools are mostly shavers, scrapers, cutters, perforators, gravers and wedges. The functional distribution closely parallels type 1 tools.

All the basic shaping strategies identified at the site were used to shape type 2 tools. These are pressure, freehand percussion, bipolar percussion, beveling and crushing. These modification techniques were often minimally used to blunt sharp edges or knock off unwanted protruding portions of the tool blank. Many of the scrapers and some perforators and shavers had manufactured hafting areas and some shavers were backed (blunted) by bevelling or crushing. I did not quantify the variety of techniques used on each tool (except the bipolar technique). Some of these tools are fine pieces of work requiring highly skilled craftsmanship. This is particularly true of the hafted endscrapers and perforators. Nevertheless, most are the minimally shaped tools expected in expedient technologies.

Medium energy input tools (Type 3) are basically expediently made bifaces made from irregularly shaped blanks. The overwhelming majority are arrow points (Table 25). Most type 3 and type 2 arrow points may have been made by people just learning to flintknapp. 


\section{Bipolar Tool shaping}

In the ranked shaping typology, I classed all the bipolar shaped tools as type 2 because the technique takes less effort to create a complete biface. I have already discussed the use of the bipolar technique as an aspect of the Meier expedient core technology. Use-wear on artifacts at Meier indicates that bipolar products were used for tools. Like freehand percussion, the bipolar technique was employed to make blanks and shape tools. A variety of bipolar product types had evidence of tool use. Many classic pieces esquillees had definite use-created crushing and polishing as well as some retouched edges. Tool shapes, location of wear, and types of wear indicated uses such as wedges, cutters and shavers. Most were not retouched. Because wedges need a strong bit, they were generally not retouched (unless retouch was bipolar). A second common bipolar core product is narrow, multifaceted pieces described as "columns". These sometimes had wear I attributed to perforating. LaBlanc (1992) also suggests their use as gravers or shavers. Extensive micro-wear analysis is needed to distinguish bipolar tools from cores and determine their functions. My guess is that I have significantly underestimated the use of small bipolar cores as tools. 


\section{Tool Hafting}

Tool hafting is used as a design strategy to facilitate maintenance by providing a replaceable working edge (Bleed 1986). Investments in making haftable parts is an indication of curation. At least $30 \%$ of the stone tools exhibited hafting elements (a margin shaped for hafting). These include mostly projectile points and scrapers, but also knives, perforators, shavers, and gravers (Table 27).

Many hafted stone tools probably did not have formal hafting elements. For example, microliths are minimally altered, if at all, before hafting. The few micro-blade cores in the Meier assemblage suggest a microlith industry. If the microlith production technology was primarily expedient, then microliths may be difficult to identify as compared to those made from standardized blade cores. Hicks (1991) posits the use of biface flakes as microlith tools on the Northwest Coast. Also on the Northwest Coast, Flenniken (1981) demonstrates the use of bipolar flakes as hafted blades at the Hoko River site. Hence, it is possible that small bipolar flakes and pressure flakes could be used as microliths.

At Meier, 10 of the 30 used flakes in the microwear analysis were biface thinning flakes and three were retouch flakes (Table 34, appendix 1). Nine of these 13 flakes were pressure flakes. These small used flakes suggest that an expedient microlith industry may have been present at Meier. 
Additionally, side-shavers at Meier may have been hafted as macro-blades, explaining the minimal backing on these tools and their redundant form. Analysis aimed at hafted "blade" technologies is necessary to determine more fully the role of hafted stone tools in the Meier assemblage.

\section{TOOL USE}

As expected for a residential site, small flaked-stone tools were used for a broad range of tasks. Functional classes include scrapers, shavers, cutters, gravers, perforators, wedges, knives, saws and projectile points. Although the functional categories can be broken into subtypes (see appendix 4 for a description of these artifacts), these broad tool classes are sufficient for my general comments about tool use within the lithic system.

Functional

Class

Count

Arrow point ${ }^{a}$

Hafted scraper

End-scraper ${ }^{5}$

Hafted shaver

Hafted knife

Hafted perforator

Hafted graver

1010

98

34

8

8

7

Total

1136

Oonly includes specimens with hafting element present.

Most end-scrapers are probably hafted scrapers.

Table 27. Number of Hafted Tools. 
TOOL REUSE

Reuse is the maintenance, multi-use and recycling of tools. Multi-use and recycling increase the functional diversity and lengthen the use-life of tools. Maintenance, on the other hand, is specifically geared at lengthening the use-life while keeping the function constant. Although the degree of maintenance is fast becoming a measured variable in lithic analysis (eg. Grimes and Grimes 1985; Shott 1989; Kuhn 1990), I only recorded maintenance as present or absent on tools. In general, the less reuse in an assemblage, the more expediently the tools were used.

Forty-one percent of the tools were maintained and $59 \%$ were expedient (Table 24). Additional evidence of reuse is the 96 multi-use and 149 recycled tools. Much of the multiuse and recycling may have been secondary selection from a

\begin{tabular}{|lrccr|}
\hline $\begin{array}{l}\text { Functional } \\
\text { Class }\end{array}$ & curated & Expedient & $\begin{array}{c}\text { Not } \\
\text { Analyzed }\end{array}$ & Totals \\
\hline Projectile & 1126 & - & - & 1126 \\
Knife & 21 & 1 & - & 22 \\
Scraper & 229 & 162 & 4 & 395 \\
Shaver & 70 & 79 & 2 & 151 \\
Cutter & 20 & 82 & - & 102 \\
Saw & - & 9 & - & 9 \\
Graver & 8 & 18 & 6 & 26 \\
Perforator & 17 & 46 & 1 & 32 \\
Wedge & 2 & 29 & 24 & 52 \\
Tool & 12 & 16 & & \\
\hline
\end{tabular}

Table 28. Number of Expedient and Curated Tools for each Functional Class. 
stockpile. Overall, the proportion of maintained tools, retouched multi-use tools, and recycled tools is quite high indicating a heavy reliance on tool reuse. The overwhelming majority of these are small, pressure flaked arrow points (Table 28). This curation is related to making arrow points reliable for hunting (Bleed 1986) and maintainable to minimize re-hafting costs. The reliable design minimizes the likelihood of tool failure when capturing animals that move quickly (Torrence 1989, Bleed 1986), while a maintainable design is less costly in material and time than replacing the tip of arrows each time they become dull or break. Many hafted scrapers were also maintained. Presumably, these were also curated to maximize reliability and minimize re-tooling and shaping costs. Finally, shavers and cutters were often maintained, probably to compensate for the difficulty in obtaining blanks that have long working edges.

\section{SUMMARY}

I have examined data in six components of the Meier fine-grained lithic industry. The technology was based on the procurement of alluvial gravels. Many of the cobbles were poor quality but were collected without being tested, a likely response to time constraints while on resource forays (eg. fishing), proximity to the site, and ease of transport 
using a canoe.

Blank production was based on generalized core reduction. Only two standardized cores were identified. Additionally, 151 small bipolar cores (biface and tabular) may be expedient, standardized cores. However, standardized bipolar flake blanks have not been identified in the assemblage. Generalized cores included various polyhedral cores, biface cores, and tabular cores. To accommodate the need for tools with long, maintainable working edges, a low number of high-quality standardized cores and possibly tool blanks were acquired through trade or during longer forays up the Columbia River, perhaps while fishing for salmon at Celilo Falls.

Most tool blanks were produced by expediently reducing the more abundant and easily obtained cobbles. Both percussion and bipolar techniques were used to maximize the blank utility of cobbles while maintaining expediency. Although freehand percussion products were most often used for flake blanks, bipolar reduction was usually used to begin and finish core reduction. Adding to the diverse source of blanks from generalized core products, tool-blanks were opportunistically selected from heat treatment debris such as potlids, exhausted tools and cores, biface manufacture debitage and presumably debitage from the manufacture of other tools.

Low energy investments in raw material procurement and 
blank acquisition indicate that large quantities of raw material were brought into the site and stored. A stockpile is a somewhat informal and probably communal means of storing raw material in all stages of the reduction sequence for use as needed. The stockpile provides a means of storing debris that would otherwise be wasted from expedient strategies of core reduction and tool use. From the stockpile, people at Meier chose core blanks from unmodified cobbles, partially reduced cores, core fragments, large flakes, discarded preforms, and exhausted tools. The tool blanks selected from the stockpile included cores at all stages of reduction, tool shaping debitage, heat treatment debris, and presumably core reduction products that were not immediately used.

Most blanks were not shaped or maintained for use as tools. The most abundant high-energy shaped tools were small, pressure flaked arrow points. These were also the most commonly maintained. Only six bifacial tools fit the expectations for a high mobility tool-kit. Most other tools were either expedient or minimally shaped for specific processing tasks. Functions included hide-scrapers, other scrapers, side-shavers, other shavers, cutters, perforators, gravers, saws, and wedges. While gravers and wedges were never maintained, scrapers, shavers, cutters, and perforators had significant proportions of both maintained and expedient varieties (Table 28). Of these, cutters were 
the least maintained, presumably because retouched edges are less efficient than clean feather terminations. Of the more abundant tools, arrow points, shavers and cutters were made from mostly high-quality material while a higher proportion of scrapers were made from low-quality material (Table 21).

Heat treatment was applied to facilitate flaking in all stages of reduction (core, blank, preform, and tool), but mostly to flake blanks before shaping. Heat treatment of flake blanks demonstrates the need to carefully shape tools

\begin{tabular}{|c|c|c|c|c|c|c|}
\hline $\begin{array}{l}\text { Functional } \\
\text { Class }\end{array}$ & $\begin{array}{l}\text { Re- } \\
\text { use }\end{array}$ & Poor & Fair & Good & $\begin{array}{l}\text { Excel - } \\
\text { lent }\end{array}$ & Exotic \\
\hline $\begin{array}{l}\text { Projectile } \\
\text { point }\end{array}$ & $\begin{array}{l}\mathrm{cu} \\
\mathrm{ex}\end{array}$ & $\begin{array}{r}6 \\
\mathrm{NA}\end{array}$ & $\begin{array}{l}32 \\
\text { NA }\end{array}$ & $\begin{array}{r}245 \\
\mathrm{NA}\end{array}$ & $\begin{array}{l}\mathrm{NA} \\
\mathrm{NA}\end{array}$ & $\begin{array}{l}\text { NA } \\
\text { NA }\end{array}$ \\
\hline Knife & $\begin{array}{l}\text { cu } \\
\text { ex }\end{array}$ & 1 & 5 & $\begin{array}{l}8 \\
1\end{array}$ & - & - \\
\hline Scraper & $\begin{array}{l}\mathrm{cu} \\
\mathrm{ex}\end{array}$ & $\begin{array}{l}6 \\
3\end{array}$ & $\begin{array}{l}50 \\
51\end{array}$ & $\begin{array}{l}37 \\
25\end{array}$ & $\begin{array}{l}8 \\
3\end{array}$ & 5 \\
\hline Shaver & $\begin{array}{l}\text { cu } \\
\text { ex }\end{array}$ & $i$ & $\begin{array}{l}11 \\
15\end{array}$ & $\begin{array}{l}19 \\
22\end{array}$ & $\begin{array}{l}9 \\
9\end{array}$ & $\begin{array}{r}12 \\
3\end{array}$ \\
\hline Cutter & $\begin{array}{l}c u \\
e x\end{array}$ & $\begin{array}{l}1 \\
2\end{array}$ & $\begin{array}{r}2 \\
15\end{array}$ & $\begin{array}{r}7 \\
18\end{array}$ & $\begin{array}{l}1 \\
7\end{array}$ & 1 \\
\hline Saw & $\begin{array}{l}\text { cu } \\
\text { ex }\end{array}$ & - & $\overline{5}$ & 3 & - & - \\
\hline Graver & $\begin{array}{l}\mathrm{cu} \\
\mathrm{ex}\end{array}$ & - & - & $\begin{array}{l}3 \\
9\end{array}$ & $\begin{array}{l}4 \\
2\end{array}$ & - \\
\hline Perforator & $\begin{array}{l}\text { cu } \\
\text { ex }\end{array}$ & $\overline{1}$ & 13 & $\begin{array}{r}3 \\
14\end{array}$ & 5 & 1 \\
\hline Wedge & $\begin{array}{l}\text { cu } \\
\text { ex }\end{array}$ & $\overline{1}$ & - & $\frac{1}{7}$ & $\begin{array}{l}1 \\
1\end{array}$ & - \\
\hline
\end{tabular}

Table 29. Raw Material Quality of Expedient and Curated Tools for each Functional class. 
for curation. A diverse set of material types, shapes, and sizes was heat treated, corresponding to the expedient nature of the technology. 


\section{CHAPTER 6}

\section{CONCLUSION}

\section{DIBCUSBION}

The Meier site provides a chance to study the finegrained lithic technology used at a hunter-gatherer longterm sedentary residential site. I set out to test the hypothesis that a sedentary residential group will have an expedient technology through the use of a stockpile,

\begin{tabular}{llll} 
& \multicolumn{3}{c}{ Energy Input } \\
\cline { 2 - 3 } Data set & Low & High & $\begin{array}{c}\text { Technological } \\
\text { Strategy }\end{array}$ \\
\hline (1) Raw material procurement & $100 \%$ & $0.1 \%$ & Exped \\
(2) Core material quality & $64 \%$ & $36 \%$ & Exped \\
(3) Core strategy & $100 \%$ & $0.2 \%$ & Exped \\
(4) Heat treatment & $64 \%$ & $23 \%$ & Curated \\
(5) Tool material quality & $31 \%$ & $69 \%$ & Curated \\
(6) Tool shaping & $69 \%$ & $31 \%$ & Cur-exp \\
(7) Tool maintenance & $59 \%$ & $41 \%$ & Curated \\
(8) Tool hafting & $70 \%$ & $30 \%$ & Curated \\
\hline
\end{tabular}

KEY:

(1) Raw material procurement based on source location. Exotic is curated, alluvial gravel and low guality outcrop are expedient (Table 10).

(2) Core material quality (Table 13).

(3) Core atrategy (Table 19).

(4) Heat treatment of total assemblage. Heat treated $1 \mathrm{~s}$ curated, non-heat altered 18 expedient. Heat damaged epecimens are not included (Table 21).

(5) Tool material quality (Table 14).

(6) Tool shaping based on ranked shaping types: type 1 and type 2 are expedient, type 3 and type 4 are curated (Table 24).

(7) Tool maintenance (Table 24).

(8) Tools with hafting elements (Table 27).

Table 30. Data Summary. 
provided sufficient raw material does not naturally occur at the site. Abundant alluvial gravels are locally (but seasonally) available throughout the wapato Valley region. Such abundance undoubtedly enhanced the ability to maintain a stockpile and use expedient technologies. Nevertheless, the Meier evidence suggests that stockpiling was used to facilitate a significant curated technology as well as an expedient technology. Although the use of a curated technology was anticipated, the use was expected to be minimal at a sedentary residential site with abundant local material (Nelson 1991). By assessing the investment of energy in each behavioral component, I have determined that strategies of lithic procurement and blank acquisition were more like that expected of an expedient technology, while tool shaping and tool reuse tended toward characteristics of a curated technology (Table 30, Table 31).

\section{Meier site Technological organization}

I propose a model for the Meier site lithic technology

\begin{tabular}{|lll|}
\hline $\begin{array}{l}\text { Activity } \\
\text { Set }\end{array}$ & $\begin{array}{l}\text { Energy } \\
\text { Input }\end{array}$ & $\begin{array}{l}\text { Strategy } \\
\text { Correlate }\end{array}$ \\
\hline Lithic procurement & Low & Expedient \\
Blank acquisition & Low & Expedient \\
Tool shaping & Mid & Curated-expedient \\
Tool use/reuse & High & Curated \\
Heat treatment & High & Curated \\
\hline
\end{tabular}

Table 31. Evaluation of Energy Invested in Each Activity Set of the Lithic Technology. 
rooted in the costs and benefits of expedient and curated strategies and the dynamics of using a stockpile. This model is consistent with the expectations for stockpiling as outlined by Parry and Kelly (1987) and Nelson (1991). I argue that the use of a stockpile allowed the expedient acquisition of tool-blanks for curated tools that did not have to meet the high standards required of tools designed for high mobility (eg. transportable designs; large, functionally generalized, bifaces). At the same time, the stockpile provided a place to store ample blanks for cores and tools for an expedient technology. The stockpile had exceptional raw material and shape diversity to facilitate the quick production of all tool types for opportunistic, expedient, and curated technologies.

No formal storage features were identified at the Meier site. A spatial analysis of lithics is necessary to elucidate patterns of storage and/or workshop areas. I use the term stockpile loosely, to represent the strategies of storing bulk raw material at the site.

At present, the most compelling evidence of a stockpile is the way Meier people acquired blanks for cores and tools. Core-blanks included a variety of types including not only raw cobbles, but also core fragments, large percussion flakes, and exhausted tools. The variety of core-blanks suggests that material was probably not reduced in one sitting. Rather, material was stored in a variety of forms 
and reduced as needed for tool blanks. The reduction process was unstandardized, but flexible. It integrated bipolar percussion and freehand percussion in order to quickly and effectively reduce core-blanks of a variety of shapes, sizes, and raw material types. The stockpile was apparently created and maintained to have ready access to a store of raw material in these various stages of reduction.

A stockpile provided a means of storing tool-blanks that were previously made, as well as the core-blanks for manufacturing new ones. Storing large quantities of material in all stages of reduction compensated for the wasteful unstandardized reduction used to produce flakes for immediate tasks and curated tools, both of which require certain blank characteristics (shapes, sizes, raw material qualities). All the materials that were not selected at the time of core reduction were stored for tool-blanks that required a different set of characteristics. These requirements are not necessarily foreseen because unplanned tasks, as well as planned, are carried out by the group. The stockpile not only provided a place to store flakes derived from generalized core reduction, but also exhausted cores, exhausted tools, tool shaping debitage, and heat treatment debris. These "opportunistically selected" toolblanks, like the variety of core-blanks, indicate the ease at which material was stored and accessible at the site. This is most convincingly indicated by the use of biface 
manufacture flakes for tool-blanks.

Storing large quantities of material compensated for the difficulty of acquiring blanks of adequate raw material quality from expediently obtained, relatively poor quality alluvial cobbles. For tools requiring high quality material, such as cutters and various curated tools, high quality cobbles and pockets (areas in pieces that were free of flaws) were sought for reduction. The highest quality pieces were most intensively reduced (used). Tool types that were not as dependant on absence of flaws could be selected from the poorer quality material stored in the stockpile. For example, at Meier scrapers were made from lower quality material than cutters and side-shavers. This selection process undoubtedly pertained, as well, to variations in raw material durability and sharpness. The stockpile served as a storage facility for all kinds of raw materials in all stages of reduction. Standardized bifacial cores of exotic material supplemented the stockpile when it could not provide adequate quality material for blanks. Side-shaver blanks are the most abundant evidence for this standardized technology.

The evidence supports the use of a stockpile to store raw materials in all stages of reduction for a variety of purposes. Many of these tools were curated. Investment in curation is indicated by high frequencies of shaped and reused tools. The reasons tools were curated while (easily) 
maintaining a stockpile are probably most related to function. Additional functional analysis is needed to refine correlations between curation and certain tool types. However, I can provide some rather general explanations based on my data. Curated tools were, for the most part, designed for specific tasks, rather than designed for transportability. Artifacts that were potentially designed for transportability are six bifacial knives, one microblade core, and one standardized biface core. Most of the remaining curated tools were designed for specific tasks. These include arrow points, side-shavers, end-scrapers, and a few perforators.

All arrow points and many scrapers were hafted. Hafted tools suggest the need for reliability (Bleed 1986). Maintenance of these hafted tool-heads was likely used to minimize re-hafting effort. Reliable arrows are needed to minimize failure rates when hunting animals (Bleed 1986). Reliable hide-scrapers may be desirable because hide processing is most effectively carried out in a limited amount of time.

Side-shavers were probably maintained to conserve blanks that had characteristics that were difficult to obtain. Side-shavers were dependant on high quality material for long, straight working edges. The blanks for such tools were harder to make than most others from a stockpile of relatively small, poor quality material. This 
is verified by the unexpectedly high frequency of standardized tools of exotic material for side-shavers. Unfortunately, the function of these side-shavers has yet to be determined. Future micro-wear analysis may provide some insights. Certain types of larger perforators were probably maintained for similar reasons, although shaping of the blank was more extensive for perforators than side-shavers.

\section{Logistical Mobility}

My discussion has emphasized residential sedentism and stockpiling. Logistical mobility plays an integral role in the organization of technology. Logistical decisions of concern here are the amount and type of raw material procured and size of tool-kits on forays. A foraging pattern of subsistence using canoes enhanced the ability to procure large amounts of local alluvial gravels for stockpiling at the residential site. Whether or not raw material collecting was imbedded in other resource procurement activities is in question. Certainly they could have spent a day collecting cobbles. However, imbedding procurement with other activities may have been a preferable and more efficient strategy. The canoe's ability to carry bulk material makes an imbedding strategy even more feasible. Studies aimed at correlating the distribution of stone sources with food resources should illuminate plausible patterns of imbedded procurement. 
Canoes alleviated constraints imposed upon tool-kit size as well as allowing for bulk procurement of raw material. This should have allowed for larger, less materially efficient tools to be carried on forays. For example, regarding fine-grained lithics, generalized cores and specialized stone tools could easily be carried with other gear. Evidence in the Meier assemblage is consistent with this expectation and should apply, as well, to composite tools and tool-kits made with other materials.

\section{CONCLUSION}

Sedentism allows the stockpiling of large quantities of raw material. The stockpile functions as a storage facility for raw material of many types in all stages of manufacture. This provides a variable raw material base for all three lithic technologies- opportunistic, expedient, and curated. At Meier, the effects of stockpiling are especially evident by expedient procurement of unmodified, poor quality cobbles and unstandardized reduction of cores. The strategies of raw material procurement and blank production are wasteful in terms of tools per unit of mass but low in energy expenditure. Storing material in stockpiles compensates for some of the wasted material by keeping partially and fully reduced material available for use when needed as blanks. Nevertheless, even in a sedentary situation, extensive tool 
shaping and reuse is desired in many circumstances, depending on functional requirements of tools. At Meier, arrow points and hide-scrapers (both with hafting elements) are the most abundant examples. Exotic material can supplement lower quality sources in some situations where especially high quality material is preferred. Energy expenditure should be greater in all components of the lithic reduction system for the more expensive material. overall, sedentism provides the ability to stockpile, effectively alleviating the pressure to invest time/energy in making standardized cores and blanks for material conservation. Curation is minimized, only being applied to a few specialized tool types that require reliable designs or expensive raw material.

The concept of stockpiling should be extrapolated to other materials used in tools. Comparatively more energy was undoubtedly expended in these other industries. For example, on the Northwest coast at the Hoko River and ozett sites where fiber, wood, and bone/antler are preserved, Dale Croes (1994) estimates that lithic artifacts compose only $4 \%$ - 58 of the assemblages. Based on excavation and laboratory observation of artifacts recovered at Meier, I expect that bone, antler and course-grained cobbles were also stockpiled at the site. Such stockpiling should have effects that are similar to those I found for the fine-grained lithic industry. However, expediency in one industry may allow 
more time to invest in other industries that are of greater "importance."

Spacial analysis should provide information about the location of stockpiles and the relationship between communal stockpiling and personal caches for each industry. Analysis geared at technological time/energy investment for each industry should lead to hypotheses about the value of different material types and the differential use of various materials within a ranked social structure. For example, within the household, the use of high quality raw material should correlate with high ranking members. similarly, expedient flake technologies may have been used primarily by low status members for household processing and manufacturing tasks.

Directions for future research are numerous. My study should be viewed as a preliminary technological analysis of the fine-grained lithic industry at Meier. studies aimed at particular aspects of the system are needed. For example, a detailed functional analysis with the inclusion of microdebitage samples is necessary to illuminate functional variability and the role of microliths within the technological organization.

Additionally, the functional role of small bipolar cores and flakes is not clear. This role has yet to be adequately determined at Meier or regionally for the Northwest Coast. At Meier, the paucity of bipolar flake 
blanks is suspect given the large number of small bipolar cores. I have argued that bipolar reduction of small cores can be an expedient, standardized core technology. If so, we need to understand its efficiency in producing flake blanks. The shaping and maintaining of the bipolar cores takes less effort and skill than standardized biface and blade cores, but reducing them to the point of standardized flake production is probably just as expensive (if not more expensive) in raw material. Recycling of tools and core debris could compensate for some of the initial shaping costs of these cores. Because the intended purpose of bipolar flakes is unknown, an estimate of the success rate (ratio of used to wasted material) of bipolar reduction is difficult to determine. Again, functional analysis of bipolar micro-debitage might be fruitful.

Another area of study is raw material resources. Detailed studies of lithic raw material distribution and an assessment of the quality, abundance, and seasonal availability of these sources is necessary to clarify the availability and utility of regional resources. Lithological sourcing of Meier raw material within this regional context should make possible a better understanding of the role of exotic and local raw materials and their relationship to logistical mobility and imbedded strategies of procurement.

My analysis serves as an empirical case study. 
Comparative analysis of assemblages throughout the region is essential for making more valid inferences about the causal relations between technology and mobility. Spatial and chronological variation in technological organization should be understood within the development of a ranked social structure in the Greater Lower Columbia Region.

The technological model presented above highlights the efficiency of combining generalized core technologies with long term, bulk storage. The Meier site technological system minimizes time/effort in core preparation while maintaining tool potential with respect to quantity and functional diversity. Secondary selection of "bi-products" can be used to its fullest potential in a sedentary situation in which continual storage and availability is possible. The utilization of bi-products to effectively minimize material waste while maintaining expedient strategies for tool production may be sedentism's greatest economic advantage in overall technological effort. Ultimately, societies with long-term foresight can combine curation and stockpiling to minimize material waste, effectively avoiding over exploitation of critical resources. 


\section{REFERENCES CITED}

Ames, K., D. Raetz, S. Hamilton, T. McAfee

1992 Household Archaeology of a Southern Northwest

Coast Plankhouse. Journal of Field Archaeology

$19(3): 275-290$.

Amick, D.S. and R.P. Mauldin

1986 Comments on Sullivan and Rozen's "Debitage

Analysis and Archaeological Interpretations." American

Antiquity $54(1): 166-168$.

Bamforth, D.

1986 Technological Efficiency and Tool Curation.

American Antiquity 51:38-50.

1991 Technological organization and Hunter-Gatherer Land Use: A California Example. American Antiquity

$56(2): 216-234$.

Binford, L.

1977 Forty-Seven Trips. In stone Tools as Cultural

Markers, edited by R.V.S. Wright, pp. 24-26. Australian Institute of Aboriginal Studies, Canberra.

1978a Dimensional Analysis of Behavior and Site

Structure: Learning from an Eskimo Hunting Stand.

American Antiquity $43(2): 330-61$.

1978b Nunamiut Ethnoarchaeology. Academic Press, New York.

1979 Organization and Formation Processes: Looking at Curated Technologies. Journal of Anthropological Research 35:255-273.

1980 Willow Smoke and Dog's Tails: Hunter-Gather Settlement Systems and Archaeological site Formation. American Antiquity 45:4-20.

Bleed, P.

1986 The Optimal Design of Hunting Weapons:

Maintainability or Reliability? American Antiquity 51:547-562.

Boyd, R.

1975 Another Look at the "Fever and Ague" of Western Oregon. Ethnohistory $22(2): 135-154$.

Boyd, R. and Y. Hajda

1987 Seasonal population movement along the lower Columbia River: the social and ecological context. American Ethnologist $14(2): 309-326$.

Burchard, G.

1990 The Columbia South Shore Project: A Sample Archaeological Reconnaissance of the Airport Way urban Renewal Area, Portland, Oregon. Laboratory of Archaeology and Anthropology Cultural Resource Investigation Series No. 2, Portland State University, Portland. 
Callahan, E.

1979 The Basics of Biface Knapping in the Eastern Fluted Point Tradition: A Manual for Flint Knappers and Lithic Analysts. Archaeology of Eastern North America $7(1)$ : 1179 .

Collins, M.B.

1975 Lithic Technology as a Means of Processual

Inference. In Lithic Technology: Making and Using Stone

Tools, edited by E.Swanson, pp. 15-34. Mouton

Publishers, Paris.

Cotterell, B. and J. Kamminga

1979 The Mechanics of Flaking. In Lithic Use-wear

Analysis, edited by B. Hayden, pp.97-121. Academic

Press, New York.

1987 The Formation of Flakes. American Antiquity 52:675708.

1990 Mechanics of Pre-Industrial Technology. Cambridge University Press, New York.

Crabtree, D.E.

1972 An Introduction to Flintworking. Occasional Papers

of the Idaho State University Museum, No. 28.

Crabtree, D.E. and R. Butler

1964 Notes on Experiments in Flint Knapping: 1. Heat

Treatment of Silica Minerals: Tebiwa 7:1-6.

Croes, D.

1994 Hoko River Wet/Dry Site Artifact Interpretive and

Comparative Summary. Paper presented at the 47 th

Annual Northwest Anthropological Conference, Spokane.

Draper, J.A.

1992 Bipolar Reduction: A Perspective from the Southern

Northwest Coast and Interior Plateau. Paper presented

at the 45th Northwest Anthropological Conference.

Eckert, A.W.

1987 Earth Treasures Volume 3: The Northwestern Quadrant.

Harper and Row, Cambridge.

Ensor, H.B. and E. Roemer, Jr.

1986 Comments on Sullivan and Rozen's "Debitage Analysis and Archaeological Interpretations." American

Antiquity 54 (1):175-178.

Flenniken, J.J.

1981 Replicative Systems Analysis: A Model Applied to

the Vein Quartz Artifacts from the Hoko River Site.

Washington State University Laboratory of Anthropology

Reports of Investigations No. 59, Washington state

University.

Gero, J.M.

1989 Assessing Social Information in Material objects:

How Well Do Lithics Measure Up? In Time, Energy and

stone Tools, edited by Robin Torrence, pp.92-105.

Cambridge University Press. 
Goodman, M.E.

1944 The Physical Properties of stone Tool Materials. American Antiquity 4:415-433.

Goodyear, A.C.

1979 A Hypothesis for the Use of Cryptocrystalline Raw Materials among Paleo Indian Groups of North America. Research Manuscript Series 156, Institute of Archaeology and Anthropology, University of South Carolina.

Grimes, J.R. and B.G. Grimes

1985 Flakeshavers: Morphometric, Functional and Lifecycle Analysis of a Paleoindian Unifacial Tool class. Archaeology of Eastern North America 13:35-52. Hajda, Y.

1984 Regional Social organization in the Greater Lower Columbia, 1792-1830. Unpublished Ph.D. dissertation, University of Washington.

Hamilton, $\mathbf{S}$.

1989 The Meier Site Lithic Technology. Paper presented to the 37th Annual Northwest Anthropological Meetings, Spokan.

1990a Site-catchment Analysis of the Meier Site (35C05). Paper presented to the 38 Annual Northwest

Anthropological Meetings, Eugene. On file at Portland State University.

1990b Posy Project Lithic Technology and Function. In The Posy Archaeological Project: Upland Use of the Central Cascades; Mt. Hood National Forest, oregon, edited by G. Burtchard, pp. 24-54. Report on file, Mt. Hood National Forest.

Hard R. J. and W. L. Merrill

1992 Mobile Agriculturalists and the Emergence of Sedentism: Perspectives from Northern Mexico. American Anthropologist 94(3): 601-620.

Hayden, B.

1979 Snap, Shatter, and Superfractures: Use-Wear of Stone Skin Scrapers. In Lithic Use-Wear Analysis, edited by Hicks, B. B. Hayden, pp. 207-229. Academic Press, New York.

1993 Interpreting the Role of Microblades in Northwest Coast Aboriginal Sites. Paper presented at the 46 th Annual Northwest Anthropological Conference, Bellingham, Washington.

Jochim, M.A.

1989 Optimization and stone Tool studies: Problems and Potentials. In Time, Energy and Stone Tools, edited by Robin Torrence, pp. 106-120. Cambridge University Press.

Johnson, $J$.

1979 Archaic Biface Manufacture: Production Failures, A Chronicle of the Misbegotten. Lithic Technology 8 (2) : 25-35 
Keeley, L.

1980 Experimental Determination of Stone Tool Uses: A

Microwear Analysis. University of Chicago Press, Chicago

Keene, A.S.

1983 Biology, Behavior, and Borrowing: A Critical

Examination of optimal Foraging Theory in Archaeology. In Archaeological Hammers and Theories, edited by J.A. Moore and A.S. Keene, pp. 135-156. Academic Press, New York.

Kelly, R.

1983 Hunter-Gatherer Mobility Strategies. Journal of Anthropological Research 39(3):272-306.

1985 Hunter-Gatherer mobility and sedentism: A Great

Basin study. Unpublished Ph.D. dissertation, University of Michigan.

1988 The Three Sides of a Biface. American Antiquity $53: 717-734$.

1992 Mobility/Sedentism: Concepts, Archaeological

Measures, and Effects. Annual Review of Anthropology $21: 43-66$.

Kobayashi, H.

1975 The Experimental Study of Bipolar Flakes. In Lithic Technology: Making and Using Stone Tools, edited by E. Swanson, pp. 115-127. Mouton Publishers, Paris.

Koldehoff, B.

1987 The Cahokia Flake Tool Industry: Socio-economic

Implications for Late Prehistory in the Central

Mississippi valley. In The organization of Core

Technology, edited by J. Johnson and C. Morrow, pp.

151-185. Westview Press, Boulder.

Kuhn, $\mathbf{S}$.

1990 A Geometric Index of Reduction for Unifacial Stone

Tools. Journal of Archaeological Science 17:583-593.

1991 "Unpacking" Reduction: Lithic Raw Material Economy

in the Mousterian of West-Central Italy. Journal of

Anthropological Archaeology 10:76-106.

LeBlanc, $R$.

1990 Wedges, Pieces Esquillees, Bipolar Cores, and other

Things: An Alternative to Shott's View of Bipolar

Morrow, $C$.

Industries. North American Archaeologist 13(1):1-14.

1987 Blades and Cobden Chert: A Technological Argument

for Their Roles as Markers of Regional Identification

During the Hopewell Period in Illinois. In The

organization of Core Technology, edited by J. Johnson

and C. Morrow, pp. 119-149. Westview Press, Boulder

Mullineaux, D.R., R.E. Wilcox, W.F. Ebaugh, R. Fryxell, and

M. Rubin

1978 Age of the Last Major Scabland Flood of the Columbia Plateau in Eastern Washington. Quaternary Research 10:171-180. 
Nelson, M.C.

1991 The Study of Technological Organization. In Archaeological Method and Theory, edited by M.B. Schiffer, pp. 57-100. University of Arizona Press, Tucson.

Novick, A.L.

1987 Traveling Light: Lithic Inference, site structure and Hunter-gatherer Mobility strategies at Gatecliff Shelter, Nevada. Unpublished Ph.D. dissertation, washington State University.

Parry, W. and R. Kelly

1987 Expedient Core Technology and Sedentism. In The organization of Core Technology, edited by $J$. Johnson and C. Morrow, pp. 285-304. Westview Press, Boulder.

Pettigrew, R.M.

1977 A Prehistoric Culture sequence in the Portland Basin of the Lower Columbia Valley. Unpublished Ph.D. dissertation, University of Oregon.

1981 Prehistoric Culture Sequences in the Portland Basin of the Lower Columbia Valley. Anthropological Papers No. 22, University of Oregon, Eugene.

Purdy, B.A.

1975 Fractures for the Archaeologist. In Lithic Technology: Making and Using Stone Tools, edited by $\mathrm{E}$. Swanson, pp. 133-141. Mouton Publishers, Paris.

Ranere, A.J.

1975 Toolmaking and Tool Use Among the Preceramic Peoples of Panama. In Lithic Technology: Making and Using stone Tools, edited by E. Swanson, pp. 115-127. Mouton Publishers, Paris.

Ruby, R.H. and H.A. Brown

1976 The Chinook Indians: Traders of the Lower Columbia River. University of Oklahoma Press.

Saleeby, B.

1983 Prehistoric settlement Patterns in the Portland

Basin on the Lower Columbia River: Ethnohistoric,

Archaeological and Biogeographic Perspectives.

Unpublished $\mathrm{Ph} . \mathrm{d}$. dissertation, University of Oregon. Schiffer, M.B.

1976 Behavioral Archaeology. Academic Press, New York.

1987 Formation Processes of the Archaeological Record. Semenov, $\mathbf{S}$. University of New Mexico Press, Albuquerque.

1964 Prehistoric Technology, translation by M. Thompson. Adams and Dart, Bath, England. Shott, M.

1986 Technological Organization and Settlement Mobility: An Ethnographic Examination. Journal of Anthropological Research 42:15-51.

1989a Bipolar Industries: Ethnographic Evidence and Archaeological Implications. North American

Archaeologist $10(1): 1-24$. 
1989b On Tool-class Use Lives and the Formation of Archaeological Assemblages. American Antiquity 54(1): 9-30. Smith, C.

1992 Microwear Examination of a Sample of Stone Flakes from the Meier site. Paper on file at Portland state University.

Sullivan III, A.P. and K. Rozen

1985 Debitage Analysis and Archaeological

Interpretation. American Antiquity 50(4):755-779.

Teltser, P.

1991 Generalized Core Technology and Tool Use: A

Mississippian Example. Journal of Field Archaeology

Tirsk, A. $18(3): 363-375$.

1979 Regarding Fracture Initiation. In Lithic Use-wear Analysis, edited by B. Hayden, pp. 83-96. Academic Press, New York.

Torrence, $R$.

1983 Time-Budgeting and Hunter-Gatherer Technology. In

Prehistoric Hunters and Gatherers in Europe, edited by

G. Bailey, pp. 11-22. Cambridge University Press, New York.

1989 Time, Energy, and Stone Tools. Cambridge University Press, New York.

Vaughn, P.C.

1985 Use-wear Analysis of Flaked Stone Tools.

University of Arizona Press, Arizona.

Winterhalder B. and Smith E. A.

1981 Hunter-Gatherer Foraging Strategies: Ethnographic

and Archeological Analyses. University of Chicago

Press, Chicago. 
APPENDIX 1

\author{
SUMMARY OF C. SMITH'S \\ MICROWEAR ANALYSIS ${ }^{1}$
}

The scope of the microwear analysis was to determine the proportion of used flakes contained within a single "debitage" field bag from the Meier site (35C05). This goal was met by identifying the presence of use-wear on flakes. Functional interpretations were not a goal of this preliminary analysis. The data provides a ratio of tools (used flakes) to debitage (waste flakes) contained in the debitage field bags. The proportion of used flakes contained within this sample can be used as a bases for estimating the approximate proportion of used flakes in the Meier assemblage that have not been cataloged and analyzed as tools.

c. Smith's method appears to be sound. Based on experimental blind tests conducted by $C$. Smith for his B.A. thesis, he is accurate at determining worked regions on flake tools at a rate of $84.0 \%$. The success rate is equivalent to other qualified microwear analysts.

${ }^{1}$ The summary is based on a graduate paper authored by Cameron Smith (1992) entitled Microwear Examination of a Sample of stone Flakes from the Meier site. The paper was written at Portland State University under the direction of Dr. K. Ames. I provide my own conclusions based on this data and take full responsibility for any errors. 
Flakes examined were from unit S8-10/E28-30 Level 3 , depth 50.5 to $70.5 \mathrm{~cm}$ BSD. These flakes were recovered from 1/4" mesh screen. The specimens were examined using a Bausch and Lomb ASz25 10 - 25x binocular microscope. A total of 1,493 flakes were examined.

Traces of use-wear were identified on 30 of the 1,493 specimens studied (excluding the biface preform). Hence, $2.07 \%$ of the sample is determined to be used tools. Five of these were classed as "perhaps" because the edge attrition was "...nearly, but not completely, diagnostic of use." Table 32 and summarizes the results of the study. Some observations C. Smith notes are as follows: (1) all used flakes are interior flakes; (2) most are longer than they are wide; (3) most micro-flake scars occurred on the dorsal surface of the flake; (4) some use-polishing was observed, but higher magnifications are necessary to identify polishes; (5) none of the specimens were reworked (maintained).

Table 33 provides the statistical breakdown of weights for used and unused flakes. Generally, used flakes are larger (by weight) than unused flakes. Additionally, variance illustrates that there is greater homogeneity in the used tools than debitage. Smith states that some used flakes may be fragments of larger flake tools. This problem is pointed out as a possible bias on determining original tool sizes. 
The following conclusions can be drawn from the data. No tools are maintained or shaped. These I class as type I, expedient. The flakes chosen for tools are from late stages of reduction (100\% interior flakes). Based on my technological classification of these tools, 13 of the 30 specimens were either retouch flakes or biface thinning flakes. Nine of these are pressure flakes. Thus, most of the tools are probably from biface manufacture debris (eg. arrow points) and resharpening debris. These are opportunistic blanks and may represent secondary selection (from a stockpile) of flake blanks for expedient tools. Many of these tools may be expedient microliths such as those posited by Hicks (1991) for the Northwest coast. The fact that most used flakes are longer than they are wide supports such on assertion.

Based on my raw material quality typology, I have determined that all the used flakes are of high quality. Twenty two are excellent quality and 8 are good quality. The unusually high proportion of high quality raw material, as compared to other tool classes, may be in large part the result of having been removed from high quality flake-blanks during the manufacture of arrow points.

The absence of bipolar blanks in the microwear tool sample suggests that bipolar reduction may not be a method for producing microliths. However, the large number of small bipolar cores in the Meier assemblage suggests the 
production of flake-blanks for some unknown purpose. Analysis of micro-debitage may illuminate these matters.

A total of 30 flakes were found to be used. This is approximately $2 \%$ of the debitage sample analyzed. By extrapolating this proportion to the remainder of the debitage assemblage, I predict that the number of expedient, type 1 tools is significantly higher than originally estimated based on the cataloged artifacts. I estimate that approximately 1,530 expedient, type 1 tools are contained within the debitage field bags. Because there is tremendous spacial variation in other assemblages (faunal, bone tools, ground stone) throughout the site, we expect significant spatial variation in used flake distribution. Nevertheless, after analyzing a sample of debitage from most of the remaining units, the assemblage average appears to be only slightly lower at $1.8 \%$ (Smith, personal communication 1994). The technological variation has not been determined but significant differences are possible. For this thesis I use the original estimate of 28 for making inferences about technological organization at the Meier site. 


\begin{tabular}{|c|c|c|c|c|c|c|c|}
\hline Tleke Nober & Meletat (a) & $\operatorname{Ienth}(\sigma)$ & Nodth $(\sigma)$ & Endilten $7 \times 02$ & Confincition & Oee-kent focation & Kodification troe (o) \\
\hline $\begin{array}{l}1 \\
2 \\
3 \\
4 \\
3\end{array}$ & $\begin{array}{l}0.2 \\
0.2 \\
1.2 \\
0.3 \\
1.3 \\
\end{array}$ & $\begin{array}{l}1.0 \\
1.6 \\
2.3 \\
1.5 \\
2.2 \\
\end{array}$ & $\begin{array}{l}0.8 \\
0.7 \\
1.7 \\
0.6 \\
1.2 \\
\end{array}$ & $\begin{array}{llll}\text { I } & \text { BF } & \text { RET } & \text { PRES } \\
\text { I } & \text { CF } & \text { BTF } & \text { PRES } \\
\text { I } & \text { FF } & \text { PERC } \\
& \text { I } & \text { BF } & \text { PERC } \\
\text { I } & \text { BF } & \text { PERC } \\
\end{array}$ & $\begin{array}{l}\text { Used } \\
\text { Used } \\
\text { Perhaps } \\
\text { Used } \\
\text { Used } \\
\end{array}$ & $\begin{array}{c}D 3,5,6 \\
D 2,3 \\
V 2,3 \\
V \quad 5,6 \\
D \quad 5,6 \\
\end{array}$ & $\begin{array}{c}M F \\
M F, \mathrm{POL} \\
\mathrm{MF} \\
\mathrm{MF} \\
\mathrm{MF} \\
\end{array}$ \\
\hline $\begin{array}{r}6 \\
7 \\
8 \\
9 \\
10\end{array}$ & $\begin{array}{l}0.2 \\
2.7 \\
0.3 \\
0.6 \\
0.4\end{array}$ & $\begin{array}{l}1.5 \\
2.3 \\
1.1 \\
2.0 \\
2.0\end{array}$ & $\begin{array}{l}0.8 \\
2.0 \\
1.0 \\
1.0 \\
1.0\end{array}$ & 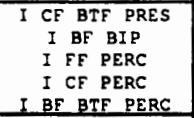 & $\begin{array}{l}\text { Used } \\
\text { Used } \\
\text { Used } \\
\text { Used } \\
\text { Used } \\
\end{array}$ & $\begin{array}{l}D 4,5,6 \\
V 1 \\
D 2,3 \\
D \quad 1,2,3 \\
D 2,3\end{array}$ & $\begin{array}{c}\text { MF } \\
M F \\
M F \\
\text { EFMF } \\
M F, P O L\end{array}$ \\
\hline $\begin{array}{l}11 \\
12 \\
13 \\
14 \\
15\end{array}$ & $\begin{array}{l}0.1 \\
0.7 \\
0.2 \\
0.2 \\
0.6\end{array}$ & $\begin{array}{l}0.8 \\
2.9 \\
1.3 \\
1.7 \\
1.5\end{array}$ & $\begin{array}{l}0.8 \\
2.2 \\
0.6 \\
0.6 \\
1.5\end{array}$ & 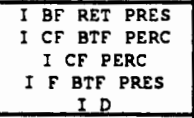 & $\begin{array}{l}\text { Perhaps } \\
\text { Used } \\
\text { Used } \\
\text { Used } \\
\text { Used } \\
\end{array}$ & 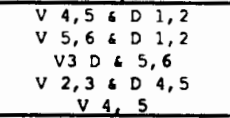 & $\begin{array}{l}\text { EFMF } \\
\text { MF, PCL } \\
\text { MF } \\
\text { MF } \\
\text { MF }\end{array}$ \\
\hline $\begin{array}{l}16 \\
17 \\
18 \\
18 \\
20\end{array}$ & $\begin{array}{l}0.6 \\
0.3 \\
1.2 \\
0.7 \\
0.8\end{array}$ & $\begin{array}{l}2.2 \\
1.6 \\
2.0 \\
1.6 \\
2.6\end{array}$ & $\begin{array}{l}1.1 \\
1.1 \\
1.3 \\
1.0 \\
1.3\end{array}$ & $\begin{array}{l}\text { I FF PERC } \\
\text { I CF BTF PRES } \\
\text { I CF PERC } \\
\text { I FF PERC } \\
\text { I FF PERC }\end{array}$ & $\begin{array}{l}\text { Used } \\
\text { Used } \\
\text { Perhaps } \\
\text { Used } \\
\text { Used }\end{array}$ & $\begin{array}{c}v 2,3 \in D 4,5,6 \\
v 4,5 \in D 1,2 \\
V 2,3,6 \& D 5,6 \\
(1 r r e g) D 5,6 \\
v 5,6: D 2,3\end{array}$ & $\begin{array}{l}\text { MACF, } M F \\
M F \\
M F \\
M F \\
\text { EFMF, MF }\end{array}$ \\
\hline $\begin{array}{l}21 \\
22 \\
23 \\
24 \\
25 \\
\end{array}$ & $\begin{array}{l}0.6 \\
0.2 \\
0.4 \\
0.4 \\
0.2 \\
\end{array}$ & $\begin{array}{l}2.6 \\
1.9 \\
2.0 \\
1.4 \\
3.7 \\
\end{array}$ & $\begin{array}{l}0.6 \\
0.6 \\
1.0 \\
1.1 \\
2.6 \\
\end{array}$ & $\begin{array}{l}\text { I } \\
\text { I FF PERC } \\
\text { I BF BTF PRES } \\
\text { BIF PRES } \\
\text { I FF PPERC } \\
\end{array}$ & $\begin{array}{l}\text { Used } \\
\text { Used } \\
\text { Used } \\
\text { Perhaps } \\
\text { Used } \\
\end{array}$ & $\begin{array}{ccc}\text { (Irreg) } & V 5,6 \\
\text { (Irreg) } & V 5,6 \\
\text { V 4 \& D } 2 \\
\text { see text } \\
\text { (Irreg) D } 4,5,6 \\
\end{array}$ & $\begin{array}{c}\text { EFMF, MF } \\
\text { MF, POL } \\
\text { MF } \\
\text { see text } \\
\text { MF, POL } \\
\end{array}$ \\
\hline $\begin{array}{l}26 \\
27 \\
24 \\
29 \\
30 \\
31\end{array}$ & $\begin{array}{l}0.2 \\
0.7 \\
0.7 \\
0.6 \\
0.1 \\
0.3\end{array}$ & $\begin{array}{l}1.0 \\
3.1 \\
1.5 \\
2.2 \\
1.7 \\
1.2\end{array}$ & $\begin{array}{l}0.8 \\
0.9 \\
1.0 \\
1.5 \\
1.0 \\
0.9\end{array}$ & $\begin{array}{l}\text { I FF RET PRES } \\
\text { I FF BTF PERC } \\
\text { I FF PERC } \\
\text { I BF BTF PERC } \\
\text { I CF PERC } \\
\text { I BF BTF PRES } \\
\end{array}$ & $\begin{array}{l}\text { Used } \\
\text { Perhaps } \\
\text { Used } \\
\text { Used } \\
\text { Used } \\
\text { Used } \\
\end{array}$ & $\begin{array}{c}V 1,2,3 \& D 4,5,6 \\
V 1,2 \& D 4,5 \\
\text { (Irreg) V } 2,3 \\
D 1,4 \\
V 2,3 \& D 5,6 \\
V 5,6 \& D 2,3\end{array}$ & $\begin{array}{c}\text { EFMF, MF } \\
\text { MF, POL } \\
\text { MF } \\
\text { MF } \\
\text { EFMF, MF, POL } \\
\text { EFME, MF }\end{array}$ \\
\hline
\end{tabular}

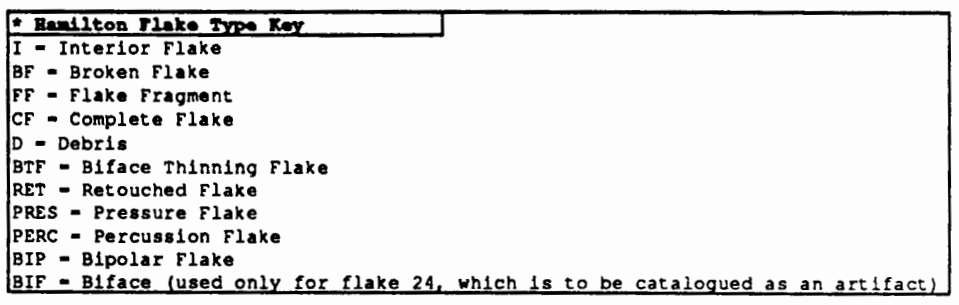

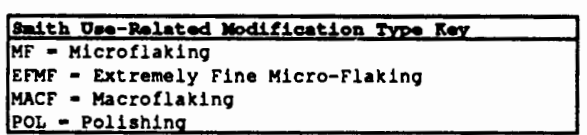

MACF - Macrorlaking

(Irreg) - Doral or Ventral surfaces not readily apparent, and a guess has been made based on flake shape

Table 32. Used Flake Dimensions, Typology and Microwear Traces (Smith 1992:8). 


\begin{tabular}{|lcc|}
\hline Statistic & Unused Flakes & Used Flakes \\
\hline Number of Flakes & 1462 & 31 \\
Minimum & 0.19 & $0.1 \mathrm{~g}$ \\
Maximum & 9.59 & $2.7 \mathrm{~g}$ \\
Range & $9.4 \mathrm{~g}$ & $2.6 \mathrm{~g}$ \\
Mean & $.357 \mathrm{~g}$ & $.551 \mathrm{~g}$ \\
Variance & .387 & .262 \\
Standard Deviation & .622 & .512 \\
\hline
\end{tabular}

Table 33. Basic Statistics of Used and Unused Flake Weights (Smith 1992:9).

\section{Summary Data:}

Total Debitage 1987 - 1990 field seasons $=72,160$

Microwear Sample $=1,462 \quad(.0203)$

Used Flakes $=30 \quad(.0205)$

Biface Preform $=1$

\section{Material Quality:}

$\begin{array}{lrrr}\text { Excellent } & = & 22 & (.7333) \\ \text { Good } & = & 8 & (.2666)\end{array}$

\section{Flake Blank:}

\begin{tabular}{|c|c|c|c|c|}
\hline $\begin{array}{l}\text { Percussion flake } \\
\text { Pressure flake } \\
\text { Bipolar flake } \\
\text { Unknown }\end{array}$ & $\begin{array}{l}=19 \\
=\quad 9 \\
=1 \\
=1\end{array}$ & $\begin{array}{l}(.6333) \\
(.3000) \\
(.0333) \\
(.0333)\end{array}$ & $\begin{array}{l}\text { BTF } \\
\text { Retouch }\end{array}$ & $\begin{array}{r}=10(.3333) \\
=3(.1000)\end{array}$ \\
\hline
\end{tabular}

Heat Treatment stage:

Not heat treated $=9$

Post discard damage $=2$

Heat treated core $=20$

Table 34. Summary of Microwear Analysis Data. 


\section{APPENDIX 2}

ORIGINAL AND REVISED ARTIFACT FREQUENCIES

\section{Non-debitage Assemblage: Population 2}

$\begin{array}{ccccccc}\text { Sample } & n & \text { Tool } & \begin{array}{l}\text { Pre- } \\ \text { form }\end{array} & \text { Core } & \text { Misc } & \text { Total } \\ 1,2 & 5222 & .3801 & .3481 & .2210 & .0507 & .9999 \\ 3^{*} & 5222 & .4212 & .3381 & .1800 & .0507 & .9900 \\ 4^{*} & 6752 & .5600 & .2615 & .1392 & .0392 & .9999\end{array}$

Total Assemblage: Population 1 and $2(n=77,382)$

\begin{tabular}{ccccccc} 
Sample & Tool & $\begin{array}{l}\text { Pre- } \\
\text { form }\end{array}$ & Core & Misc & $\begin{array}{l}\text { Deb- } \\
\text { tage }\end{array}$ & Total \\
\hline 1,2 & .0257 & .0235 & .0149 & .0034 & .9325 & 1.000 \\
3 & .0284 & .0228 & .0121 & .0034 & .9325 & .9992 \\
4 & .0489 & .0228 & .0121 & .0034 & .9127 & .9999 \\
\hline \hline
\end{tabular}

Sample 1,2 = original counts.

Sample 3 = re-examination of non-debitage artifacts. Sample 4 = debitage microwear analysis.

*The number of artifacts increases because tools identified in the debitage (population 1) were added to the non-debitage specimens (population 2).

Table 35. Original and Revised Artifact Proportions Based on Re-examination of Assemblage Samples. 


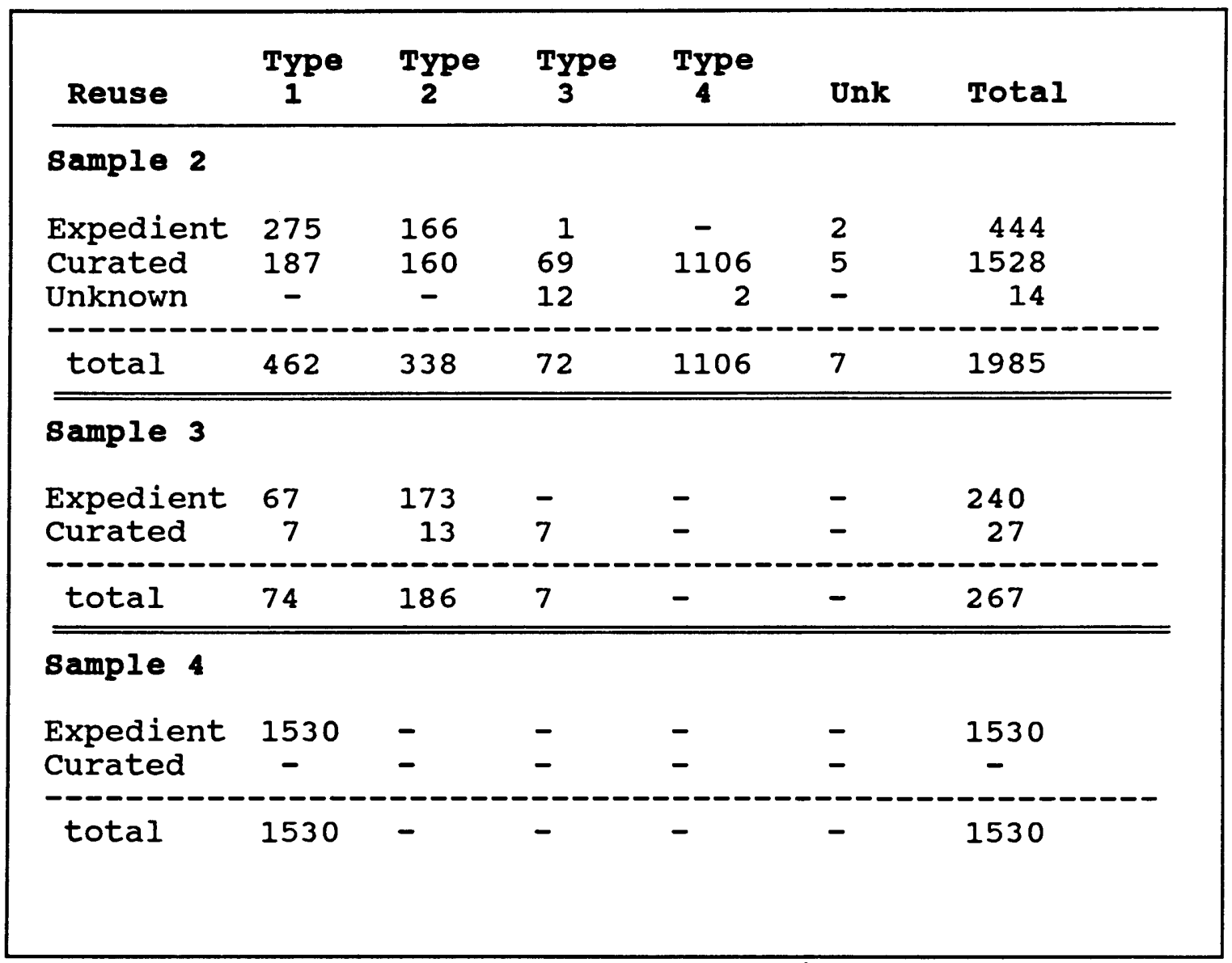

Table 36. Absolute Frequency of Tools in each Sample According to Ranked shaping Type and Reuse. 


\section{original count}

\begin{tabular}{|c|c|c|c|c|c|c|}
\hline Reuse & $\begin{array}{c}\text { Type } \\
1\end{array}$ & $\begin{array}{c}\text { Type } \\
2\end{array}$ & $\begin{array}{c}\text { Type } \\
3\end{array}$ & $\begin{array}{c}\text { Type } \\
4\end{array}$ & Unk & Total \\
\hline$\underset{q}{\text { Exped }}$ & $\begin{array}{r}275 \\
.1385\end{array}$ & $\begin{array}{r}166 \\
.0836\end{array}$ & .0005 & - & $\begin{array}{c}2 \\
.0010\end{array}$ & $\begin{array}{r}444 \\
.2237\end{array}$ \\
\hline$\underset{f}{\text { Curated }}$ & $\begin{array}{r}187 \\
.0942\end{array}$ & $\begin{array}{r}160 \\
.0806\end{array}$ & $\begin{array}{c}69 \\
.0348\end{array}$ & $\begin{array}{r}1106 \\
.5572\end{array}$ & $\begin{array}{c}5 \\
.0025\end{array}$ & $\begin{array}{r}1528 \\
.7698\end{array}$ \\
\hline $\begin{array}{l}\text { Unknown } \\
\frac{q}{6}\end{array}$ & - & $\begin{array}{c}12 \\
.0060\end{array}$ & $\begin{array}{c}2 \\
.0010\end{array}$ & - & - & $\begin{array}{c}14 \\
.0071\end{array}$ \\
\hline$\underset{q}{\text { total }}$ & $\begin{array}{r}462 \\
.2327\end{array}$ & $\begin{array}{r}338 \\
.1703\end{array}$ & $\begin{array}{c}72 \\
.0363\end{array}$ & $\begin{array}{r}1106 \\
.5572\end{array}$ & $\begin{array}{c}7 \\
.0035\end{array}$ & 1985 \\
\hline
\end{tabular}

\section{Revised Estimates}

\begin{tabular}{lcccccc} 
Reuse & Type & Type & Type & Type & & \\
1 & 2 & 3 & 4 & Unk & Total \\
\hline $\begin{array}{c}\text { Exped } \\
\frac{6}{6}\end{array}$ & 1872 & 339 & 1 & - & 2 & 2214 \\
& .4951 & .0897 & .0003 & - & .0005 & .5856
\end{tabular}

$\begin{array}{crrcrcr}\text { Curated } & 194 & 173 & 76 & 1106 & 5 & 1554 \\ \& & .0513 & .0457 & .0201 & .2925 & .0013 & .4110\end{array}$

\begin{tabular}{|c|c|c|c|c|c|c|}
\hline $\begin{array}{l}\text { Unknown } \\
q\end{array}$ & - & $\begin{array}{c}12 \\
.0032\end{array}$ & $\begin{array}{c}2 \\
.0005\end{array}$ & - & - & $\begin{array}{c}14 \\
.0037\end{array}$ \\
\hline$\underset{f}{\operatorname{total}}$ & $\begin{array}{r}2066 \\
.5464\end{array}$ & $\begin{array}{r}524 \\
.1384\end{array}$ & $\begin{array}{c}79 \\
.0209\end{array}$ & $\begin{array}{r}1106 \\
.2925\end{array}$ & $\begin{array}{c}7 \\
.0019\end{array}$ & 3781 \\
\hline
\end{tabular}

Table 37. Original and Revised Estimates of Tools for each Ranked Shaping Type and Reuse. 


\section{APPENDIX 3 \\ MINERALOGICAL CLASSIFICATION \\ AND DESCRIPTION}

Obsidian is a volcanic glass formed by extremely rapid cooling of granitic lava, which gives it an amorphous, noncrystalline structure. Its texture is generally glassy smooth. Obsidian may be translucent to transparent, and black, grey, green, brown or any combination of these. The term obsidian also includes ignimbrite. Ignimbrite is welded tuff, but has physical properties closely resembling obsidian.

Cryptocrystalline and microcrystalline varieties of silica (both termed CCS) include chalcedony, jasper and chert. Textures vary tremendously within each of these subcategories. The Meier ccs sample shows this variability. All three subcategories are well represented in the assemblage. Colors span the entire spectrum and texture ranges from glassy opalites to medium grained silicious material equivalent in physical characteristics to silicified sandstone. For this reason I opted to lump all ccs into a single category (although defining finer categories of material types may be useful, particularly for functional analysis).

Quartzites are coarser grained than CCS, having a 
sugary appearance. They range in color from white to orange to grey. The most common colors at the Meier site are shades of white, yellow and orange.

Basalt and felsite are lavas. Both vary in crystalline size but are generally considered medium grained. The colors include black, green, grey, brown, dark red, and pale yellow.

Manufactured glass is an artificial microcrystalline silica. It's physical characteristics approximates obsidian but with a wider range of possible colors. Colors at Meier include aqua, clear, olive green, emerald green, amber and lavender.

Miscellaneous other are those specimens that could not be classed in any of the above categories because of condition (burned) or my ignorance. 


\section{APPENDIX 4}

\section{FUNCTIONAL ANALYSIS}

\section{METHODOLOGY}

\section{Defining Tools}

Tools were identified as such by shape and/or presence of retouch and use-wear. Different attributes were useful for different general tool types (eg. used-flakes, unifaces, bifaces). Bifaces with finely worked edges were generally considered tools. Minimally shaped items and non-shaped items were most readily identified as tools by retouch and to a lesser extent use-wear. If no retouch was evident, then only use-wear was available for defining the piece as a tool. This latter type represents the classic expedient tool (ie. used-flake). Unfortunately, they are the most difficult to identify without careful microscopic analysis. A more careful sampling strategy was conducted to identify the percentage of non-shaped, non-retouched tools. A microscope was used to a limited extent in the sample 2 reexamination and more intensely by Smith (1992) for the sample 3 debitage analysis to find used-flakes. Edge angles were used to define some functional categories (cutters, shavers, scrapers). Edge angles were estimated without using an instrument. 


\section{Use-wear}

Use was identified by patterned crushing, abrasion, rounding, polishing and small flaking. Most was identified with the un-aided eye. Small flaking wear was distinguished from retouch by flake scar length. Flake scars greater than $3 \mathrm{~mm}$ were considered retouch (or sometimes manufacture) while specimens with patterned flake scars of less than $3 \mathrm{~mm}$ were considered use-wear. Distinguishing between intentional bevelling and use was often problematic. The decision was usually based on bevelling location, other edge characteristics, and location of other use-wear. Specimens with widely dispersed, random flaking patterns were assumed to be caused by agents other than use, probably trampling. These edge damaged artifacts often had deep bending flake scars.

Use-wear was used to identify the function of some tools. For example, extensive unifacial use-flaking was considered scraper and shaver wear while bifacial useflaking more commonly cutter wear. And, unifacial flaking on pointed specimens was considered graver wear while a perforator has wear on alternate margins circumventing the bit. Use-wear was never used without considering the usemargin shape and edge angle.

\section{Retouch}

Retouch was generally patterned parallel pressure 
flaking along an edge. The flake scars must be $3 \mathrm{~mm}$ or longer.

\section{Shape}

Gross morphological categories were used to determine the function of the tool. Once a tool was identified, the use-margins were the primary location of study. Primary considerations were overall use-margin shape and edge angle. For example, cutters have relatively straight margins with edge angles less than 30 degrees. Shavers have relatively straight margins with edge angles ranging from 30-60 degrees. Scrapers have relatively straight margins with edge angles greater than 60 degrees, usually approaching 90 degrees. If there was ambiguity in the morphology, use-wear was used. For example, although gravers and perforators have pointed bits, gravers tend to have unifacial wear while perforators have alternate or bifacial wear. A more detailed description of functional classes is described below. Edge angles were determined by sight and overall impression of the working edge rather than using an instrument.

Tool Classes

Projectile point:

Projectile points were usually obvious, although some 
were recycled into drills and one into a graver. Almost all were arrow points as suggested by hafting widths of less than $7.0 \mathrm{~mm}$. Although side-notched specimens often approached $8.0 \mathrm{~mm}$, these were also considered arrow points based on thinness and size. The absence of use-wear (eg. impact fractures) and resharpening on unnotched and unnstemmed bifaces (Pettigrew's [1977] type 6, type 14, and type 16 projectile points) suggests that they were not finished projectile points. Unstemmed and unnotched triangular to convex based bifaces were therefore classed as projectile point preforms.

\section{Knive:}

Knives are bifacially flaked tools that can be used for a variety of tasks (generalized) such as cutting, sawing, and scraping. The working edge is bifacially flaked and strong (larger edge angle as compared to arrow points and cutters). Two working margins usually intersect at a functional point. Knives usually have a manufactured hafting element or incorporated handle.

\section{Graver:}

Gravers have pointed use-margins that are relatively strong. The pointed use-margin is less elongate than perforators giving them more strength for working forces perpendicular to the long axis of the bit. The edge-angle 
is usually 90 degrees or greater, often described as obtuse.

\section{Perforator:}

Perforators have pointed use-margins that are generally more delicate and elongate than graver bits. Perforators include both drills and awls. They may have bifacial, round, or triangular bits. Some bits are sharp and others blunt. Wear patterns tend to be on alternate margins or on all faces (bifacial on each edge) of the tool bit.

\section{Scraper:}

Scrapers have relatively straight margins with edge angles 60 degrees or greater. Usually, the margin approximates 90 degrees and sometimes slightly greater on heavily retouched specimens. Although I describe the margin as "relatively straight", the margins are often convex and less often concave. Retouch on scrapers is almost exclusively unifacial and often has a high polish at the use-margin indicating that curated scrapers were mostly used for soft, pliable materials such as hides. Some had intentionally been serrated at the use-margin. Nonretouched specimens may have been used on a variety of other materials.

\section{Shaver:}

Most shavers have relatively straight margins with edge 
angles 30 to 60 degrees (between cutters and scrapers). The margins are often retouched to a gentle concave outline. Retouch is invariably unifacial. Polishes are rarely visible with the un-aided eye. Spokeshaves were also included in the shaver category. This variety has a pronounced concave use-margin that approaches a notch in appearance and is often intentionally manufactured.

\section{Cutter:}

Cutters have relatively straight use-margins with edge angles less than 30 degrees. The margins are relatively straight and infrequently retouched. Retouch may be bifacial or unifacial. Use-wear may be either bifacial or unifacial, but more often bifacial.

Saw:

Saws are heavy duty cutters. They usually have heavy bifacial use-wear including crushing, rounding, and flaking. The flake scars are often a result of bending flakes (sensu Cotterell and Kamminga 1990) and are often quite random. Informal experiments that I conducted in cutting/sawing (girdling) green bone and dry bone suggest that some edgemodified flakes I classed as edge damaged (eg. trampling wear) may have been saws or heavy duty cutters. 
Wedge:

Wedges have flat, strong bits. They are often rectangular in general form with a consistent transversal edge angle from proximal to distal end between 25 and 35 degrees. Use-wear is commonly crushing at the wedge tip and polishing and crushing on the flake scar ridges on the face of the tool. Because platform crushing on bipolar cores can look similar to use crushing on wedges, polishing and crushing on the face of the tool is more diagnostic as a defining characteristic (LeBlanc 1990).

\section{ANALYTIC RESULTS}

I divided tools into nine morphofunctional categories based on gross morphological attributes and to some extent on macro wear. I present here a brief description of these morphofunctional categories identified at Meier. Descriptive data on functional categories is not quantified and is incomplete. Most of the information summarizes general observations made during data recording. The functional categories are very broad, obscuring the great variety of morphological and functional subtypes existing within the working typology. In accordance, the summary of each is vague, relying heavily on qualitative terms such as "most" and "some." 
Projectile Point $(n=1126)$ :

Most projectile points are minimally shaped functional arrow points. Table 1 shows the frequency of arrow point basal types. The arrow points are consistent with those described for Meier by Pettigrew (1977). Small stemmed bases (Pettigrew type $7,8,9,10$ ) were the predominant arrow points in the collection with side-notched specimens second in frequency (Pettigrew type 11, 12). Other varieties (eg. Pettigrew type 15) present at the site will provide data for interesting stylistic analysis. Basal fragments were the prominent element suggesting broken arrow points were removed from the haft and replaced during onsite retooling.

I classed most bifaces that were described by Pettigrew as small unnotched and unstemmed varieties of projectile points as preforms (type 6, type 14, and type 16). My

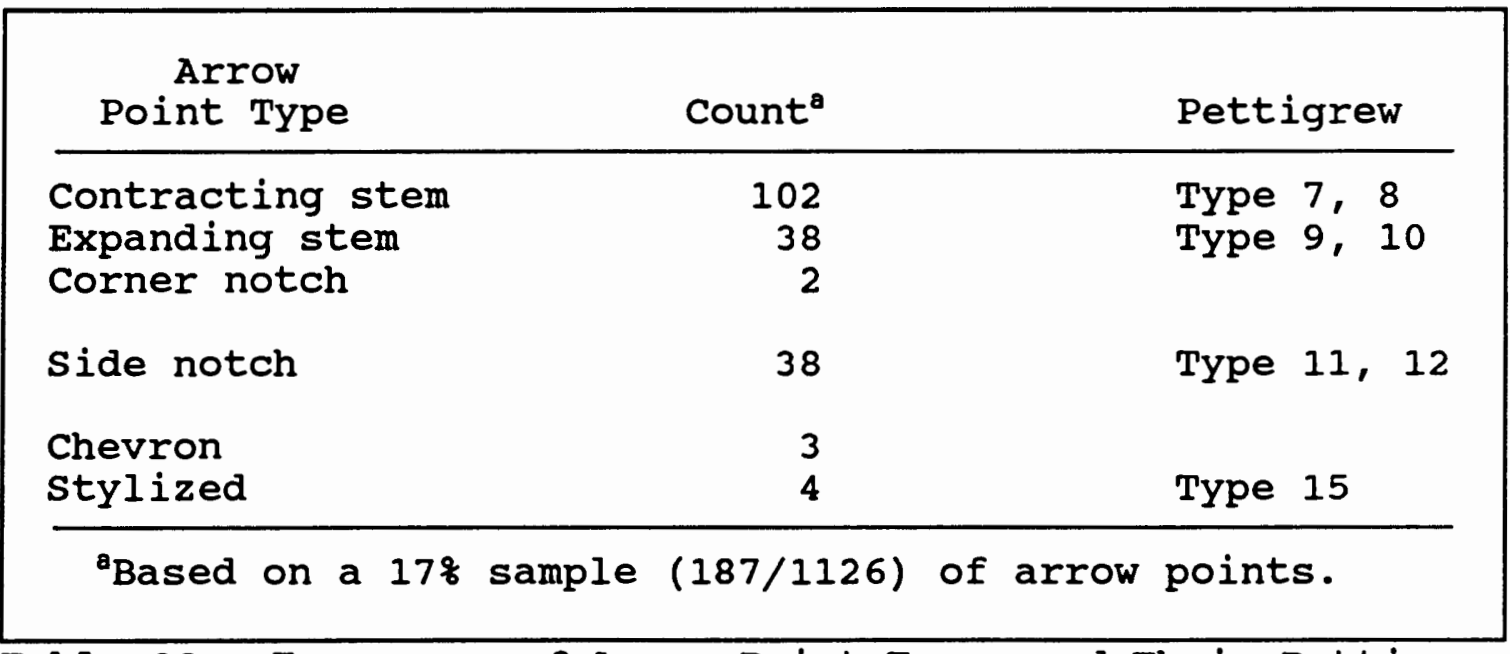

Table 38. Frequency of Arrow Point Types and Their Pettigrew (1977) Typology Correlates. 
classification of them as preforms is substantiated by the fact that no unnotched basal fragments had impact fractures from use as projectiles. In addition, resharpening was not evident on these specimens.

One other less significant note on Pettigrew's typology is related to the barbed vs. shouldered varieties of arrow points. The barbed and shouldered varieties are most likely related to rejuvenation of broken barbs and blade resharpening than to intentional stylistic variation. This is in agreement with both types having been recovered from the same strata in Pettigrew's (1977) analysis.

As expected at a residential site, the collection most likely includes arrow points made by people just learning and highly skilled flintknappers. Many appear to be barely functional and some probably were used as toys. Although the overwhelming majority are type 4, some are type 3 and a few type 2. All were considered curated, although no resharpening was evident on some.

All stages of arrow point preforms were recovered. These revealed a diversity of flaking patterns for making arrow points. The overwhelming majority were exclusively pressure flaked. Most flake blanks were percussion flakes. When percussion flaking was used for shaping, it was applied minimally. The shapes were roughed out by simultaneously edging and shaping the tool. Sometimes the hafting area was roughed out before the blade and visa versa. The assemblage 
contained a few finely shaped, unnotched triangular and foliate preforms.

Rnife $(n=22)$ :

The knife category includes mostly large bifaces. Some had manufactured hafting elements. Basal types included chevron, pentagonal, concave, and corner notched. They were made by mostly pressure with some percussion flaking on a few specimens. The difficult distinction between some bifacial knives and perforators exemplifies the flexible design of these generalized tools. In this case, the flexibility is a serial design (Nelson 1992). When reduced to a certain point (reshaped), the knives can be used as perforators.

Cutter $(n=102)$ :

Cutters were mostly non-shaped, non-curated tools. some curated specimens may actually be early retired sideshavers. Cutters are less often retouched because the best cutting edge for fine work is an unmodified feather type margin. Although the tools were not morphofunctionally classed in the micro-wear study by Smith (nd.), most of these tools are probably cutters. No attempt to identify macroliths and microliths was made during this study but they are likely contained within this class of tools. 
saw $(n=9)$ :

Saws may be best perceived as heavy-duty cutters. Many saws were probably not classed as a tool, but misidentified as non-use damage (ie. trampling damage). In addition, bifacial knives and preforms can be effectively used as saws. Micro-wear analysis may discover more saws. All identified saws were type 1 and 2 , non-curated. All are best described as expedient tools.

scraper $(n=395)$ :

Scrapers were both hafted and hand held (hafted $=98$; maintained end-scraper $=34$ ). They were made using all tool shaping techniques except possibly bipolar. Sizes and shapes of scrapers varied considerably, even within the curated category. All scrapers were type 1 and 2 . The usemargins were generally straight to convex. A few margins were intentionally retouched to form a serrated or denticulate working edge. Retouch and manufacture was mostly unifacial, although bifacial strategies were also applied. Retouched scrapers include scrapers commonly described as thumbscrapers, snub-nose scrapers, endscrapers, and discoid scrapers.

The flake blanks of large hafted scrapers were often percussion flakes removed from cores, but some were bipolar flakes. The proximal end (hafted end) was usually the flake-blank platform. Many had extensive polishing on the 
use-margin and were extensively retouched. The polish and general morphology is typical of hide-scrapers from all over North America (eg. see Hayden 1979).

shaver $(n=151)$ :

Shavers are those tools that had working margins with edge angles between classic scrapers and cutters. Most shavers had long, relatively straight use-margins. Many shavers had slightly concave use-margins from resharpening. Flat blade-like percussion flake blanks were often used for the larger shavers. Most shavers were type 1 and type 2 .

A common subclass is side-shavers. These had long, straight to slightly concave unifacially resharpened margins parallelling the long axis of the tool. They were often backed by beveling, crushing, or retouch pressure flaking. The backing and morphological redundancy of these blade-like tools suggests that they may have been hafted as macroliths. And, the carefully retouched unifacial edge indicates that they were made for a specific task. The difficulty in obtaining a blank that provides such a margin explains the use of exotic raw material for many of these tool types.

In addition to the more common shavers described above, three bifacially shaped shavers had clear hafting elements and were classed as type 4-curated. Spokeshaves (with deep, concave use-margins) were included as shavers, but few were found. 
Graver $(n=26)$ :

Gravers are probably under represented because of the difficulty in identifying use-wear on obtuse angles. The overall artifact collection has a plethora of obtuse angles that could be used as gravers. Nevertheless, more type 2 gravers were identified than type 1 gravers. This could be a result of a bias toward identifying gravers with a manufactured use-margin. In general, gravers are best described as expedient, even the retouched specimens. No burin type gravers were identified. The plethora of obtuse angles on bipolar debris and fractures from raw material flaws may have provided most of the needed graver working edges. Given the heavy reliance on bone technology at Meier, I expect that there exist more gravers then were identified.

Perforator $(n=69)$ :

There are many types of perforators in the collection. They ranged from highly maintained type 4 to non-curated type 1. Perforator bits (the working end) ranged in a continuum from delicate drills to heavy duty awls. Use-wear and size paralleled this gradient. Some bits are bifacially flaked while others are triangular. Some tips are blunt and others sharp. Handles are both manufactured and opportunistic. Some handles are "T" shaped, some are "L" shaped, and some are "I" shaped. All shaping techniques 
were used in different combinations to shape handles and bits.

Wedge $(n=32)$ :

The frequency of wedges is vastly under represented because use-wear variables were not defined until the end of data recording. Micro-wear analysis is desperately needed to identify these tools from the core assemblage, particularly bipolar cores. Based on the sample 3 reanalysis, an estimated 98 of tabular and bifacial cores (percussion and bipolar) are wedges. Most wedges were made using the bipolar technique, although in some instances a combination of percussion and bipolar was used and in at least one case, only percussion. In addition, some wedges were type 1. Few were identified as curated, but bipolar retouch may be confused with shaping or use modification. 


\section{APPENDIX 5}

DEBITAGE DATA SUMMARY

(key at end of tables)

\section{ccs Debris and Complete Flakes}

\begin{tabular}{|c|c|c|c|c|c|c|c|c|c|c|}
\hline & \multirow{2}{*}{$\begin{array}{c}\text { SR } \\
\text { Type }\end{array}$} & \multirow{2}{*}{$\begin{array}{l}\text { St- } \\
\text { age }\end{array}$} & \multirow[b]{2}{*}{ Tech } & \multicolumn{6}{|c|}{ Size $(\mathrm{cm})$} & \multirow[b]{2}{*}{ Total } \\
\hline & & & & $.5-1$ & $1-2$ & $2-3$ & $3-4$ & $4-5$ & 5- & \\
\hline \multirow[b]{5}{*}{ Tot. } & D & INT & NA & 17 & 359 & 156 & 27 & 3 & - & 562 \\
\hline & D & DEC & $\mathrm{NA}$ & 1 & 70 & 43 & 10 & 1 & - & 125 \\
\hline & D & blnk & $\mathrm{NA}$ & - & 2 & - & - & - & - & 2 \\
\hline & D & misc & NA & - & - & - & - & - & - & 2 \\
\hline & D & & 2 & 18 & 431 & 199 & 37 & 4 & - & 691 \\
\hline & CF & INT & PERC & 4 & 281 & 121 & 27 & 1 & - & 434 \\
\hline & CF & INT & BIP & - & 32 & 33 & 8 & - & - & 73 \\
\hline & CF & INT & PRES & 27 & 153 & 6 & - & - & - & 186 \\
\hline & CF & INT & blnk & 1 & 4 & 2 & - & - & - & 7 \\
\hline & $C F$ & INT & misc & & 2 & 1 & - & - & - & 3 \\
\hline & $\mathrm{CF}$ & INT & & 32 & 472 & 163 & 35 & 1 & - & 703 \\
\hline & $C F$ & PD & PERC & - & 5 & 5 & 7 & 3 & 1 & 21 \\
\hline & CF & PD & BIP & - & 4 & 9 & 5 & - & - & 18 \\
\hline & $C F$ & PD & PRES & - & - & - & - & - & - & - \\
\hline & CF & PD & blnk & - & - & - & - & - & - & - \\
\hline & $C F$ & $\mathrm{PD}$ & & - & 9 & 14 & 12 & 3 & 1 & 39 \\
\hline & CF & SD & PERC & - & 12 & 12 & 18 & 3 & - & 45 \\
\hline & CF & SD & BIP & - & 5 & 6 & 5 & - & - & 16 \\
\hline & CF & SD & PRES & 1 & 2 & 1 & - & - & - & 4 \\
\hline & CF & SD & blnk & - & - & - & - & - & - & - \\
\hline & $C F$ & SD & & 1 & 19 & 19 & 23 & 3 & - & 65 \\
\hline Tot. & $C F$ & & & 33 & 500 & 196 & 70 & 7 & 1 & 807 \\
\hline
\end{tabular}




\section{cCs Broken Flakes}

\begin{tabular}{|c|c|c|c|c|c|c|c|c|c|}
\hline \multirow{2}{*}{$\begin{array}{l}\text { SR } \\
\text { Type }\end{array}$} & \multirow{2}{*}{$\begin{array}{l}\text { st- } \\
\text { age }\end{array}$} & \multirow[b]{2}{*}{ Tech } & \multicolumn{6}{|c|}{ Size (cm) } & \multirow[b]{2}{*}{ Total } \\
\hline & & & $.5-1$ & $1-2$ & $2-3$ & $3-4$ & $4-5$ & $5-$ & \\
\hline BF & INT & PERC & 11 & 327 & 124 & 21 & 5 & - & 489 \\
\hline BF & INT & BIP & 1 & 26 & 13 & 2 & - & - & 42 \\
\hline $\mathrm{BF}$ & INT & PRES & 43 & 243 & 3 & 2 & - & - & 292 \\
\hline BF & INT & blnk & 1 & 8 & - & - & - & - & 9 \\
\hline BF & INT & misc & - & - & - & - & - & - & 2 \\
\hline BF & INT & 2 & 56 & 604 & 140 & 27 & 5 & - & 834 \\
\hline BF & PD & PERC & - & 6 & 5 & 1 & - & - & 12 \\
\hline $\mathrm{BF}$ & PD & BIP & - & 6 & 11 & 3 & - & - & 20 \\
\hline $\mathrm{BF}$ & PD & PRES & - & 1 & - & - & - & - & 1 \\
\hline BF & PD & blnk & - & - & 1 & - & - & - & 1 \\
\hline BF & PD & & - & 13 & 17 & 4 & - & - & 34 \\
\hline BF & SD & PERC & - & 14 & 5 & 7 & - & - & 26 \\
\hline BF & $S D$ & BIP & - & 4 & 7 & 4 & - & 2 & 17 \\
\hline $\mathrm{BF}$ & SD & PRES & - & $i$ & - & - & - & - & 1 \\
\hline $\mathrm{BF}$ & SD & blnk & 1 & - & - & - & - & - & 1 \\
\hline BF & SD & & 1 & 19 & 12 & 11 & - & 2 & 45 \\
\hline $\mathrm{BF}$ & & 2 & 57 & 636 & 169 & 42 & 5 & 2 & 913 \\
\hline
\end{tabular}


CC8 Flake Fragments

\begin{tabular}{|c|c|c|c|c|c|c|c|c|c|c|}
\hline & & & & & & Size & ( cm) & & & \\
\hline & Type & age & Tech & $.5-1$ & $1-2$ & $2-3$ & $3-4$ & $4-5$ & $5-$ & Total \\
\hline & FF & INT & PERC & 11 & 529 & 164 & 36 & - & - & 741 \\
\hline & $\mathrm{FF}$ & INT & BIP & 1 & 10 & 6 & - & - & - & 17 \\
\hline & FF & INT & PRES & 35 & 116 & 2 & 1 & - & - & 154 \\
\hline & FF & INT & blnk & 6 & 33 & 5 & 2 & - & - & 46 \\
\hline & $\mathbf{F F}$ & INT & misc & - & - & - & - & - & - & 1 \\
\hline & FF & INT & 1 & 53 & 689 & 177 & 39 & - & - & 959 \\
\hline & FF & $\mathrm{PD}$ & PERC & - & 15 & 6 & 1 & 1 & 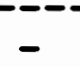 & 23 \\
\hline & FF & PD & BIP & - & 3 & 5 & 2 & - & - & 10 \\
\hline & FF & PD & PRES & - & - & - & - & - & - & - \\
\hline & FF & PD & blnk & - & 2 & 3 & - & - & - & 5 \\
\hline & FF & PD & & - & 20 & 14 & 3 & 1 & - & 38 \\
\hline & FF & SD & PERC & - & 19 & 20 & 3 & 2 & - & 44 \\
\hline & FF & SD & BIP & - & 5 & 5 & 3 & - & - & 13 \\
\hline & FF & SD & PRES & - & - & - & - & - & - & - \\
\hline & FF & SD & blnk & - & 1 & 1 & 1 & - & - & 3 \\
\hline & FF & SD & & - & 25 & 25 & 7 & 2 & - & 60 \\
\hline Tot. & FF & SD & 1 & 53 & 734 & 217 & 49 & 3 & - & 1057 \\
\hline
\end{tabular}

TOTAL CCS

$\begin{array}{lllllll}161 & 2462 & 781 & 198 & 19 & 3 & 3624\end{array}$ 


\section{OBEIDIAN}

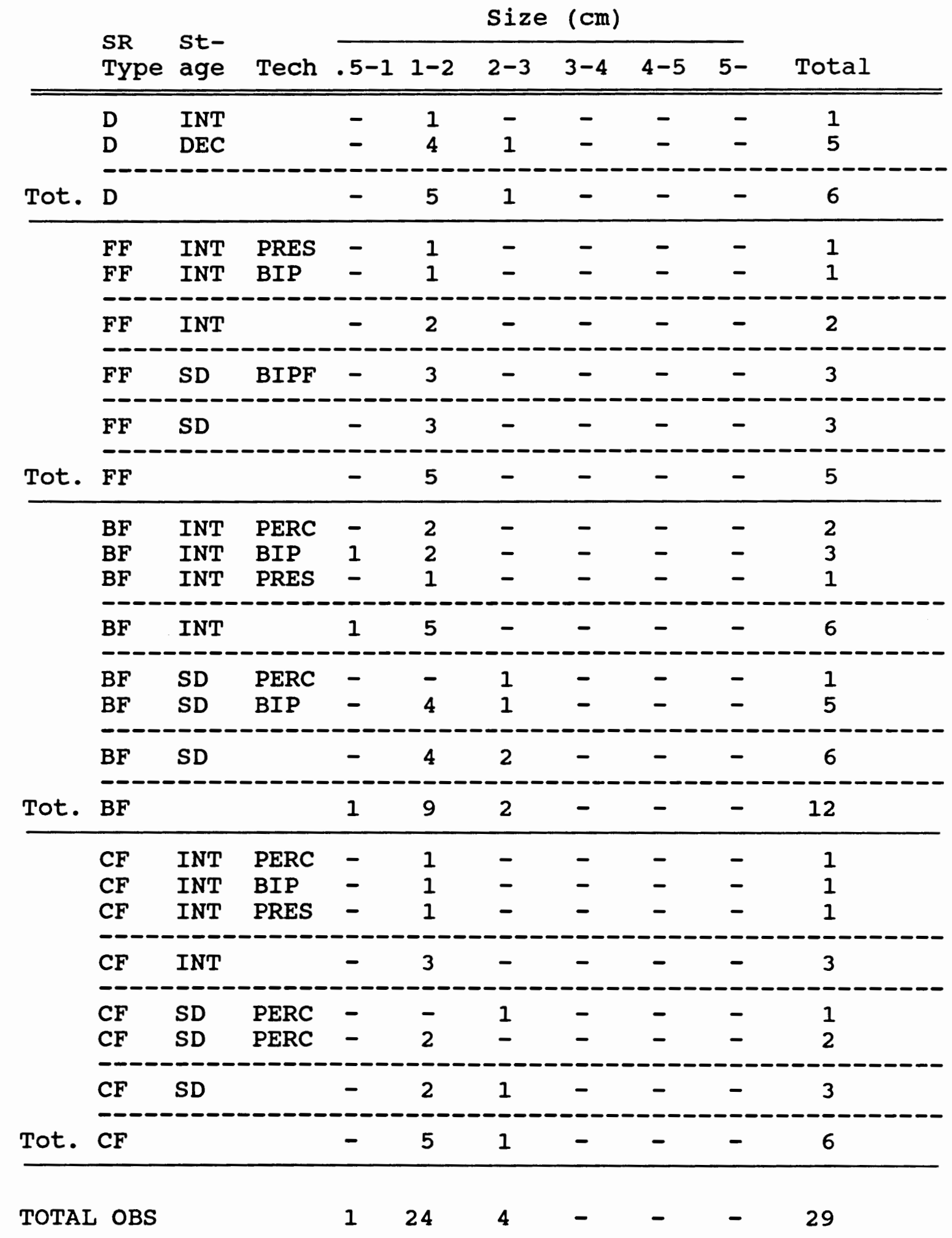


OTHER MATERIAL

Mat-

er- SR st-

Size (cm)

ial Type age Tech .5-1 $1-2$ 2-3 $3-4$ 4-5 $5-$ Total

\begin{tabular}{|c|c|c|c|c|c|c|c|c|c|c|}
\hline QZT & $\begin{array}{l}\text { BF } \\
\text { BF } \\
C F \\
C F \\
C F \\
C F\end{array}$ & $\begin{array}{l}\text { SD } \\
\text { INT } \\
\text { INT } \\
\text { INT } \\
\text { SD } \\
\text { PD }\end{array}$ & $\begin{array}{l}\text { PERC } \\
\text { BIP } \\
\text { PERC } \\
\text { BIP } \\
\text { PERC } \\
\text { BIP }\end{array}$ & $\begin{array}{l}- \\
- \\
- \\
- \\
-\end{array}$ & $\begin{array}{l}1 \\
- \\
- \\
- \\
1 \\
-\end{array}$ & $\begin{array}{l}- \\
1 \\
1 \\
- \\
- \\
-\end{array}$ & $\begin{array}{l}- \\
- \\
- \\
- \\
\overline{1}\end{array}$ & $\begin{array}{l}- \\
- \\
- \\
- \\
-\end{array}$ & $\begin{array}{l}- \\
- \\
- \\
- \\
-\end{array}$ & $\begin{array}{l}1 \\
1 \\
1 \\
1 \\
1 \\
1\end{array}$ \\
\hline Tot & & & & - & 2 & 2 & 1 & 1 & - & 6 \\
\hline BLT & $\begin{array}{l}D \\
D \\
F F \\
F F \\
B F \\
B F \\
C F \\
C F \\
C F\end{array}$ & $\begin{array}{l}\text { INT } \\
\text { PD } \\
\text { INT } \\
\text { PD } \\
\text { INT } \\
\text { SD } \\
\text { INT } \\
\text { SD } \\
\text { PD }\end{array}$ & $\begin{array}{l}\text { PERC } \\
\text { PERC } \\
\text { PERC } \\
\text { PERC } \\
\text { PERC } \\
\text { PERC } \\
\text { PERC }\end{array}$ & $\begin{array}{l}- \\
- \\
- \\
- \\
- \\
- \\
- \\
-\end{array}$ & $\begin{array}{l}1 \\
- \\
- \\
- \\
- \\
- \\
- \\
-\end{array}$ & $\begin{array}{l}- \\
1 \\
2 \\
1 \\
- \\
1 \\
- \\
- \\
2\end{array}$ & $\begin{array}{l}- \\
- \\
- \\
- \\
1 \\
- \\
1 \\
2 \\
-\end{array}$ & $\begin{array}{l}- \\
- \\
- \\
- \\
- \\
- \\
- \\
-\end{array}$ & $\begin{array}{l}- \\
- \\
- \\
- \\
- \\
- \\
- \\
-\end{array}$ & $\begin{array}{l}1 \\
1 \\
2 \\
1 \\
1 \\
1 \\
1 \\
2 \\
2\end{array}$ \\
\hline Tot. & & & & - & 1 & 7 & 4 & - & - & 12 \\
\hline FEL & $\begin{array}{l}\text { D } \\
\text { FF } \\
\text { FF } \\
\text { CF }\end{array}$ & $\begin{array}{l}\text { INT } \\
\text { INT } \\
\text { SD } \\
\text { INT }\end{array}$ & $\begin{array}{l}\text { PERC } \\
\text { PERC } \\
\text { PERC }\end{array}$ & $\begin{array}{l}- \\
- \\
-\end{array}$ & $\begin{array}{l}- \\
1 \\
-\end{array}$ & $\begin{array}{l}2 \\
1 \\
1 \\
-\end{array}$ & $\begin{array}{l}- \\
- \\
-\end{array}$ & $\begin{array}{l}- \\
- \\
1\end{array}$ & $\begin{array}{l}- \\
- \\
-\end{array}$ & $\begin{array}{l}2 \\
2 \\
1 \\
1\end{array}$ \\
\hline Tot. & & & & - & 1 & 4 & - & 1 & - & 6 \\
\hline
\end{tabular}

TOTAL OTH

$\begin{array}{lllll}-43 & 4 & 2\end{array}$




\section{REY}

Raw Material Type

$\begin{array}{ll}\text { CCS } & =\text { Cryptocrystalline Silicate } \\ \text { OBS } & =\text { Obsidian } \\ \text { QZT } & =\text { Quartzite } \\ \text { BLT } & =\text { Basalt } \\ \text { FES } & =\text { Felsite } \\ \text { GLS } & =\text { Glass }\end{array}$

Sullivan and Rozen Flake Type (SR Type)

$\mathrm{CF}=$ Complete Flake
$\mathrm{BF}=$ Broken Flake
$\mathrm{FF}=$ Flake Fragment

Reduction stage (Stage)

INT $=$ Interior Flake

$\mathrm{SD}=$ Secondary Decortication Flake

$\mathrm{PD}=$ Primary Decortication Flake

$\mathrm{DEC}=$ Decortication

Flaking Technology (Tech)

$\mathrm{PERC}=$

BIP =

Percussion

PRES =

Bipolar

blnk $=$ Not analyzed

misc $=$ Unknown 